Copyright

by

Qiyuan Liu

2013 
The Thesis Committee for Qiyuan Liu Certifies that this is the approved version of the following thesis:

\section{Solar Radiation-Enhanced Dissolution (Photodissolution) of Particulate Organic Matter in Texas Estuaries}

APPROVED BY

SUPERVISING COMMITTEE:

Supervisor:

G. Christopher Shank

Wayne S. Gardner

Zhanfei Liu 
Solar Radiation-Enhanced Dissolution (Photodissolution) of Particulate Organic Matter in Texas Estuaries

by

Qiyuan Liu, B.S.

\author{
Thesis \\ Presented to the Faculty of the Graduate School of \\ The University of Texas at Austin \\ in Partial Fulfillment \\ of the Requirements \\ for the Degree of
}

Master of Science in Marine Science

The University of Texas at Austin

May 2013 


\section{Dedication}

I dedicate this work to my parents and grandmother, for their love and support. 


\section{Acknowledgements}

I would like to acknowledge my advisor Dr. G. Christopher Shank for leading me to the wonderful world of sediment biogeochemistry and for being like a father in the past three years. I would also like to thank my committee members, Drs. Wayne Gardner and Zhanfei Liu, for their invaluable suggestions, support and help. Special thanks to Drs. Wayne Gardner, Zhanfei Liu, Jim McClelland, as well as their students, post-doctoral fellows and visiting scholars (Ruihua Dai, Zucheng Wang, Matt Khosh, Claire Griffin, and many more) for opening their lab to me and helping me with my experiments. Also, I would like to give many thanks to Kim Jackson for taking samples for me. Thanks to the Mission-Aransas NERR staff (Rae Mooney, Lindsey Pollard, Britt Dean and many more) and staff in Dr. Ken Dunton's lab (Kim Jackson, Joe Stachelek, Susan Linn and many more) for letting me join them for their field trips.

Thank Leslie Patterson, Crystal Chaloupka and Nathalie Arnone for their help with my experiments and the wonderful time together in the lab. Thank all my friends at MSI for their moral support. 


\begin{abstract}
Solar Radiation-Enhanced Dissolution (Photodissolution) of Particulate Organic Matter in Texas Estuaries
\end{abstract}

\author{
Qiyuan Liu, MSMarineSci \\ The University of Texas at Austin, 2013
}

Supervisor: G. Christopher Shank

Dissolved organic matter (DOM) is crucial to carbon and nutrient biogeochemical cycling in the marine environment because it helps fuel heterotrophic microbial activity by providing substrates for degradation and remineralization. This study shows that substantial production of DOM in Texas estuaries can result from the solar radiation-enhanced dissolution (photodissolution) of particulate organic matter (POM). Experimental results showed that 0.4-6.6 $\mathrm{mg} \mathrm{C} \mathrm{L}^{-1} \mathrm{~g}_{\text {sed }}{ }^{-1}$ of dissolved organic carbon (DOC) and 0.03-0.93 $\mathrm{mg} \mathrm{N} \mathrm{L}^{-1} \mathrm{~g}_{\text {sed }}{ }^{-1}$ of total dissolved nitrogen (TDN) can be produced from irradiated sediment suspensions within 24 hours, and further that photodissolution may augment DOC and TDN loads in Texas estuarine waters by as much as 3-85\% and 4-75\%, respectively. Photodissolution can also enhance the optical thickness of the water column via the release of chromophoric dissolved organic matter (CDOM), which may subsequently further enhance photochemical processes in surrounding waters. Photoproduced CDOM appears to be of relatively high molecular weight and dominantly exhibits humic-like fluorescence, suggesting that photodissolution primarily occurs for 
humic moieties. Photodissolution was also observed for sterilized sediment suspensions, indicating that photochemical degradation of POM is the primary pathway of DOM production during photodissolution, as opposed to microbial mediated degradation or stimulation of benthic primary production by benthic phytoplankton or algae.

Environmental and mechanistic factors controlling the extent of photodissolution in Texas estuaries may include sediment desiccation, water organic content, and sediment characteristics (organic content and lability of POM). Desiccated-rewetted sediments suspended in artificial seawater under solar irradiation produced $\sim 40 \%$ more DOC and TDN than wet sediments, indicating the sediment dry-wet cycle may alter the 3-D structure of sediment grain matrices and thus might be a major controlling factor of photodissolution in salt marsh systems. The organic content of water used in sediment suspensions did not significantly influence DOC or TDN photoproduction by itself, but the combined influence of water organic content and sediment dry-rewet event played a substantial role in controlling the extent of photodissolution. In contrast to the results in artificial seawater, wet sediments produced slightly more DOC $\left(\triangle \mathrm{DOC}=0.10 \mathrm{mg} \mathrm{C} \mathrm{g}_{\text {sed }}{ }^{-1}\right)$ and substantially more $\mathrm{TDN}\left(\triangle \mathrm{TDN}=0.14 \mathrm{mg} \mathrm{N} \mathrm{ged}^{-1}\right)$ than dry-rewetted sediments in organic-rich Nueces Marsh water during 24 hours of photoincubation. Photodissolution dominantly produced humic-like DOM even though biologically labile organic matter was available in sediments, indicating that photochemical reactions preferentially occur with humic-like rather than protein-like organic matter. DOC and TDN production during photodissolution was strongly proportional to the amount of POC in sediment suspensions. On average, $69.2 \pm 11.0 \mathrm{mg} \mathrm{C}$ of DOC and $9 \pm 3.1 \mathrm{mg} \mathrm{N}$ of TDN was produced from $1 \mathrm{~g}$ of organic carbon in sediment suspensions after 24 hours of photodissolution. 


\section{Table of Contents}

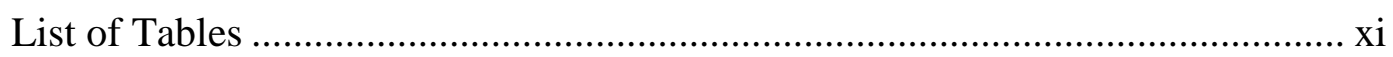

List of Figures .............................................................................................

Chapter 1: Solar Radiation-enhanced Dissolution (Photodissolution) of Particulate Organic Matter from Estuarine Suspended Sediments and the Mechanisms .1

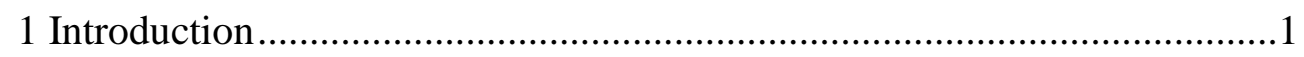

1.1 DOM in aquatic systems ...........................................................1

$1.2 \mathrm{CDOM}$ in aquatic systems ............................................................

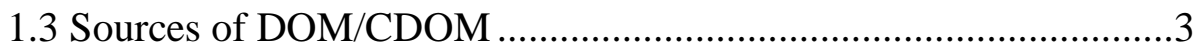

1.4 Sedimentary POM......................................................................

1.5 Bioavailability of dissolved nitrogen to aquatic organisms .............. 4

1.6 Previous studies on POM photochemical processes ..........................5

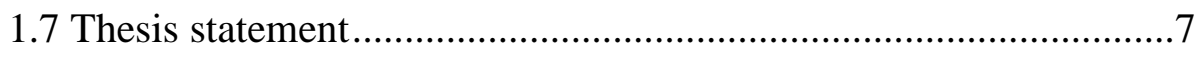

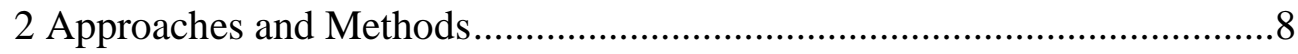

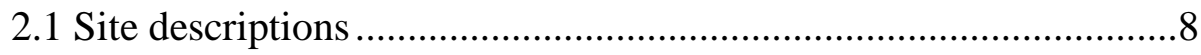

2.2 Sample collection........................................................................

2.3 Analytical methods ..................................................................12

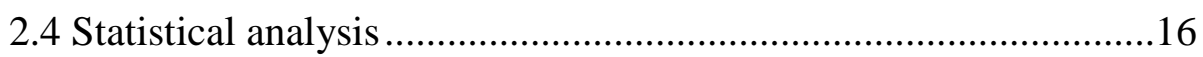

2.5 Photodissolution experiments ........................................................

2.6 Photodissolution experiments using raw VS. sterilized sediments 16

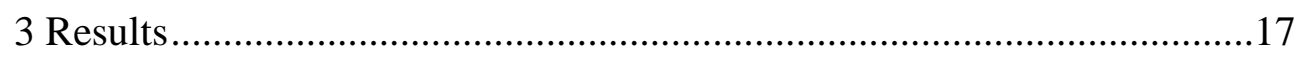

3.1 Photodissolution of sedimentary POM ……………........................

3.2 Spectral characteristics of irradiated sediment suspensions ..........20

3.3 Characterization of products from photodissolution using Excitation-Emission Matrix Spectra (EEMs) analysis ................22

3.4 Photochemical VS. biotic activity-mediated DOM production in

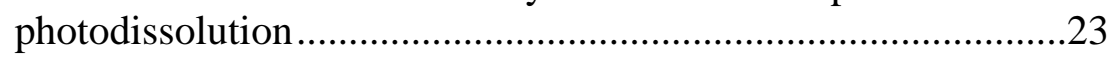

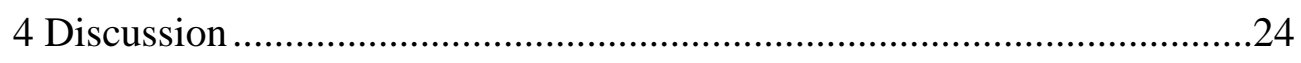

4.1 Production of DOC and TDN in POM photodissolution experiments 
4.2 CDOM production during photodissolution.

4.3 Characterization of products from photodissolution using EEMs

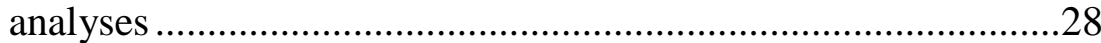

4.4 Photochemical VS. biotic activity-mediated DOM production in photodissolution ................................................................28

Chapter 2: Environmental and Mechanistic Limiting Factors on Photodissolution of Particulate Organic Matter in Texas Estuaries.............................................51

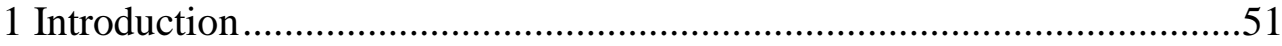

1.1 Sediment desiccation ..................................................................51

1.2 Interaction between DOM and POM in photoreactions ...............52

1.3 Characteristics of sedimentary POM ........................................53

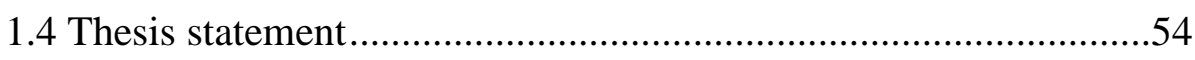

2 Approaches and Methods............................................................54

2.1 Desiccated sediment suspension photodissolution experiments....54

2.2 Photodissolution experiments using organic rich VS. organic poor

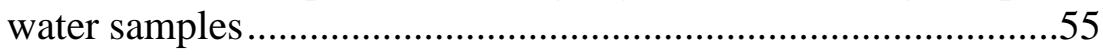

2.3 Photodissolution experiments using upper $\sim 5 \mathrm{~mm}$ VS. upper $\sim 2 \mathrm{~cm}$

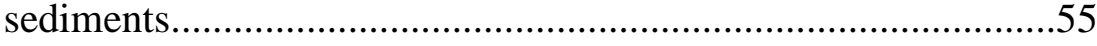

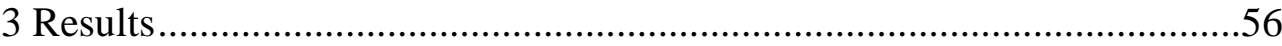

3.1 Influence of desiccation-rewet on photodissolution ....................56

3.2 Influence of organic content of water on photodissolution ...........57

3.3 Combined influence of water organic content and desiccation on

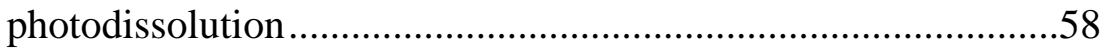

3.4 Substrate preference during photodissolution.............................58

3.5 Influence of sediment organic content (\%OC) on photodissolution59

4 Discussion .60

4.1 Influence of sediment desiccation on photodissolution .60

4.2 Combined influence of sediment desiccation and water organic content on photodissolution 61

4.3 Substrate preference during photodissolution. 62

4.4 Influence of sediment organic content (\%OC) on photodissolution63 


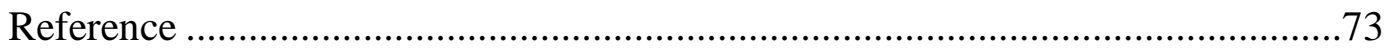

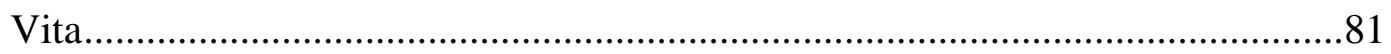




\section{List of Tables}

Table 1.1: $\quad$ DOC and TDN production after 24 hours of solar irradiation in sediment

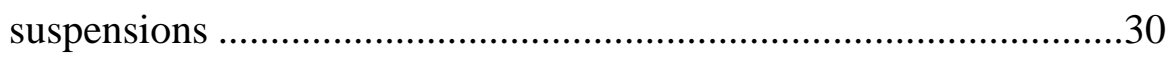




\section{List of Figures}

Figure 1.1: Schematic showing carbon budget during photodissolution of sedimentary POM

Figure 1.2: Map of the Texas coastline showing the locations of the major estuarine systems 32

Figure 1.3: Locations of sample sites 33

Figure 1.4: Changes in DOC and TDN concentrations with time normalized to $1 \mathrm{~g}$ of Nueces Marsh sediment (dry weight) addition for irradiated sediment suspensions (light with sediments) and sediment suspensions in the dark (dark with sediments) 34

Figure 1.5: $\mathrm{DON}, \mathrm{NH}_{4}{ }^{+}$, and $\mathrm{NO}_{3}{ }^{-}$concentrations in irradiated Nueces Marsh sediment suspensions for the photodissolution experiments on 5-31-2012 and $10-7-2012$ .35

Figure 1.6: Changes in DOC and TDN concentrations with time normalized to $1 \mathrm{~g}$ of Copano West sediment (dry weight) addition for irradiated sediment suspensions (light with sediments) and sediment suspensions in the dark (dark with sediments) 36

Figure 1.7: Changes in DOC and TDN concentrations with time normalized to $1 \mathrm{~g}$ of MANERR seagrass bed sediment (dry weight) addition for irradiated sediment suspensions (light with sediments) and sediment suspensions in the dark (dark with sediments).

Figure 1.8: $\mathrm{DON}, \mathrm{NH}_{4}{ }^{+}$, and $\mathrm{NO}_{3}{ }^{-}$concentrations in irradiated MANERR seagrass bed sediment suspensions for the photodissolution experiments on 8-16-2012. 
Figure 1.9: Changes in DOC and TDN concentrations with time normalized to $1 \mathrm{~g}$ of LLM seagrass bed sediment (dry weight) addition for irradiated sediment suspensions (light with sediments) and sediment suspensions in the dark (dark with sediments).

Figure 1.10: TDN versus DOC produced from photodissolution reactions at 24 hours normalized to $1 \mathrm{~g}$ of sediment (dry weight) addition 40

Figure 1.11: Changes in CDOM abundance ( $\left.a_{305}\right)$ with time normalized to $1 \mathrm{~g}$ of Nueces Marsh sediment (dry weight) addition for irradiated sediment suspensions (light with sediments) and sediment suspensions in the dark (dark with sediments)

Figure 1.12: Changes in CDOM abundance ( $\left.a_{305}\right)$ with time normalized to $1 \mathrm{~g}$ of Copano West sediment (dry weight) addition for irradiated sediment suspensions (light with sediments) and sediment suspensions in the dark (dark with sediments)

Figure 1.13: Changes in CDOM abundance ( $\left.a_{305}\right)$ with time normalized to $1 \mathrm{~g}$ of MANERR seagrass bed sediment (dry weight) addition for irradiated sediments suspension (light with sediments) and sediment suspensions in the dark (dark with sediments)

Figure 1.14: Changes in CDOM abundance ( $\left.a_{305}\right)$ with time normalized to $1 \mathrm{~g}$ of LLM seagrass bed sediment (dry weight) addition for irradiated sediment suspensions (light with sediments) and sediment suspensions in the dark (dark with sediments). 
Figure 1.15: Spectral slope $\left(S_{275-295}\right)$ of CDOM pools in irradiated sediment suspensions (light with sediments), sediment suspensions in the dark (dark with sediments) and irradiated water (light no sediment). Experiment was performed on 10-21-2012 using Nueces Marsh sediments and Nueces Marsh water.

Figure 1.16: Spectral slope $\left(S_{275-295}\right)$ of CDOM pools in irradiated sediment suspensions (light with sediments) and irradiated water (light no sediment). Experiment was performed on 8-16-2012 using MANERR seagrass bed sediments and Ship Channel water. .46

Figure 1.17: Spectral slope $\left(S_{275-295}\right)$ of CDOM pools in irradiated sediment suspensions (light with sediments), sediment suspensions in the dark (dark with sediments) and irradiated water (light no sediment). Experiment was performed on 6-22-2012 using LLM seagrass bed sediments and Ship Channel water mixed with Florida Key water. .47

Figure 1.18: EEMs of CDOM in irradiated Nueces Marsh sediment suspension at 24 hours. Experiment was performed on 10-7-2012. .48

Figure 1.19: EEMs of CDOM in irradiated MANERR Seagrass Bed sediment suspension at 0 hours and 24 hours. Experiment was performed on 8-16-2012.

Figure 1.20: Comparison of photodissolution experiments using raw versus autoclaved sediments 50

Figure 2.1: Comparison of photodissolution experiments using wet versus dry-rewetted sediments .65 
Figure 2.2: $\quad$ Spectral slope $\left(S_{275-295}\right)$ of CDOM pools in irradiated wet sediment suspensions (light with wet sediments) and irradiated dry-rewetted sediment suspensions (light with dry sediments)..........................66

Figure 2.3: EEMs of CDOM in irradiated wet sediment suspension and irradiated dry-rewetted sediment suspension at 24 hours

Figure 2.4: Comparison of photodissolution experiments using artificial seawater (organic-poor) versus Nueces Marsh water (organic-rich) 68

Figure 2.5: Comparison of photodissolution experiments using Ship Channel water (organic-poor) versus MANERR water (organic-rich) 69

Figure 2.6: Comparison of photodissolution experiments using wet versus dry-rewetted sediments mixed with artificial seawater (organic-poor) versus Nueces Marsh water (organic-rich) .70

Figure 2.7: EEMs of CDOM in dark upper $2 \mathrm{~cm}$ sediment suspension, dark top layer $(\sim 5 \mathrm{~mm})$ sediment suspension, irradiated upper $\sim 2 \mathrm{~cm}$ sediment suspension, and irradiated top layer $(\sim 5 \mathrm{~mm})$ sediment suspension at 24 hours .71

Figure 2.8: Correlations between DOC and TDN production at 24 hours and \%OC of sediment samples in photodissolution .72 


\section{Chapter 1: Solar Radiation-enhanced Dissolution (Photodissolution) of Particulate Organic Matter from Estuarine Suspended Sediments and the Mechanisms}

\section{Introduction}

1.1 DOM in aquatic systems

Dissolved organic matter (DOM), primarily quantified as dissolved organic carbon (DOC) in aquatic systems, is a major global carbon pool $\left(\sim 1.7 \times 10^{18} \mathrm{~g} \mathrm{C}\right)$ comparable to that of atmospheric carbon dioxide, accounting for $>97 \%$ of the total organic carbon in the global oceans (Hansell and Carlson 2002, Amon et al. 2001). Marine DOM plays an important role as a dynamic linkage among the biosphere, hydrosphere, and geosphere, and thus has a considerable influence on global biogeochemical cycles and climatic changes (Farrington 1992). Marine DOM is important because it supports heterotrophic microbial activities (Azaml et al. 1983) by providing energy and materials for consumption and remineralization, which are central to carbon cycling in the aquatic environment. Therefore, the bioavailability of DOM is a key factor determining the fate of the marine carbon pool. However, most DOM remaining in the marine environment cycles slowly and is resistant to microbial degradation (Benner et al. 1992, Ogawa and Ogura 1992, Amon and Benner 1994). Yet when sunlight is absorbed by DOM, a cascade of photochemical processes can be triggered, including the direct photomineralization of DOC to carbon dioxide or other forms of dissolved inorganic carbon (DIC), and the photolysis of DOM to smaller organic molecules (Strome and Miller 1978, Zepp et al. 1995). Photodegradation can substantially enhance DOM bioavailability for microbial activities (Geller 1986, Moran et al. 2000) due to the photoproduction of smaller, more labile organic molecules (Moran et al. 2000, McCallister et al. 2005, Daniel et al. 2006).

1.2 CDOM in aquatic systems 
The light-absorbing fraction of the DOM pool is labeled as chromophoric dissolved organic matter (CDOM). CDOM is typically a mixture of complex macromolecules with aromatic, carboxylic acid, and phenolic groups (Brezonik et al. 2005). CDOM is characterized by an absorption spectrum that is high across ultraviolet (UV) wavelengths and decreases exponentially toward longer wavelengths (Bricaud et al. 1981). On a global average, CDOM accounts for up to $90 \%$ of total absorption of underwater UV radiation and about $50 \%$ of the total non-water light absorption at $440 \mathrm{~nm}$, close to the maximum absorption by chlorophyll in phytoplankton (Siegel et al. 2005, Zepp 2003). Generally, in marine and coastal ecosystems, a high abundance of CDOM results in enhanced photochemical processes (Osburn et al. 2009). Upon light absorption, photochemical reactions lead to CDOM transformation or destruction, also known as "photobleaching" (Del Vecchio and Blough 2002). With an increased supply of labile organic matter from photobleaching, heterotrophic bacteria may outcompete phytoplankton for nutrients and have a negative impact on regional primary productivity (Thingstad et al. 2008). Since CDOM is often the major light absorbing constituent (Kirk 1994), photobleaching can also significantly increase the penetration of both UV radiation and photosynthetically available radiation (PAR) into the water column, resulting in a combination of negative and positive effects on photosynthesis, bacterial production, and other marine biological processes (Vincent and Belzile 2003). Over most of the open ocean, CDOM abundance is extremely low in surface waters due to photobleaching; however, CDOM abundance in coastal surface waters is often high because of strong influence from river discharges (Coble 2007). CDOM greatly influences the satellite remote sensing of water color for phytoplankton productivity estimation because its absorbance spectrum overlaps that of chlorophyll (Blough and Green 1995). Especially in coastal zones, remote sensing algorithms need to include CDOM abundances to obtain accurate estimations for Chlorophyll $a$ and primary productivities. On the other hand, remote sensing of CDOM is used to investigate aquatic processes, such as tracing the mixing of ocean water, refining carbon budgets and river input budgets (reviewed by Coble 2007). CDOM fluorescence can be correlated with 
DOC concentration in some waters (e.g. Hong et al. 2005, Shank and Evans 2011), thus CDOM fluorescence may be a proxy of DOC concentration, enabling the easy measurement of DOC via remote sensing. However, the estimation can be applied only in limited regions because the positive correlation only appears in areas where mixing controls the distribution of both CDOM and DOC (Blough and Del Vecchio 2002).

\subsection{Sources of DOM/CDOM}

It is challenging to differentiate the origins of both CDOM and bulk DOM in coastal and estuarine environments, due to the complexity and variability of the myriad dynamic physical and biogeochemical processes occurring at land-sea interfaces. DOM/CDOM generally fall into two categories with respect to their sources: terrestrially-derived DOM/CDOM, primarily in the form of dissolved humic substances from vegetation decomposition; and marine originated DOM/CDOM, largely derived from phytoplankton/algae and subject to microbial transformations (Mannino and Harvey 1999, Osburn and Morris 2003, Chen et al. 2004, Swan et al. 2009). Benthic fluxes driven by diffusion and advection at the sediment-water interface can also be important in situ DOM/CDOM sources to overlying waters (Alperin et al. 1999, Shank et al. 2004). Significant differences have been reported in the spectral, chemical, and photochemical properties of DOM/CDOM derived from terrestrial and in situ marine sources. The humic-like terrigenous DOM is often considered biologically refractory and can account for a major part of the coastal/marine DOM pool where freshwater inputs are important. Marine DOM is commonly composed of relatively smaller and more labile molecules including carbohydrates, proteins, and lipids (Benner 2002). The differences between terrestrial and marine DOM character were highlighted in work by Obernosterer and Benner (2004). In this study, only $27 \%$ of terrigenous DOC was subject to biodegradation while $74 \%$ of DOC derived from marine phytoplankton was mineralized by microbes. Moreover, the same study reported that $46 \%$ of the terrigenous DOC was decomposed under solar irradiation while marine DOC exhibited little photomineralization. Many other studies also indicated that UV exposure can augment the lability of terrigenous 
DOM/CDOM, while also reducing the bioavailability of algal-derived organic matter (see review by Zepp 2003).

\subsection{Sedimentary POM}

Together with DOM, particulate organic matter (POM) can fuel heterotrophic biotic activities in aquatic environments. The production, transfer, decomposition, and accumulation of POM play major roles in the biogeochemical cycling of carbon and nutrients, enabling materials and energy to cycle among organisms, water, sediments, and the atmosphere. POM includes suspended organic particles and sinking organic particles which are responsible for most of the material transport vertically throughout the water column (Wakeham and Canuel 1988). Most of the POM carried by freshwater runoff or produced in situ as detritus from plankton, seagrasses, seaweeds, and marsh plants, ends up on the sediment surface (Day et al. 1989). Deposited sediments may also serve as an important adsorbed-DOM reservoir because many organic molecules tend to strongly bind to particles (Shank et al. 2005, 2011). While sedimentary POM provides the primary energy source for bottom-dwellers and organisms living in the overlying water (Day et al. 1989) via direct consumption and microbial decomposition, photochemical processing of POM in the water column also may serve as an important source of carbon, nutrients and energy (Mayer et al. 2006, Kieber et al. 2006).

1.5 Bioavailability of dissolved nitrogen to aquatic organisms

All organisms require nitrogen. Nitrogen is often the most critical nutrient limiting primary production in estuarine and coastal environments (Ryther and Dunstan 1971, Oviatt et al. 1995). Most studies on nitrogen supply in aquatic ecosystems have focused on dissolved inorganic nitrogen (DIN, including $\mathrm{NH}^{+}, \mathrm{NO}_{3}{ }^{-}$, and $\mathrm{NO}_{2}^{-}$) because these forms of nitrogen are utilized readily by algae, benthic plants and bacteria. The largest nitrogen pool in aquatic systems, however, is dissolved organic nitrogen (DON) (Bronk 2002), which is the N-containing portion of the bulk DOM pool. While a small part of natural DON is directly available for plankton (Seitzinger et al. 2002, Bronk et al. 
2007), another fraction is not usable for plankton but can fuel bacterial activity (Seitzinger and Sanders 1997). DON accounts for 60-90\% of the total dissolved nitrogen that enters estuarine/coastal waters via freshwater inflow (Meybeck 1982). The previous view that considered terrestrial-originated DON as a bio-refractory form has been changed by recent studies on the effects of DON on coastal ecosystems (Sinsabaugh and Findlay 2003). Much of the DON that is difficult to biodegrade appears to be sensitive to photochemical decomposition, which increases its bioavailability (Bushaw et al. 1996, Obernosterer and Benner 2004). Bushaw et al. (1996) first reported that photochemical ammonification increased the bioavailable terrigenous nitrogen by $20 \%$ along the southeastern US continental shelf, altering the previous view of bioavailable nitrogen sources and estuarine/coastal nitrogen budget. Solar radiation (especially UV radiation) therefore provides a pathway for the conversion from refractory DON to labile compounds such as ammonium, nitrite, amino acids, and urea (see review by Bronk et al. 2007) that are used more easily by aquatic microorganisms.

\subsection{Previous studies on POM photochemical processes}

Less is known about POM photochemistry than DOM photochemistry. Kirk (1980) first reported that non-living POM was also able to absorb light at wavelengths similar to those of DOM and should therefore be susceptible to similar reactions. POM photochemical reactions include both direct photomineralization to inorganic carbon species (Anesio et al. 1999) and solar radiation-enhanced dissolution (also called “photodissolution") to DOM (Mayer et al. 2006). Studies on coastal and estuarine POM photochemical processes investigating the production of DOM from plant detritus (Mayer et al. 2009a) and suspended sediments (Mayer et al. 2006, Kieber et al. 2006, Shank et al. 2011, Pisani et al. 2011) concluded that POM photochemical reactions induced the breakdown of larger molecules, providing a substantial pool of smaller soluble DOM molecules. To date, all studies on photodissolution have suggested that this process is an important source of DOM and bio-available nutrients in a variety of aquatic systems, including freshwater rivers, estuaries, and along continental shelves. 
Photodissolution was investigated using sediment samples from a wide range of aquatic environments. Kieber et al. (2006) tested the contribution of sedimentary POM photochemical products to the DOM pool for the Cape Fear River estuary (North Carolina) and indicated that DOM produced through photodissolution can be more significant than either river discharge or sediment fluxes under certain conditions. Mayer et al. (2006) reported that photodissolution can remove up to one-third of the particulate organic carbon (POC) in Mississippi River suspended sediments after several days of irradiation. Riggsbee et al. (2008) exposed $\sim 325 \mathrm{mg} \mathrm{L}^{-1}$ sediments from Deep River (North Carolina) under solar irradiation and observed DOC increase of $119 \mu \mathrm{mol} \mathrm{C} \mathrm{L}^{-1} \mathrm{~d}^{-1}$ and DON increase of $1.7 \mu \mathrm{mol} \mathrm{N} \mathrm{L} \mathrm{N}^{-1}$. Southwell et al. (2010) conducted both laboratory-based and in situ photodissolution experiments with sediments from a tidal creek in North Carolina and reported an average release rate for total dissolved nitrogen (TDN) of $2.2 \pm 0.5 \mu \mathrm{mol} \mathrm{g}^{-1} \mathrm{~h}^{-1}$; the majority (87\%) of released nitrogen was DON, with the rest as ammonium. Shank et al. (2011) studied suspended sediments from Florida Bay and found that the DOC concentration increased from 0.5 to $3.0 \mathrm{mg} \mathrm{C} \mathrm{L}^{-1}$ after $24 \mathrm{~h}$ of light exposure. They also reasoned that the influence of solar radiation on organic matter cycling can be especially profound in shallow systems characterized by long water residence times (up to a few months). The consensus from all these studies is that photodissolution has the potential to markedly increase DOC, DON, and potentially ammonium levels in shallow aquatic environments.

The chemical and optical character of DOM/CDOM produced during photodissolution was characterized in a few studies (Shank et al. 2011, Pisani et al. 2011, Mayer et al. 2009a). Shank et al. (2011) irradiated sediments from Florida Bay and suggested that photolytic reactions dissolved humic-like fluorescence components primarily, with only minor photoproduction of protein-like components. Pisani et al. (2011) conducted similar experiments with flocculent material from the Florida Coastal Everglades and concluded both humic-like and protein-like components were produced upon light exposure, although terrestrial humic-like compounds accounted for up to $70 \%$ of the photoproduction while protein-like components only contributed 10-16\%. 
Similarly, Mayer et al. (2009a) examined irradiated phytoplankton detritus, showing that photoproduced CDOM exhibited humic-like fluorescence but also that photodissolved DOM demonstrated enhanced bioavailability. Overall, there appears to be a preferential photodissolution of humic-like moieties regardless of whether the particles were sedimentary or from photoplankton detritus.

The process of photodissolution appears to be driven largely by UV radiation, but PAR may also be important (Mayer et al. 2006). Kieber et al. (2006) concluded that PAR irradiations produced half as much DOC from organic-rich estuarine sediments as did UV irradiations. To this point, however, the mechanism by which UV or PAR induce photodissolution is unclear. Recently, Estapa and colleagues $(2010,2012)$ carried out a series of mechanistic photodissolution studies. They documented $\mathrm{O}_{2}$ loss and DIC production during photodissolution, as well as the involvement of photo-Fenton reactions (Estapa and Mayer 2010) (Figure 1.1). Their results indicated that POM photochemical reactions were irreversible and included the same redox reactions that were observed in DOM photochemical processes. They further quantified the rates of photodissolution reactions using Louisiana coastal sediments and showed that DOC concentrations increased approximately linearly with time during the first four hours of photoincubation, and also that the reaction rates increased with temperature indicating that indirect photochemical reactions helped drive the processes (Estapa et al. 2012).

\subsection{Thesis statement}

Reports on sedimentary POM photodissolution are limited, but all demonstrate that POM suspended in the water is subject to photochemical reactions, with a potential ability to produce important quantities of DOC and/or TDN. To date, little is known about the mechanisms of photodissolution and no study has examined photodissolution of sedimentary POM in Texas coastal systems. Bay and estuarine systems along the Texas

coast are susceptible to high photodissolution rates due to the combination of high seasonal solar irradiance, shallow water columns, long residence times, windy conditions, and frequent sediment resuspension events. As a result, comprehensive research was 
warranted to study photodissolution of POM in Texas coastal zones. Moreover, since Texas bays and estuaries include invaluable habitats such as salt marshes, mangroves, and seagrass beds, it is crucial to understand the significance of photodissolution as an unrecognized source of carbon and nitrogen to these ecosystems. The objectives of this thesis research were to:

(1) Quantify the production of DOC, TDN, and CDOM from photodissolution in shallow Texas estuarine waters under the naturally occurring environmental conditions;

(2) Study mechanisms of photodissolution, including characterization of DOM produced during photodissolution and identification of the primary reaction pathways for photodissolution.

Two main research questions and the corresponding hypotheses were:

(1) Are DOC, TDN, and CDOM produced through photodissolution of resuspended sediments important carbon and nitrogen sources to shallow Texas estuarine waters?

Hypothesis: DOC, TDN and CDOM produced through photodissolution are important carbon and nitrogen sources to shallow Texas estuarine waters.

(2) What are the chemical and optical characteristics of photodissolution products, and what are the primary pathways of sedimentary POM photodissolution?

Hypothesis: Humic-like organic compounds are involved in photodissolution and contribute to the bulk of photoproduced DOM. Photochemical reaction of the POM rather than microbial mediated degradation or stimulation of sedimentary primary producers is the main pathway for photodissolution.

\section{Approaches and Methods}

\subsection{Site descriptions}

The bay and estuary systems along the Texas coast (Figure 1.2) contain a variety of ecosystems, including salt marshes, mangroves, and seagrass beds, and thus have great commercial, recreational and conservation value. These systems are mostly shallow and ecologically complex, and serve as crucial habitats for numerous aquatic species. 
Therefore, the four sample sites selected to represent shallow, complex ecosystems along South Texas coast are station 450 in Nueces Marsh, station Copano West in Copano Bay, a seagrass site close to Copano West, and a seagrass site in the Lower Laguna Madre (Figure 1.3).

Estuaries in South Texas are highly productive, producing a tremendous amount of organic matter. The majority of the organic matter cycles within estuarine boundaries while the rest is exported seaward, providing an energy pathway to the offshore region (Day et al. 1989). The average abundance of DOC in Texas estuaries ranges from 2 to 10 mg C L ${ }^{-1}$ (Stordal 1996). Nitrogen is typically the most limiting nutrient in these waters (Gardner et al. 2006). In South Texas, fresh water inflow is a major environmental issue as these systems are limited by low rainfall and multiple freshwater demands and therefore do not gain enough freshwater to maintain the estuaries to their optimal qualities (Montagna and Kalke 1992). Moreover, South Texas estuarine water has very limited exchange with water in Gulf of Mexico; tidal forces are relatively small $(<0.3 \mathrm{~m})$ (Shideler 1978). Therefore, estuaries in South Texas generally have residence times of several months (Armstrong 1982), resulting in a shortage of bioavailable (biologically labile) DOM and nitrogen (Shank et al. 2009). On the other hand, South Texas estuaries are subject to high solar irradiance and windy conditions, which may facilitate the photodissolution process and enhance DOM and nitrogen photoproduction. Thus, the unique ecological values and environmental conditions of South Texas estuaries highlight the importance of studying photodissolution in these systems.

\subsubsection{Nueces Marsh}

The Nueces estuary consists of two coupled systems: Nueces Bay and the Nueces River delta. The $70 \mathrm{~km}^{2}$ Nueces Bay is a shallow secondary bay of Corpus Christi Bay, with a mean depth of less than one meter. The Nueces delta is a $72 \mathrm{~km}^{2}$ area with vegetated marshes, mud flats, and open water formed where the Nueces River flows into Nueces Bay. The Nueces Marsh is part of the Nueces River Delta, consisting of more than $57 \mathrm{~km}^{2}$ of wetland marshes and shallow ponds, interconnected by narrow channels 
and tidal creeks. This area is a semi-arid subtropical region, characterized by high summer temperatures, low rainfall, and high wind speeds; evaporation exceeds precipitation and hypersalinity often occurs during dry periods. Salinity in the water column typically ranges from 10 to 30 (psu), but can reach >50 during prolonged periods without rainfall or reduce quickly to $<1$ during episodic river flows (Forbes and Dunton 2006). The estuary receives $99 \%$ of its freshwater from Nueces River (Gardner et al. 2006). Since 1968, diversion of the Nueces River from the deltaic marsh system, in combination with continuous declines in freshwater inflow due to climate change and damming have resulted in higher salinities and reduced nutrient inputs (Morton and Paine 1984, White and Calnan 1990, Solis 1994).

Another important feature of the Nueces estuary is long water residence times up to several months (estimated at $0.46 \mathrm{yr}$ reported by Armstrong 1982) due to low freshwater discharge, weak tidal currents and confined topography. Because freshwater discharge events occur only sporadically, nitrogen and phosphorus influxes are regularly small (Roelke et al. 1997). The Nueces estuary is a strongly nitrogen-limited system, with the average C:N ratio as high as 35 (Twilley et al. 1999) and an N:P ratio typically much lower than Redfield stoichiometry (Roelke et al. 1997). Thus, as part of the Nueces estuary, the Nueces salt marsh is a system dependent on internal sources of nitrogen and organic carbon. The dominant sediment type is silt because low river flow allows fine sediments to settle in relatively calm waters. However, commonly windy weather results in frequent resuspension of surface sediments (Shideler 1980), and the surface sediments susceptible to resuspension contain $\sim 1 \%$ of organic carbon (by weight) (White et al. 1983, Wang et al. 2013).

\subsubsection{Copano Bay}

Copano Bay is a relatively isolated secondary bay located between Aransas Bay and Mission Bay. It is fed by salt water from the Gulf of Mexico via Aransas Bay and freshwater from Aransas River, Mission River, and Copano Creek. However, freshwater supply to Copano Bay is so low that evaporation overweighs freshwater input, and water 
residence time can be as long as three years (Armstrong 1982). Sandy mud that is carried by episodic high river discharges covers northwestern Copano Bay (CCBNEP 1996) and sediments at station Copano West typically contain 1.2-1.6\% organic carbon (by weight) (White et al. 1983). Windy weather and a shallow water column facilitate sediment

resuspension events throughout the year and sediment loads are frequently $>200 \mathrm{mgL}^{-1}$ (dry weight) (Mooney 2009). Copano Bay is part of the Mission-Aransas National Estuarine Research Reserve (MANERR) and water quality is consistently monitored at two stations within the bay.

\subsubsection{Lower Laguna Madre}

Laguna Madre is a lagoon separated from the Gulf of Mexico by Padre Island. It is naturally divided into two parts, the Upper Laguna Madre and Lower Laguna Madre (LLM), by a 32-km- long sand flat (the "Saltillo Flats"). The lagoon is shallow, with an average depth of $1.1 \mathrm{~m}$ (Onuf 2007) and the watershed of Laguna Madre covers a large area that receives very little annual precipitation. Thus, the water in Laguna Madre is clear and usually hypersaline (Buskey et al. 2001) since evaporation exceeds precipitation and water exchange with the Gulf of Mexico is very limited. Residence time for Laguna Madre waters is more than a year (Buskey et al. 1998). Seagrass meadows cover about $65 \%$ of the bottom of Laguna Madre, and serve as great habitats for fish and waterfowl (Onuf 2007). High sediment suspension loads can occur over seagrass meadows throughout the year when strong southeast and north winds blow during spring/summer and winter, respectively. Barge traffic from Port Isabel to Corpus Christi can also cause additional resuspension of sediments (Morin and Morse 1999).

\subsection{Sample collection}

Water and sediment samples were collected from four estuarine stations along the Texas coast: (1) station 450 in Nueces Marsh, (2) station Copano West in Copano Bay, (3) a seagrass site close to Copano West (also within the MANERR), and (4) a seagrass site in the Lower Laguna Madre (Figure 3). Station $450\left(27^{\circ} 52^{\prime} 26.80^{\prime \prime N}, 97^{\circ} 31^{\prime} 17.40^{\prime \prime W}\right)$ at 
the lower Rincon Bayou in Nueces Marsh is typically about $1 \mathrm{~m}$ deep. Rincon Bayou is at the head of the delta and serves as the primary distribution channel leading freshwater to the marsh during floods. Station Copano West $\left(28^{\circ} 5^{\prime} 2.76^{\prime \prime N}, 97^{\circ} 12^{\prime} 3.24^{\prime \prime W}\right)$ in Copano Bay is regularly monitored by MANERR. The seagrass site $\left(28^{\circ} 4^{\prime} 57.48^{\prime \prime} \mathrm{N}\right.$, $97^{\circ} 12^{\prime} 21.10^{\prime \prime}$ ) within the MANERR is located between the Copano West and the Aransas River mouth monitoring stations; the other seagrass bed site $\left(26^{\circ} 12^{\prime} 58.50^{\prime \prime} \mathrm{N}\right.$, $\left.97^{\circ} 12^{\prime} 30.60 " \mathrm{~W}\right)$ is located in Lower Laguna Madre. Sediment cores ( $\sim 10 \mathrm{~cm}$ deep) were collected by pressing a cylindrical corer into the sediment bed and placing a hand beneath the corer before extraction. Sediment samples were then taken from the top $\sim 2 \mathrm{~cm}$ in each core, placed on ice immediately after collection and kept frozen at $-20^{\circ} \mathrm{C}$ in the dark until analysis. Surface water samples $(<0.5 \mathrm{~m})$ for photodissolution experiments were filtered through $0.2 \mu \mathrm{m}$ polypropylene Meissner cartridge filters in the lab shortly after collection. Water samples were stored in $12 \mathrm{~L} \mathrm{HDPE}$ bottles in the dark at $4^{\circ} \mathrm{C}$ until analysis. All plastic, quartz, and glassware were acid cleaned $(10 \% \mathrm{HCl})$ and Nanopure-rinsed prior to use; all quartz and glass items were baked in a muffle furnace at $450^{\circ} \mathrm{C}$ for $4 \mathrm{~h}$ to remove any potential organic contamination.

\subsection{Analytical methods}

\subsubsection{DOC and TDN analysis}

Concentrations of DOC and TDN were analyzed by high temperature catalytic oxidation/combustion on a Shimadzu TOC-V analyzer coupled to a TNM-1 TDN analyzer. To ensure accuracy, low carbon water and seawater reference standards were measured in each analysis. Instrument precision for DOC measurement is $\sim 0.05 \mathrm{mg} \mathrm{C} \mathrm{\textrm {L } ^ { - 1 }}$ and $\sim 0.02 \mathrm{mg} \mathrm{N} \mathrm{L}^{-1}$ for TDN.

\subsubsection{Nitrate+Nitrite and Ammonium analyses}

Nitrate+nitrite concentrations were analyzed using the method modified from the "nitrate reduction by shaking with cadmium" method (Jones 1984). For each water 
sample/standard, $1 \mathrm{~mL}$ sample was mixed with $100 \mu \mathrm{l} \mathrm{NH}_{4} \mathrm{Cl}$ buffer solution $(0.7 \mathrm{M}, \mathrm{pH}$ $8.5)$ in a $2 \mathrm{ml}$ centrifuge tube and incubated with cadmium granules in a shaker for 12 hours at room temperature. After incubation, $200 \mu \mathrm{l}$ of sample was transferred into a microplate well, mixed with $20 \mu \mathrm{l}$ of $2 \%$ sulfanilamide and $20 \mu \mathrm{l}$ of $0.2 \% \mathrm{~N}$-1-napthyl ethylene diamine (NED). The microplates were then incubated in the dark for 1 hour until color was well developed. Absorbance of each sample was read at $543 \mathrm{~nm}$ on a BioTek microplate spectrophotometer. Each sample/standard was measured in triplicate.

Ammonium concentrations were analyzed with High-Performance Liquid Chromatography (HPLC) using the method established by Gardner and John (1991). Ammonium ion was measured as a fluorescent derivative of o-phthalaldehyde (OPA), and was quantified by a fluorometric detector.

DON was calculated using the formula:

$\mathrm{DON}=\mathrm{TDN}-\mathrm{NO}_{\mathrm{x}}{ }^{-}-\mathrm{NH}_{4}{ }^{+}$

\subsubsection{CDOM analysis}

CDOM abundances are typically evaluated by measuring a filtered sample's ability to absorb light over a spectrum of wavelengths. In the present study, CDOM was measured in terms of absorption coefficients $\left(a_{\lambda}\right.$ in unit of $\mathrm{m}^{-1}$ ) over a spectrum from 200 to $800 \mathrm{~nm}$ with a $1 \mathrm{~nm}$ slit using a Perkin Elmer Lambda 35 dual beam scanning spectrophotometer. Absorption coefficients $a_{\lambda}$ were calculated from absorbance values $\left(A_{\lambda}\right)$ using the following equation:

$a_{\lambda}=2.303 A_{\lambda} \mathrm{L}^{-1}$

where $\mathrm{L}$ is the light path length (in unit of $\mathrm{m}$ ), $\lambda$ is the wavelength (nm). For this study, $\mathrm{CDOM}$ abundances are reported as absorption coefficients at $305 \mathrm{~nm}\left(a_{305}\right)$, consistent with previous studies (Shank et al. 2009, Shank et al. 2011). $a_{305}$ values can vary between $<0.2 \mathrm{~m}^{-1}$ (offshore bluewater) and $>100 \mathrm{~m}^{-1}$ (blackwater river) in different types of aquatic systems, but usually range from 1 to $5 \mathrm{~m}^{-1}$ in coastal waters (Shank et al. 2009). 
The composition of the CDOM pool was described by a spectral slope coefficient $(S)$ generated from the following equation:

$a_{\lambda}=a_{\lambda_{0}} e^{-S\left(\lambda-\lambda_{0}\right)}$

where $a_{\lambda}$ is the absorption coefficient at wavelength $\lambda$ calculated from equation (1). Higher molecular weight CDOM pool $S$ values are typically smaller than for lower molecular weight CDOM pools (Kowalczuk et al. 2003, Stedmon and Markager 2003). S values can also serve as proxies for the photochemical transformation of CDOM as an increase in $S$ often reflects a decrease in the average molecular weight of the CDOM pool (Blough and Green 1995). In this study, $S$ values over a wavelength range of 275 to 295 $\mathrm{nm}\left(S_{275-295}\right)$ were used. The narrow range $(275-295 \mathrm{~nm})$ was chosen because the $S$ value within this range was reported to be most sensitive to the differences in CDOM from a variety of waters sources (river, marsh, open ocean, etc.) (Helms et al. 2008). $S_{275-295}$ can be considered as a reasonably precise proxy of DOM molecular weight, as well as photochemical-induced shifts in DOM molecular weight (Helms et al. 2008).

\subsubsection{Excitation-emission matrix spectra (EEMs)}

EEMs of water samples were generated using established methods (Santín et al. 2009, Shank et al. 2011) on a Fluoromax-4 spectrofluorometer in $1 \mathrm{~cm}$ quartz cells. Emission scans were acquired at excitation wavelengths $\left(\lambda_{\text {ex }}\right)$ between 260 and $455 \mathrm{~nm}$ at $5 \mathrm{~nm}$ intervals. The emission wavelengths were scanned from $\lambda_{\mathrm{ex}}+10 \mathrm{~nm}$ to $\lambda_{\mathrm{ex}}+250$ $\mathrm{nm}$ at $2 \mathrm{~nm}$ intervals. The instrument was configured for signal ratio mode, and excitation and emission slits were set to $5.7 \mathrm{~nm}$ and $2 \mathrm{~nm}$ band-passes, respectively. The EEMs data was corrected by subtracting Milli-Q water EEMs from the sample EEMs, and then corrected for inner filter effects using the UV-Vis absorbance spectra. The resulting corrected EEMs were plotted via MatLab toolbox with 50 contour lines. The location of maximum fluorescence $\left(\mathrm{F}_{\max }\right)$ intensity was determined within regions that was not affected by first-order and second order Rayleigh scattering (Ingle and Crouch 1988).

Three indices based on fluorescence spectra were determined from the EEMs, 
including the fluorescence index (FI), the biological index (BIX) and the humification index (HIX). FI was calculated as the ratio of the fluorescence intensities at emission wavelengths of 470 and $520 \mathrm{~nm}$ under excitation wavelength of $370 \mathrm{~nm}$. It is used to distinguish between terrestrial-derived $(\mathrm{FI}<1.4)$ and microbial derived $(1.4<\mathrm{FI}<2.0)$ fulvic acid in aquatic systems (Wickland et al. 2007). BIX was calculated as a ratio of the emission intensities at wavelengths of $380 \mathrm{~nm}$ and $430 \mathrm{~nm}$ at an excitation wavelength of $310 \mathrm{~nm}$. This index was also used to distinguish between terrestrial and microbial components, where BIX between 0.8 and 1.0 corresponds to microbial-derived fresh DOM, while BIX below 0.6 strongly indicates terrestrial-derived DOM (Birdwell and Engel 2010). As decomposition/humification proceed, the emission spectra of fluorescing molecules shifts towards longer wavelengths due to the decrease of molecular $\mathrm{H}: \mathrm{C}$ ratio (Zsolnay et al. 1999). Therefore, HIX was used as an index to compare the sum of fluorescence intensities at long wavelengths to those at short wavelengths to quantify the relative degree of humification:

$\mathrm{HIX}=\sum \mathrm{I}_{435-480} /\left(\sum \mathrm{I}_{300-345}+\sum \mathrm{I}_{435-480}\right)$

where $I_{x-y}$ is the sum of fluorescence intensities at emission wavelength $x$ to $y \mathrm{~nm}$ at excitation wavelength of $255 \mathrm{~nm}$ (Modified from Ohno 2002). HIX values range from 0 to 1 , with higher values standing for high levels of humification.

\subsubsection{Sediment treatments}

Sediment samples were thawed in the dark at room temperature and then homogenized before analysis. To determine the dry weights of the sediment samples, triplicate samples ( $3 \mathrm{~g}$ per sample) were dried in an oven for $24 \mathrm{~h}$ at $60^{\circ} \mathrm{C}$. After drying, samples were reweighed immediately. Water loss was calculated by subtracting dry weight from wet weight; water content was calculated accordingly by dividing water loss by wet weight. Sediment organic carbon composition was determined using Loss on Ignition (LOI) method. Dried sediment samples were heated at $450^{\circ} \mathrm{C}$ for $4 \mathrm{~h}$ to determine percent mass loss, the value was divided by the conversion factor 1.7 to calculate the percent organic carbon (\%OC) in sediment samples (Frangipane et al. 2009). 
Although this method can just provide an approximate of \%OC in sediment samples, it is consistent with previous studies (Shank et al. 2011, Kieber et al. 2006) and sufficient for comparison.

\subsection{Statistical analysis}

Data were analyzed using two-tail Student's t-test, $\alpha=0.05$.

\subsection{Photodissolution experiments}

Sediment suspension photochemical experiments involved $0.2 \mu \mathrm{m}$ filtered water sample and $\sim 1 \mathrm{~g} \mathrm{~L}^{-1}$ (wet weight) sediments, representing typical heavy sediment loads in the water column ( 200-500 $\mathrm{mg} \mathrm{L}^{-1}$ dry weights). Irradiated and dark sediment suspensions were prepared at identical concentrations. Sediments were kept in suspended condition with magnetic stir bars. Suspensions in $1 \mathrm{~L}$ round-bottom quartz flasks were placed under a SunTest XLS+ solar simulator equipped with a $1 \mathrm{~kW}$ Xenon lamp. The lamp was set to an output of $765 \mathrm{Wm}^{-2}$, which is equivalent to the intensity of subtropical sunlight at noon during mid-summer. Suspension temperatures were controlled via a recirculating water bath. Dark control flasks containing identical suspensions were wrapped with several layers of aluminum foil and placed in a dark cabinet under the same stirring and temperature conditions. Light control samples contained only the filtered water used for sediment suspensions. Water samples were collected from all dark and irradiated sediment suspensions and light controls at time intervals of 0,2,8 and 24 hours ( 0 hour samples were taken after few minutes of sediment addition and mixing). Contributions from sediment porewater were minor (Shank unpublished data) and were naturally included in samples taken at 0 hour. Water samples from the suspensions were filtered with $0.2 \mu \mathrm{m}$ nuclepore PC membranes (Whatman) and stored at $-20^{\circ} \mathrm{C}$ until DOC, TDN, CDOM, nitrate/nitrite and ammonium analyses.

2.6 Photodissolution experiments using raw VS. sterilized sediments

Photodissolution results using raw sediments were compared to photodissolution 
using sterilized (autoclaved) sediments to distinguish photodissolution from microbial degradation of sedimentary POM or stimulation of sedimentary primary producers. All water samples used for this set of experiments were $0.2 \mu \mathrm{m}$ filtered and autoclaved at $121^{\circ} \mathrm{C}$ for $30 \mathrm{~min}$ before use. Sediment samples for autoclaved treatments were autoclaved at $121^{\circ} \mathrm{C}$ for $30 \mathrm{~min}$, kept in a clean room at room temperature for 24 hours to let potentially alive spores develop, and then autoclaved again at $121^{\circ} \mathrm{C}$ for $30 \mathrm{~min}$ before use. Photodissolution experiments were performed as described earlier. All devices that would contact the autoclaved treatments were sterilized before use.

\section{Results}

\subsection{Photodissolution of sedimentary POM}

\subsubsection{Photodissolution of Nueces Marsh Sediments}

Irradiated suspensions (light with sediments) demonstrated pronounced increases in DOC concentrations (0.41-1.23 $\mathrm{mg} \mathrm{C} \mathrm{L}^{-1} \mathrm{~g}_{\mathrm{sed}}{ }^{-1}$ ) during 24 hours of exposures (Figure 1.4 A, C, E, G and I), as photodissolution of sedimentary POM in Nueces Marsh sediments increased DOC in the water by $4-10 \%$ (Table 1.1). DOC concentrations in irradiated suspensions were significantly higher than those in the controls after 24 hours of photoincubation ( $\mathrm{p}=0.013$ ), as DOC concentrations in irradiated water (light without sediment) and dark suspensions (dark with sediments) did not show much change throughout the incubation periods. DOC concentrations increased approximately linearly with time throughout the 24 hours of photoincubation periods (Figure 1.4 A, C, E, G and I). The results showed very similar trends for all five sets of experiments using sediments from Nueces Marsh station 450 (Table 1.1), even though the sediments were sampled in different trips at different time of a year and the water used to mix with sediments was sampled from different locations with different chemical characteristics.

Changes in TDN concentrations showed patterns similar to DOC concentrations

(Figure 1.4 B, D, F, H and J). In irradiated suspensions, TDN concentrations increased 
with time approximately linearly and were at least four times higher than the controls by the end of incubation period. Although the amount of TDN increases were not the same among the five sets of experiments due to the difference in sediment and water characteristics (Table 1.1), TDN followed the same trend and increased by $4-11 \%$ by the end of 24 hours of photodissolution.

TDN concentrations in two of the experiments (5-31-2011 and 10-7-2012) were subdivided into three fractions: nitrate, ammonium, and DON (Figure 1.5), to quantify individual nitrogen forms. The method used to determine nitrate concentration actually gave the result as nitrate+nitrite. However, since nitrite concentration was likely negligible (unpublished data), the results are reported as nitrate. Throughout the incubation period in the 5-31-2012 experiment (Figure 1.5 A), the major form of TDN produced in photodissolution was DON; ammonium accounted for most of the rest. By the end of incubation, DON, ammonium, and nitrate had contributed to $68.8 \%, 25.7 \%$, and $5.5 \%$ of the TDN increment respectively. Each component of TDN increased approximately in proportion to the increase of bulk TDN. DON, ammonium, and nitrate accounted for $75.1 \%, 23.2 \%$, and $1.8 \%$ of TDN in suspension at 0 hour, respectively; after 24 hours of solar irradiation, the percentages were $73.1 \%, 24.0 \%$, and $2.9 \%$ respectively. In the 10-7-2012 experiment (Figure 1.5 B), however, the ammonium and nitrate concentrations were consistent throughout the incubation period, while DON was the only component that increased significantly $(\mathrm{p}<0.001)$. For this experiment, $99.9 \%$ of the TDN increment was attributed to DON production. DON only accounted for $37.4 \%$ of TDN initially, but its fraction rose up to $59.3 \%$ after 24 hours of exposure to irradiation.

\subsubsection{Photodissolution of Copano Bay West Sediments}

Irradiated Copano West sediment suspensions produced more DOC and TDN than the controls (Figure 1.6). By the end of incubation periods, photodissolution of POM in Copano West sediments added 2-6\% extra DOC and 2-5\% extra TDN to in situ levels (Table 1.1). DOC and TDN concentrations increased linearly with time throughout the 24 
hours of photoincubation in the 3-29-2012 experiment (Figure 1.6 A, B). However, the DOC concentration in the 6-29-2012 experiment (Figure 1.6 C, D) increased during the first 8 hours and dropped afterwards, whereas the TDN concentration in the same experiment increased linearly throughout the photoincubation period. The DOC and TDN production rates (indicated by $\mathrm{S}$ values) during photodissolution using Copano West sediments were $0.022 \mathrm{mg} \mathrm{C} \mathrm{L}^{-1} \mathrm{~g}_{\text {sed }}^{-1} \mathrm{hr}^{-1}$ and 0.0017-0.0064 $\mathrm{mg} \mathrm{N} \mathrm{L}^{-1} \mathrm{~g}_{\text {sed }}^{-1} \mathrm{hr}^{-1}$, comparable to those in Nueces Marsh sediment photodissolution experiments (0.012-0.040 $\mathrm{mg} \mathrm{C} \mathrm{L}^{-1} \mathrm{~g}_{\text {sed }}{ }^{-1} \mathrm{hr}^{-1}$ and 0.0005-0.0095 $\mathrm{mg} \mathrm{N} \mathrm{L}^{-1} \mathrm{~g}_{\text {sed }}{ }^{-1} \mathrm{hr}^{-1}$ ).

\subsubsection{Photodissolution of MANERR Seagrass Bed Sediments}

DOC and TDN concentrations in light suspensions increased linearly with time and were significantly higher than the light and dark controls over 24 hour of incubation ( $\mathrm{p}<0.0025)$ (Figure 1.7). DOC increased by $30.4 \%$ and $26.7 \%$, and TDN increased by $38.2 \%$ and $28.1 \%$ in the two experiments (Table 1.1). Not much change in DOC or TDN concentrations was observed in the controls. DOC production rate in MANERR seagrass sediment photodissolution experiments was $0.14 \mathrm{mg} \mathrm{C} \mathrm{L}^{-1} \mathrm{~g}_{\mathrm{sed}}{ }^{-1} \mathrm{hr}^{-1}$, as compared to 0.01-0.04 mg C L L $\mathrm{g}_{\text {sed }}^{-1} \mathrm{hr}^{-1}$ in Nueces Marsh and Copano Bay sediment photodissolution experiments, suggesting that DOC photoproduction from MANERR seagrass sediments could be up to 10 times faster than those from Nueces Marsh or Copano West sediments. TDN photoproduction rate was $0.023 \mathrm{mg} \mathrm{N} \mathrm{L}^{-1} \mathrm{~g}_{\mathrm{sed}}{ }^{-1} \mathrm{hr}^{-1}$ when MANERR seagrass sediments were irradiated in organic-poor water, whereas the rates ranged from 0.0016 to $0.0095 \mathrm{mg} \mathrm{N} \mathrm{L}^{-1} \mathrm{~g}_{\text {sed }}{ }^{-1} \mathrm{hr}^{-1}$ using Nueces Marsh and Copano West sediments and organic-poor water. Thus, TDN photoproduction from MANERR seagrass sediments were 10 times faster than those from Nueces Marsh or Copano West sediments likely because sediment samples from MANERR seagrass bed contained significantly more organic carbon (7.2\%) than those from Nueces Marsh and Copano West (2.2-3.9\%) (Table 1.1).

For the bulk TDN pool, nitrate concentrations were below detection limit throughout the incubation period (Figure 1.8). Ammonium concentrations showed slight 
increases, from $0.049 \mathrm{mg} \mathrm{N} \mathrm{L}^{-1}$ at 0 hour to $0.062 \mathrm{mg} \mathrm{N} \mathrm{L}^{-1}$ at 24 hours. As a result, DON not only was the major component of TDN throughout the experiment, but also contributed the majority (90.7\%) of the TDN increment during photodissolution.

\subsubsection{Photodissolution of Lower Laguna Madre (LLM) Seagrass Bed Sediments}

DOC and TDN concentrations in irradiated LLM seagrass bed sediment suspensions increased linearly over 24 hours of incubation (Figure 1.9). At 24 hours, DOC concentrations in irradiated suspensions were significantly higher than the controls ( $\mathrm{p}<0.003$ ), with $85.0 \%$ and $25.0 \%$ increments respectively in the two experiments (6-22-2012 and 12-6-2012). Similarly, TDN concentrations increased by $74.7 \%$ and $44.0 \%$ respectively (Table 1.1). In these two experiments, DOC and TDN production rates were generally higher than those in the photodissolution experiments using Nueces Marsh and Copano West sediments, possibly related to the high \%OC of LLM seagrass bed sediments (4.6-11.6\%) (Table 1.1). On the other hand, the difference between these two LLM seagrass bed sediment photodissolution experiments were substantial: $6.62 \mathrm{mg} \mathrm{C}$ $\mathrm{L}^{-1} \mathrm{~g}_{\text {sed }}{ }^{-1}$ DOC and $0.93 \mathrm{mg} \mathrm{N} \mathrm{L}^{-1} \mathrm{~g}_{\text {sed }}{ }^{-1} \mathrm{TDN}$ were produced in the 6-22-2012 experiment (Figure 1.9 A, B), while $2.13 \mathrm{mg} \mathrm{C} \mathrm{L}^{-1} \mathrm{~g}_{\text {sed }}{ }^{-1}$ DOC and $0.31 \mathrm{mg} \mathrm{N} \mathrm{L}^{-1} \mathrm{~g}_{\text {sed }}{ }^{-1} \mathrm{TDN}$ were produced in the 12-6-2012 experiment (Figure 1.9 A, B). The difference in DOC and TDN production rates between these two experiments was likely related to the difference in \%OC of the sediment samples (11.6\% versus $4.6 \%$ ) (Table 1.1).

\subsection{Spectral characteristics of irradiated sediment suspensions}

\subsubsection{Changes in CDOM during photochemical reactions}

Although different sediments and different water were used to make sediment suspensions, all photodissolution experiments (Figure 1.11-1.14) demonstrated similar trends with regard to CDOM: CDOM abundance increased considerably in all the irradiated sediment suspensions, decreasing gradually with time in all the light controls (water without sediments under solar irradiation), and increasing slightly in all the dark 
controls (sediment suspensions in the dark). By the end of 24 hours of incubations, all the irradiated suspensions produced significantly more CDOM than the light or dark controls $(\mathrm{p}<0.002)$. The actual amount of changes in CDOM abundance varied among experiments due to the differences in sediment characteristics, water used for these photodissolution experiments and photoreactivity of photoproduced CDOM. For example, in the 10-7-2012 experiment (Figure $1.11 \mathrm{~A}$ ), artificial seawater that contained very little DOM/CDOM was used and thus CDOM abundance increased with time in irradiated suspensions. But in the 10-21-2012 experiment (Figure 1.11 B), Nueces Marsh water used for suspensions was organic-rich (DOC=7.19 $\mathrm{mg} \mathrm{C} \mathrm{L}^{-1}, \mathrm{a}_{305}=11.98 \mathrm{~m}^{-1}$ ) and was susceptible to photobleaching under solar irradiation, resulting in a loss of CDOM. Thus, CDOM abundance not only dropped dramatically in the light control, but also decreased in the irradiated suspension due to direct photobleaching of organic-rich water sample. Nevertheless, the CDOM decline in the irradiated suspension was less than that in the light control because photochemical reactions on sediments dampened the progress of photobleaching. Photodissolution co-occurred with photobleaching; CDOM was being produced while being broken down. Moreover, suspended sediment particles reflected and/or absorbed light that would have photobleached ambient CDOM. The experiments using sediments from other systems (Figure 1.12-1.14) showed similar patterns as in the 10-7-2012 experiment (Figure 1.11 A) because relatively organic-poor water was used in each experiment. Overall, both photobleaching and photodissolution controlled CDOM in sediments suspensions under solar irradiation.

Note that the increases in CDOM abundance were logarithmic with time in irradiated suspensions when organic-poor water was used for photodissolution (Figure 1.11 A, Figure 1.12-1.14). CDOM abundances decreased logarithmically with time in irradiated water (light controls) (Figure 1.11-1.14). In general, the kinetics of CDOM photochemical reactions followed logarithmic changes: photodissolution reactions produced CDOM logarithmically while photobleaching reactions consumed CDOM logarithmically with time. Similar to the changes of DOC and TDN, CDOM production rates in photodissolution experiments using MANERR and LLM seagrass bed sediments 
were generally higher than those in the photodissolution experiments using Nueces Marsh and Copano West sediments, likely due to the difference in organic contents of sediment samples.

\subsubsection{Changes of CDOM spectral slopes in photochemical reactions}

Spectral slope $(S)$ can be a proxy for the molecular weight of the bulk CDOM pools, as an increase in $S$ often reflects decreases in the average molecular weight of the CDOM pool (Blough and Green 1995). In all the photodissolution experiments, spectral slope demonstrated similar trends of changes (Figure 1.15-1.17): $S$ increased with time in all the light controls (water without sediments), indicating decreases in the average molecular weight of CDOM pools. Variations in $S$ in dark sediment suspensions were relatively small and occurred in random directions. In the irradiated sediment suspensions, $S$ values generally decreased with time during the first 8 hours of incubations, indicating that organic matter of higher molecular weight had been produced in photodissolution and had contributed to the increase of average CDOM molecular weight. After 8 hours, $S$ values increased slightly in the 8-16-2012 and 6-22-2012 experiments (Figure 1.16 and 1.17), suggesting that CDOM molecular weight began to decline due to further photobleaching of photoproduced CDOM. However, the 10-21-2012 experiment using Nueces Marsh sediments (Figure 1.15) seemed to be an exception because organic-rich water was used in sediment suspensions. In the irradiated suspension in this experiment, CDOM photodegradation was still a dominant process, hence the overall molecular weight of CDOM pool decreased ( $S$ value increased) even through high-molecular-weight CDOM was being produced in photodissolution. On the other hand, the average CDOM molecular weight in the irradiated suspension was still higher than the light control throughout the incubation period due to photodissolution of sedimentary POM.

3.3 Characterization of products from photodissolution using Excitation-Emission Matrix Spectra (EEMs) analysis 
FI, BIX, and HIX values suggested that DOM produced in photodissolution using Nueces Marsh and MANERR seagrass bed sediments were strongly humified (Figure 1.18 and 1.19). In both photodissolution experiments, humic-like DOM was produced dominantly during 24 hours of photoincubation as indicated by the positions of $F_{\max }$. The suspensions using Nueces Marsh sediments and artificial seawater exhibited very weak fluorescence signals at time zero (QSE $<0.5$, unpublished data), whereas suspensions using MANERR seagrass bed sediment and Ship Channel water exhibited stronger signals with $\mathrm{F}_{\max }$ at $(265,450 \mathrm{~nm})$ at 0 hour (Figure $\left.1.19 \mathrm{~A}\right)$. Thus the actual values of FI, BIX and HIX at 24 hours should not be directly compared between the two experiments (10-7-2012 and 8-6-2012) because different water was used to prepare suspensions and the FI, BIX and HIX values at 24 hours were influenced by the initial values at 0 hour.

3.4 Photochemical VS. biotic activity-mediated DOM production in photodissolution

Two possible explanations for why solar irradiation produces DOM from sediment suspensions are: (1) solar irradiation (photons) stimulates chemical reactions or directly participates in chemical reactions and therefore accelerates degradation of POM; (2) solar irradiation stimulates biotic activities, including bacterial degradation of POM and benthic algal photosynthesis that produce DOM. To test which of the two pathways is more important in photodissolution of sedimentary POM, a comparison was made between raw sediment suspensions and sterilized (autoclaved) sediment suspensions.

Both the raw and the sterilized (autoclaved) sediment suspensions released DOC and TDN during photodissolution (Figure 1.20). DOC and TDN concentrations increased gradually with time in both treatments, but raw sediment suspensions produced more DOC and TDN than autoclaved sediment suspensions under irradiation $(\mathrm{p}<0.04)$. At 24 hours, raw suspensions produced $2.13 \mathrm{mg} \mathrm{C} \mathrm{L}^{-1} \mathrm{~g}_{\text {sed }}{ }^{-1}$ DOC and $0.31 \mathrm{mg} \mathrm{N} \mathrm{L}^{-1} \mathrm{~g}_{\text {sed }}{ }^{-1} \mathrm{TDN}$, whereas the autoclaved suspensions produced $1.53 \mathrm{mg} \mathrm{C} \mathrm{L}^{-1} \mathrm{~g}_{\text {sed }}{ }^{-1} \mathrm{DOC}$ and $0.18 \mathrm{mg} \mathrm{N}$ $\mathrm{L}^{-1} \mathrm{~g}_{\text {sed }}{ }^{-1} \mathrm{TDN}$. On the other hand, DOC and TDN concentrations at 0 hour were substantially different in the raw versus autoclaved suspensions because autoclaving resulted in a pulse release of DOM (unpublished data). It may be speculated that 
autoclaving should have altered the chemical characteristics of sediment suspensions, including their photochemical reactivity. Thus, it is difficult to quantitatively compare the amount of DOC and TDN photoproduced in these two treatments, further estimating the contributions from photochemical versus biotic pathways is difficult. But it is clear that photochemical degradation largely contributed to photodissolution of POM.

\section{Discussion}

\subsection{Production of DOC and TDN in POM photodissolution experiments}

\subsubsection{Experimental settings}

Only one sample bottle was used for each treatment for some of the photodissolution experiments in which no replicates were set up due to limited space in the incubator (water bath). However, the trends are considered reliable since the subsamples taken at different times of incubation (2, 8 and 24 hours) always demonstrated the same direction of alterations (e.g. consistent increases with time). Moreover, some photodissolution experiments were repeated multiple times using sediments sampled in different trips but at the same location and the results were similar (e.g. 5-31-2012 and 10-7-2012 experiments). Although the actual amount of changes were sometimes different due to the differences in sediment and water characteristics, the trend of changes were the same; therefore the reproducibility of photodissolution experiments further strengthen the reliability of the results.

\subsubsection{Production of DOC and TDN in POM photodissolution}

Although sediment samples were collected from four different estuarine systems along Texas coastal zones, photodissolution experiment results were similar:

(1) DOC/CDOM and TDN abundances increased significantly in all the irradiated suspensions, but showed either decline or no change in light controls, and fluctuated within relatively small ranges in dark suspensions. 
(2) Irradiated sediment suspensions with $200-500 \mathrm{mg} \mathrm{L}^{-1}$ sediments (dry weight) increased background DOC concentration by 0.4-6.6 $\mathrm{mg} \mathrm{C} \mathrm{L}^{-1} \mathrm{~g}_{\text {sed }}{ }^{-1}$ (3-85\%) and TDN concentration by 0.03-0.93 $\mathrm{mg} \mathrm{N} \mathrm{L}^{-1} \mathrm{~g}_{\mathrm{sed}}{ }^{-1}$ (4-75\%) within 24 hours (Table 1.1).

My results agreed with previous studies in which photodissolution was identified as an important source of DOM and bio-available nutrients in a variety of aquatic systems (e.g. Kieber et al. 2006, Riggsbee et al. 2008, Southwell et al. 2010, Shank et al. 2011, Pisani et al. 2011). Kieber et al. (2006) irradiated $\sim 1-2 \mathrm{~g} \mathrm{~L}^{-1}$ (wet weight) sediments from the Cape Fear River estuary (North Carolina) and found that DOC was produced at the rates of 3-150 $\mu \mathrm{mol} \mathrm{L}^{-1}$ per gram dry sediment after 9 hours of photoincubation. Riggsbee et al. (2008) exposed $\sim 325 \mathrm{mg} \mathrm{L}^{-1}$ (dry weight) sediments from the Deep River (North Carolina) to solar irradiation and observed DOC increases of $119 \mu \mathrm{mol} \mathrm{C} \mathrm{L}^{-1} \mathrm{~d}^{-1}$ and DON increases of $1.7 \mu \mathrm{mol} \mathrm{N} \mathrm{L}{ }^{-1} \mathrm{~d}^{-1}$. Southwell et al. (2010) conducted photodissolution experiments using $\sim 410 \mathrm{mg} \mathrm{L}^{-1}$ sediments from a tidal creek in North Carolina and reported an average release rate for TDN of $2.2 \pm 0.5 \mu \mathrm{mol} \mathrm{g}_{\mathrm{sed}}{ }^{-1} \mathrm{~h}^{-1}$ during 8 hours of photoincubation. Shank et al. (2011) studied photodissolution of sediments from Florida Bay and found that the DOC concentration increased by $1-4 \mathrm{mg} \mathrm{C} \mathrm{L}^{-1}$ with $\sim 400 \mathrm{mg} \mathrm{L}^{-1}$ sediment loads after $48 \mathrm{~h}$ of light exposure. Pisani et al. (2011) performed photodissolution experiments using natural flocculent material from the Florida Coastal Everglades and observed up to $259 \mathrm{mg} \mathrm{C} \mathrm{gC}{ }^{-1}$ of DOC production and $5.2 \mathrm{mg} \mathrm{N} \mathrm{gsed}^{-1}$ of TDN production after 7 days of radiation exposure. The magnitudes of DOC and TDN photoproduction in my study are comparable to the results from those studies discussed above. My results also showed that DON was the major form of TDN produced in photodissolution with ammonium accounted for most of the rest, which agreed with the results in the study by Southwell et al. (2010) concluding that the majority (87\%) of photoreleased nitrogen was DON, with the rest as ammonium.

\subsubsection{Significance of photoproduced DOC and TDN to Texas estuaries}

Texas coastal estuaries typically have long residence time (several months) with limited water exchange with the open ocean and sediment resuspension events are 
common due to wind-induced turbulences and human activities. In addition, Texas coastal waters are shallow and subject to strong sunlight throughout most of the year. As a rough estimation based on the results from this study ( 24 hours of artificial irradiation was considered equivalent to 4 days of natural solar radiant), 0.1-0.2 $\mathrm{mg} \mathrm{C} \mathrm{L}^{-1}$ DOC and 0.02-0.04 mg N L $\mathrm{m}^{-1} \mathrm{TDN}$ may be photoproduced every day with $200-500 \mathrm{mg} \mathrm{L}^{-1}$ sediment load. Photoproduced carbon and nitrogen from suspended POM may supply up to $30 \%$ of primary production (103-250 $\mathrm{g} \mathrm{C} \mathrm{m}^{-2}$ year $^{-1}$ ) in South Texas estuaries (Flint and Kamykowski 1984). Mission-Aransas, Nueces and Laguna Madre estuarine systems span $\sim 500,000$ acres in total. Assuming that only $0.5 \mathrm{~m}$-deep water column is subject to solar irradiation and contains $200-500 \mathrm{mg} \mathrm{L}^{-1}$ suspended sediment particles, 3-6 $\times 10^{9} \mathrm{~g} \mathrm{C}$ of DOC and 0.6-1.2 $\times 10^{9} \mathrm{~g} \mathrm{~N}$ of TDN may be photoproduced within a month among these three estuarine systems. Therefore, photodissolution is likely a greatly important carbon and nitrogen source to Texas estuarine waters.

Photoproduced biologically labile DOC and TDN, such as amino acid, urea, and ammonium, may be immediately available for bacteria and primary producers. However, based on my results, the majority of photodissolved DOC and TDN should be biologically refractory materials that cannot be directly used by bacteria or algae, such as humic-like DOM. Nevertheless photoproduced DOM is continually exposed to irradiation and is susceptible to further photodegradation since humic-like DOM is known to be "photo-labile" (Granéli et al. 1996). Solar radiation converts bio-refractory DOM to labile molecules such as DIC, ammonium and nitrate (Moran and Zepp 1997, Bronk et al. 2007), which may lead to enhanced microbial activities in the ambient waters and accelerated net degradation rates in the system. Over all, the ultimate fate of DOC and TDN produced in photodissolution is to be degraded to bio-available forms and cycle within the system before being exported. Thus, photodissolution of POM may be an important internal source of bio-available carbon and nitrogen for both heterotrophic microbes and primary producers in Texas estuaries.

\subsubsection{Photoproduction of DOC versus TDN}


DOC and TDN were produced in proportion in photodissolution reactions: about 0.12 mole of $\mathrm{N}$ as TDN was produced along with 1 mole $\mathrm{C}$ as DOC in photodissolution (DOC:TDN=8.5) (Figure 1.10). The data points representing photodissolution of sediments from Nueces Marsh and Copano Bay were close to the origin in Figure 1.10, indicating that the reaction rates were lower when Nueces Marsh and Copano Bay sediments were used in comparison to those of the photoreactions using MANERR or LLM seagrass bed sediments.

\subsection{CDOM production during photodissolution}

Since CDOM is a fraction of the bulk DOM pool, the changes in its abundances followed the same patterns as the changes in DOM (measured in terms of DOC concentrations). CDOM abundance increased significantly in all the irradiated suspensions, and the average molecular weight of CDOM pool was consistently higher than the light controls in each experiment, suggesting that CDOM of relatively high molecular weight was produced from sediment suspensions in photodissolution. In contrast, CDOM and its average molecular weight decreased with time in all the light controls due to photobleaching that broke down a portion of CDOM molecules. In all the dark controls, CDOM abundances and average molecular weight did not change much but fluctuated within small ranges due to microbial activities, absorption and desorption.

Photodissolution of POM in estuaries leads to augmented CDOM abundance and can further result in enhanced photochemical processes in estuarine waters (Osburn et al. 2009). Therefore, photodissolution may continuously supply CDOM for photobleaching reactions that break down CDOM molecules to smaller, more labile molecules (Mayer et al. 2009a). Additionally, the "priming effect" in aquatic DOM suggests that biologically recalcitrant DOM may become available for bacterial utilization via co-metabolism when a pulse of biologically labile DOM is provided (reviewed by Bianchi 2011). Previous studies have also observed that photochemical reactions can be an important source of the "pulse of biologically labile DOM" (reviewed by Bianchi 2011). If enhanced photobleaching that supplies biologically labile materials can accelerate biological 
metabolic rates, the biologically refractory CDOM molecules may also be bio-degraded at a faster rate. Over all, photodissolution may augment the degradation rates of organic matter in aquatic systems via both biological and photochemical pathways. Besides photoreactivity, photodissolution can alter other optical characteristics of water such as water color. As CDOM being photoproduced, the penetration of both UV radiation and PAR into the water column decreases, which may result in a negative effect on photosynthesis (Vincent and Belzile 2003). Photoproduction of CDOM may also interfere with remote sensing as the quantitative correlation between CDOM abundance and other water quality parameters might be diminished by the addition of photoproduced CDOM.

\subsection{Characterization of products from photodissolution using EEMs analyses}

FI, BIX, HIX values and the positions of $\mathrm{F}_{\max }$ indicated that humic-like DOM was primarily produced in photodissolution using Nueces Marsh and MANERR seagrass bed sediments; photoproduced DOM was strongly humified. My results were in agreement with previous studies on characterizations of photoproduced DOM (Shank et al. 2011, Pasani et al. 2011). Shank et al. (2011) and Pasani et al. (2011) both performed photodissolution experiments using Florida coastal sediments and concluded that terrestrial humic-like DOM was the main component of photoproduced DOM. Previous studies (reviewed by Zepp 2003, Obernosterer and Benner 2004) also compared the effects of different substrates on the extents of photodegradation and demonstrated that photochemical degradation occurs primarily for humic-like, bio-refractory organic substrates, but much less so for algal-derived bio-labile organic matter. In addition, Mayer et al. (2009a) analyzed the photoproducts from irradiated phytoplankton detritus and also suggested that photoproduced CDOM exhibited humic-like fluorescence. In conclusion, photodissolution primarily dissolves humic moieties, regardless of the origin or bioavailability of the substrates. The extent of photochemical reaction is largely determined by the amount of available substrates.

4.4 Photochemical VS. biotic activity-mediated DOM production in photodissolution 
Significant releases of DOC and TDN were observed in sterilized sediment suspensions with autoclaved sediments and $0.2 \mu \mathrm{m}$ filtered water under solar irradiation. Since autoclaving killed living organisms in sediment suspensions and therefore ruled out the contribution from microbes or algae, radiation-stimulated photochemical degradation (as opposed to microbial-mediated degradation or stimulation of primary production by benthic algae) likely explained the mechanism of DOC and TDN production in photodissolution. Moreover, although the releases of DOC and TDN in sterilized suspensions were less than those in raw sediment suspensions, the magnitudes of reactions in both types of treatments were comparable, indicating that photochemical degradation was the primary pathway of photodissolution. However, autoclaving alters the 3-D structure of POM in sediment samples (Tuominen et al. 1994) by facilitating desorption and reducing surface areas of sediment particles (Anderson and Magdoff 2005). DOC and TDN abundances at time zero were substantially higher in autoclaved sediment suspensions than raw sediment suspensions (unpublished data, Tuominen et al. 1994). Therefore, the actual amounts of DOC and TDN releases should not be directly compared quantitatively to estimate the contributions from biotic activities. My results agreed with a previous study (Southwell et al. 2010) in which the authors conducted similar photodissolution experiments and concluded that increases in dissolved nutrients were the result of predominantly photochemical processes. In addition, it was observed that when photochemical reactions occur in irradiated water samples containing humics, microbial metabolic activities are inhibited, possibly due to the action of oxidants (e.g. hydroxyl radicals) produced in UV-driven photochemical reactions on humic substances (Lund and Hongve 1994). There has also been evidence showing that microbial activity can be inhibited under intense sunlight as in the solar simulator (Xie and Zafiriou 2009, Mayer et al. 2009b). These results from previous studies further strengthened my conclusion that microbial mediated degradation and/or benthic primary production played a minor role in photodissolution while photochemical reactions on POM acted as the primary mechanism. 
Table 1.1. DOC and TDN production after 24 hours of solar irradiation in sediment suspensions. Data shown here are the average values if replicates were analyzed in experiments. Each column represents (in order from left to right): source of sediment sample, experiment date, source of water sample, sediment organic content, amount of photoproduced DOC (mg C $\left.\mathrm{L}^{-1}\right)$, DOC concentration in water at the sample site $\left(\mathrm{mg} \mathrm{C} \mathrm{L}^{-1}\right)$, percent increase of DOC concentration after photodissolution compared to the in situ value, amount of DOC photoproduction normalized to $1 \mathrm{~g}$ (dry weight) of sediment addition (mg C $\mathrm{L}^{-1}$ $\mathrm{g}_{\text {sed }}{ }^{-1}$ ), amount of photoproduced TDN $\left(\mathrm{mg} \mathrm{N} \mathrm{L}^{-1}\right)$, TDN concentration in water at the sample site $\left(\mathrm{mg} \mathrm{N} \mathrm{L}^{-1}\right)$, percent increase of TDN concentration after photodissolution compared to the in situ value, and amount of TDN photoproduction normalized to $1 \mathrm{~g}$ (dry weight) of sediment addition $\left(\mathrm{mg} \mathrm{N} \mathrm{L}^{-1} \mathrm{~g}_{\text {sed }}{ }^{-1}\right)$.

\begin{tabular}{|c|c|c|c|c|c|c|c|c|c|c|c|}
\hline $\begin{array}{c}\text { Sediment } \\
\text { source }\end{array}$ & $\begin{array}{l}\text { Experiment } \\
\text { date }\end{array}$ & Water source & $\% \mathrm{OC}$ & $\begin{array}{c}\triangle \mathrm{DOC} \\
\mathrm{mg} \mathrm{C} \mathrm{L}^{-1}\end{array}$ & $\begin{array}{l}\text { in situ water } \\
\text { DOC } \mathrm{mg} \mathrm{C} \mathrm{L} \mathrm{L}^{-1}\end{array}$ & $\begin{array}{c}\text { Increment } \\
\% \\
\end{array}$ & $\begin{array}{c}\Delta \mathrm{DOC} \mathrm{g}^{-1} \\
\mathrm{mg} \mathrm{C} \mathrm{L}^{-1} \mathrm{~g}_{\text {sed }}\end{array}$ & $\begin{array}{c}\Delta \mathrm{TDN}^{-1} \\
\mathrm{mg} \mathrm{N} \mathrm{L}^{-1}\end{array}$ & $\begin{array}{l}\text { in situ water } \\
\text { TDN } \mathrm{mg} \mathrm{N} \mathrm{L}^{-1}\end{array}$ & $\begin{array}{c}\text { Increment } \\
\% \\
\end{array}$ & $\begin{array}{c}\Delta \mathrm{TDN} \mathrm{g}^{-1} \\
\mathrm{mg} \mathrm{N} \mathrm{L}^{-1} \mathrm{~g}_{\text {sed }}^{-1} \\
\end{array}$ \\
\hline \multirow{5}{*}{$\begin{array}{l}\text { Nueces Marsh } \\
\text { station } 450\end{array}$} & $9-30-11$ & Artificial Seawater & 2.78 & 0.40 & 8.63 & 4.63 & 0.41 & 0.06 & 0.94 & 5.96 & 0.06 \\
\hline & $5-31-12$ & Artificial Seawater & 3.86 & 0.73 & $\begin{array}{c}7.30 \\
\text { (estimated) }\end{array}$ & $\begin{array}{c}10.00 \\
\text { (estimated) }\end{array}$ & 1.23 & 0.07 & $\begin{array}{c}0.63 \\
\text { (estimated) }\end{array}$ & $\begin{array}{c}10.79 \\
\text { (estimated) }\end{array}$ & 0.12 \\
\hline & $7-5-12$ & Ship Channel & 3.29 & 0.29 & 7.19 & 4.03 & 0.64 & 0.10 & 1.02 & 9.80 & 0.22 \\
\hline & $10-7-12$ & Artificial Seawater & 2.20 & 0.25 & 7.19 & 3.48 & 0.47 & 0.05 & 1.02 & 4.51 & 0.09 \\
\hline & $10-21-12$ & Nueces Marsh 450 & 2.20 & 0.24 & 7.19 & 3.33 & 0.45 & 0.11 & 1.02 & 10.78 & 0.20 \\
\hline \multirow{2}{*}{ Copano West } & $3-29-12$ & Florida Key & 3.66 & 0.24 & 4.07 & 5.89 & 0.80 & 0.02 & 0.43 & 4.92 & 0.07 \\
\hline & $6-29-12$ & Copano West & 3.76 & 0.13 & 5.06 & 2.57 & 0.38 & 0.01 & 0.51 & 2.15 & 0.03 \\
\hline \multirow{2}{*}{$\begin{array}{l}\text { MANERR } \\
\text { Seagrass bed }\end{array}$} & $\begin{array}{l}7-30-12 \\
8-16-12 \\
\end{array}$ & Ship Channel & 7.24 & 1.05 & 3.45 & 30.43 & 3.83 & 0.15 & 0.40 & 38.23 & 0.58 \\
\hline & $7-17-12$ & $\begin{array}{c}\text { MANERR } \\
\text { Seagrass bed }\end{array}$ & 7.21 & 0.92 & 3.45 & 26.67 & 3.41 & 0.11 & 0.40 & 28.10 & 0.41 \\
\hline \multirow{2}{*}{$\begin{array}{c}\text { LLM } \\
\text { Seagrass bed }\end{array}$} & $6-22-12$ & $\begin{array}{c}\text { Ship Channel \& } \\
\text { Florida Key }\end{array}$ & 11.62 & 1.53 & 1.80 & 85.00 & 6.62 & 0.22 & 0.29 & 74.74 & 0.93 \\
\hline & $12-6-12$ & Ship Channel & 4.62 & 0.75 & 3.00 & 25.00 & 2.13 & 0.11 & 0.25 & 44.00 & 0.31 \\
\hline
\end{tabular}




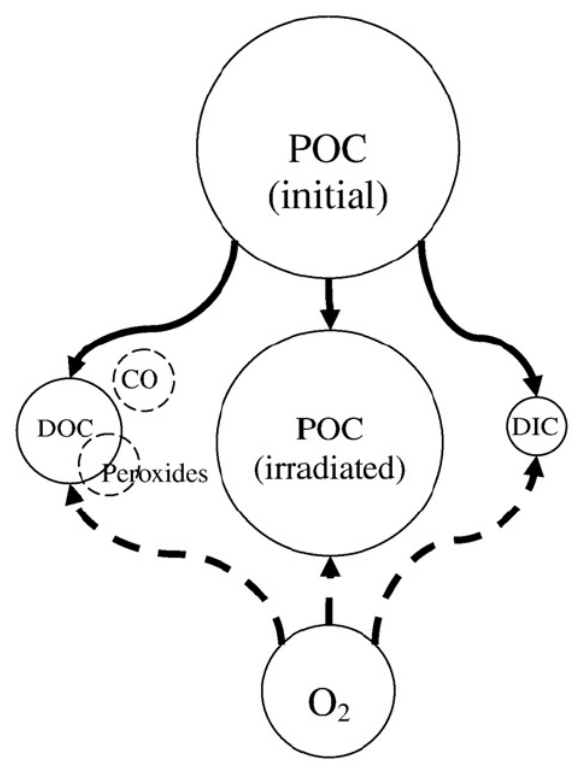

Figure 1.1. Schematic showing carbon budget during photodissolution of sedimentary POM. Areas of solid-line (POC, DOC, DIC, and $\mathrm{O}_{2}$ ) circles represent relative concentrations of labeled pools; dashed-line circles represent pools of unknown size (peroxides and CO). Solid arrows show known carbon fluxes during photodissolution, and dashed arrows show possible direction of unknown oxygen fluxes (Estapa and Mayer 2010). 


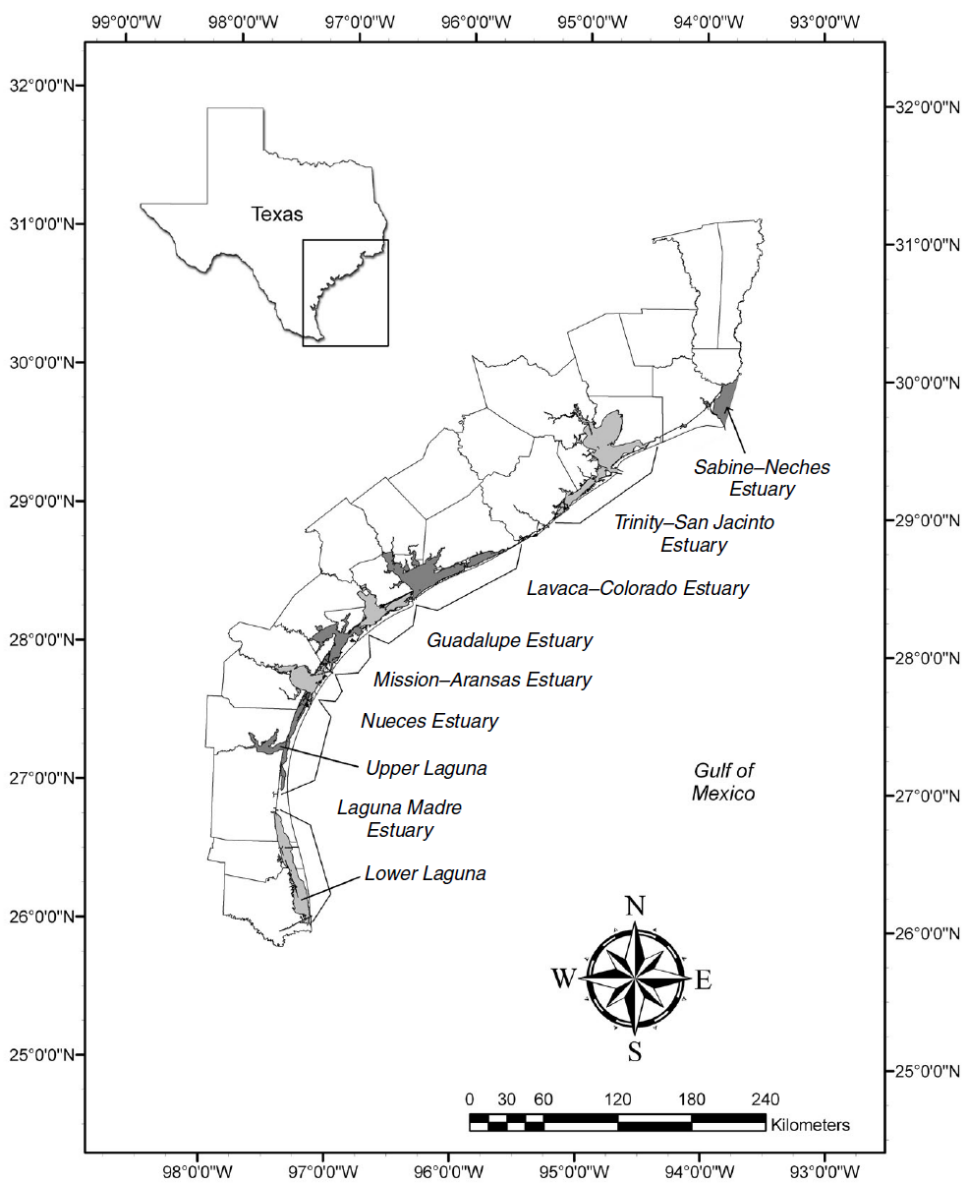

Figure 1.2. Map of the Texas coastline showing the locations of the major estuarine systems (Tolan and Fisher 2009). 


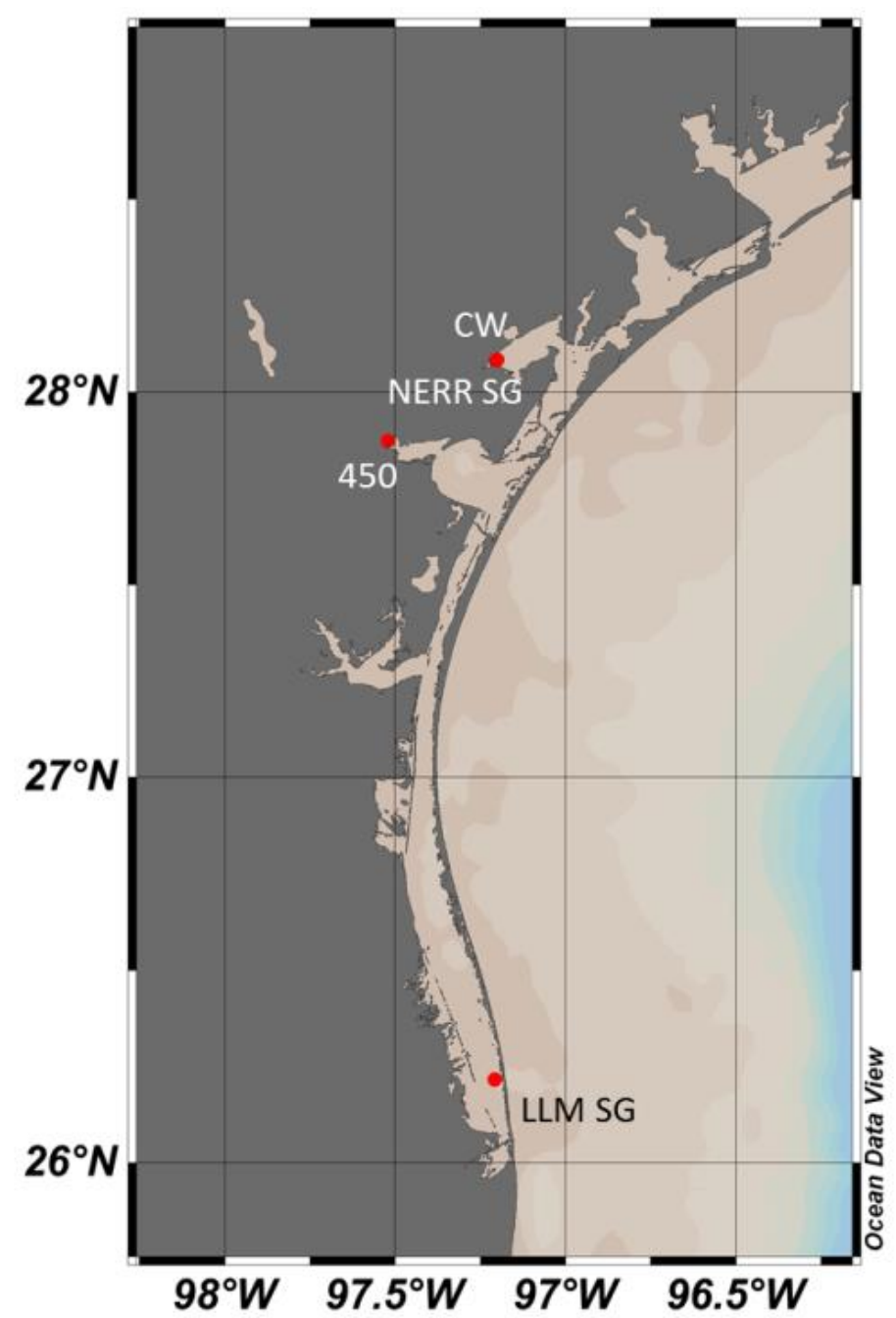

Figure 1.3. Locations of sample sites: station 450 in Nueces Marsh (450), station Copano West in Copano Bay (CW), a seagrass site within the MANERR (NERR SG, very close to $\mathrm{CW}$ ), and a seagrass site in the Lower Laguna Madre (LLM SG). 

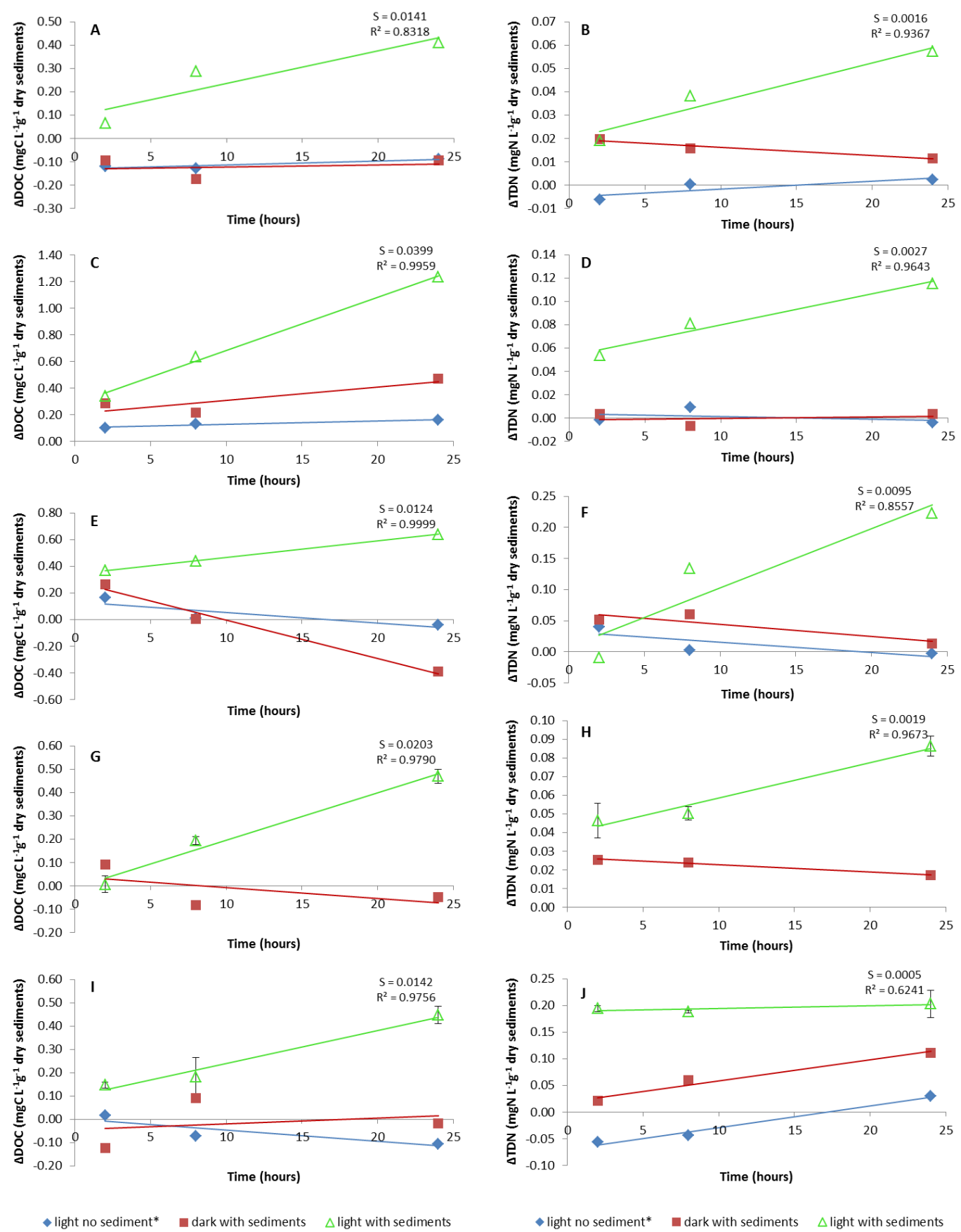

Figure 1.4. Changes in DOC (left) and TDN (right) concentrations with time normalized to $1 \mathrm{~g}$ of Nueces Marsh sediment (dry weight) addition for irradiated sediment suspensions (light with sediments) and sediment suspensions in the dark (dark with sediments). Photodissolution experiments were performed on 9-30-2011 (A, B), 5-31-2012 (C, D), 7-5-2012 (E, F), 10-7-2012 (G, H) and 10-21-2012 (I, J). Error bars represent \pm 1 standard deviation ( $\mathrm{N}=2$ or 3 ). Lines are trend lines with linear regressions; $\mathrm{S}$ is the slope of trend line for the irradiated suspension.

* Concentrations in "light no sediment" (irradiated water) treatments were not normalized. Data shown here represent the actual changes in DOC and TDN concentrations in each treatment. 

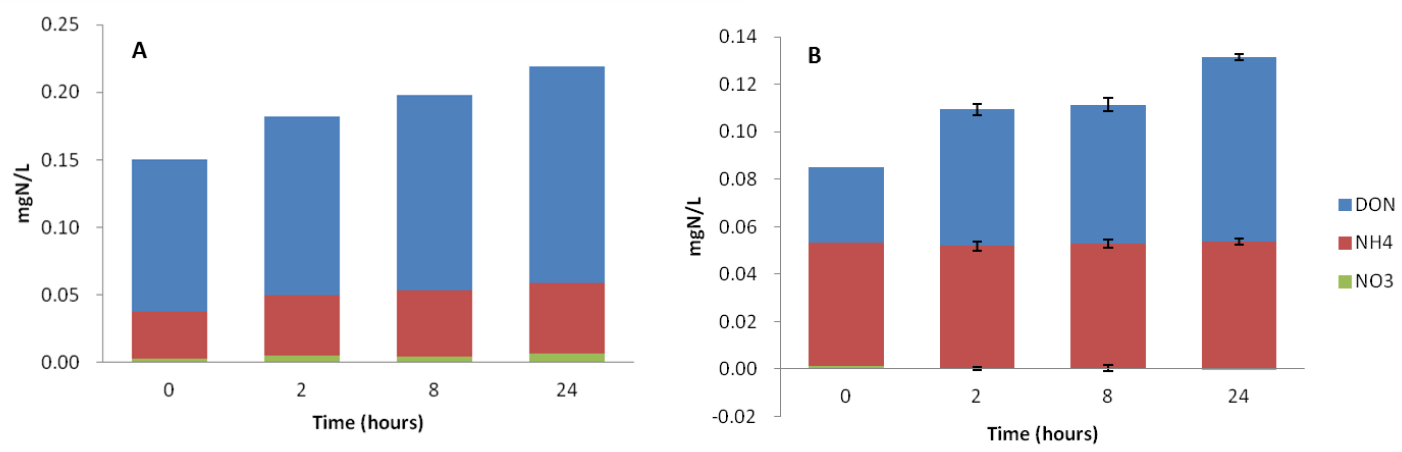

Figure 1.5. DON, $\mathrm{NH}_{4}{ }^{+}$, and $\mathrm{NO}_{3}{ }^{-}$concentrations in irradiated Nueces Marsh sediment suspensions for the photodissolution experiments on 5-31-2012 (A) and 10-7-2012 (B). Error bars represent \pm 1 standard deviation $(\mathrm{N}=2$ or 3$)$. 

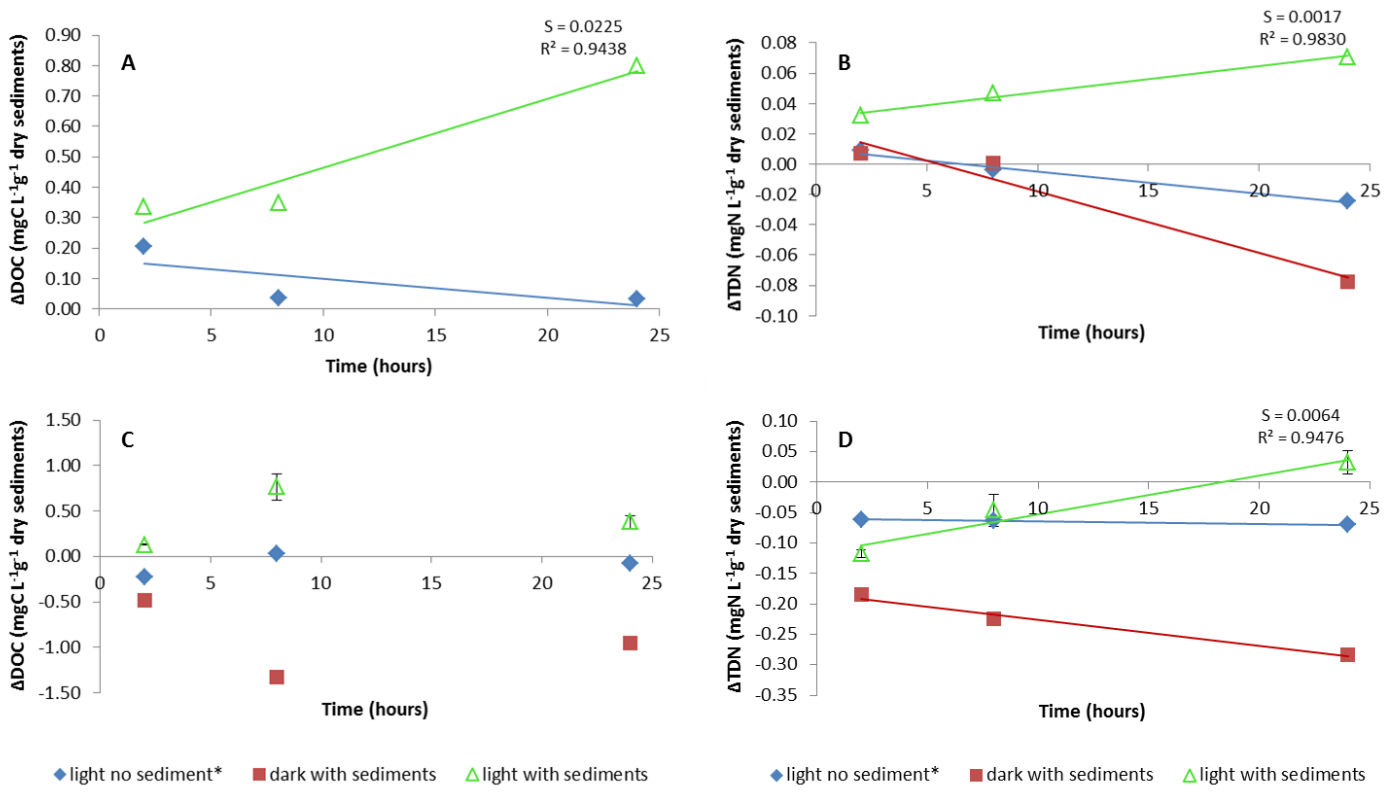

Figure 1.6. Changes in DOC (left) and TDN (right) concentrations with time normalized to $1 \mathrm{~g}$ of Copano West sediment (dry weight) addition for irradiated sediment suspensions (light with sediments) and sediment suspensions in the dark (dark with sediments). Photodissolution experiments were performed on 3-29-2012 (A, B) and 6-29-2012 (C, D). Error bars represent \pm 1 standard deviation $(\mathrm{N}=2)$. Lines are trend lines with linear regressions; $\mathrm{S}$ is the slope of trend line for the irradiated suspension indicating the rate of DOC/TDN production.

* Concentrations in "light no sediment" (irradiated water) treatments were not normalized. Data shown here represent the actual changes in DOC and TDN concentrations in each treatment. 

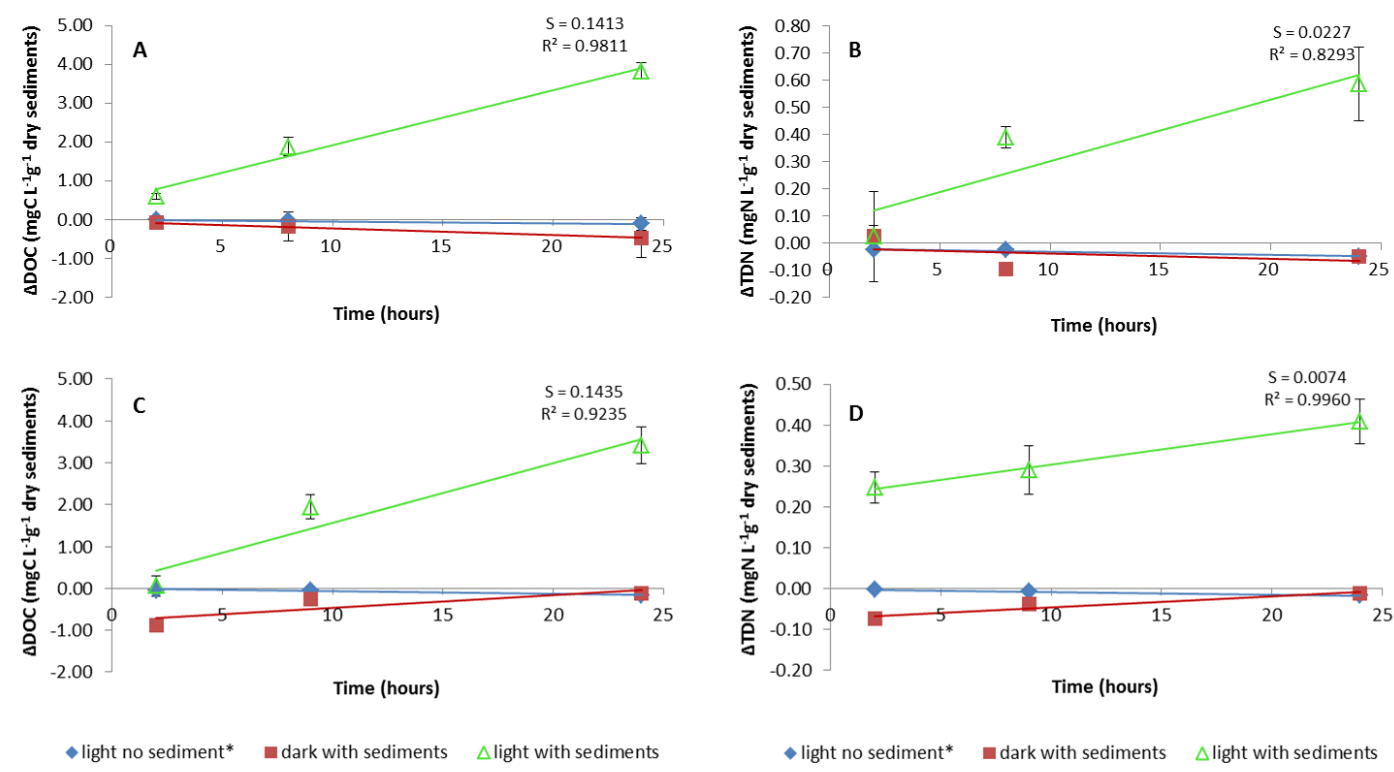

Figure 1.7. Changes in DOC (left) and TDN (right) concentrations with time normalized to $1 \mathrm{~g}$ of MANERR seagrass bed sediment (dry weight) addition for irradiated sediment suspensions (light with sediments) and sediment suspensions in the dark (dark with sediments). Photodissolution experiments were performed on 7-30-2012 \& 8-16-2012 (A, B) and 7-17-2012 (C, D). Error bars represent \pm 1 standard deviation $(\mathrm{N}=2$ or 3$)$. Lines are trend lines with linear regressions; $\mathrm{S}$ is the slope of trend line for the irradiated suspension indicating the rate of DOC/TDN production.

* Concentrations in "light no sediment" (irradiated water) treatments were not normalized. Data shown here represent the actual changes in DOC and TDN concentrations in each treatment. 


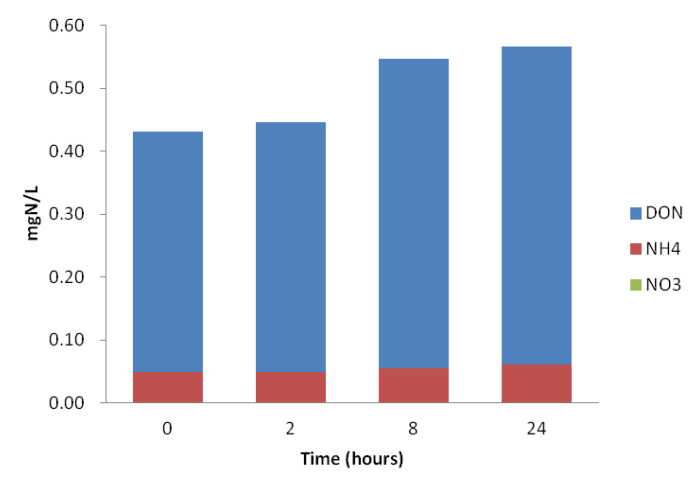

Figure 1.8. DON, $\mathrm{NH}_{4}{ }^{+}$, and $\mathrm{NO}_{3}{ }^{-}$concentrations in irradiated MANERR seagrass bed sediment suspensions for the photodissolution experiments on 8-16-2012. 

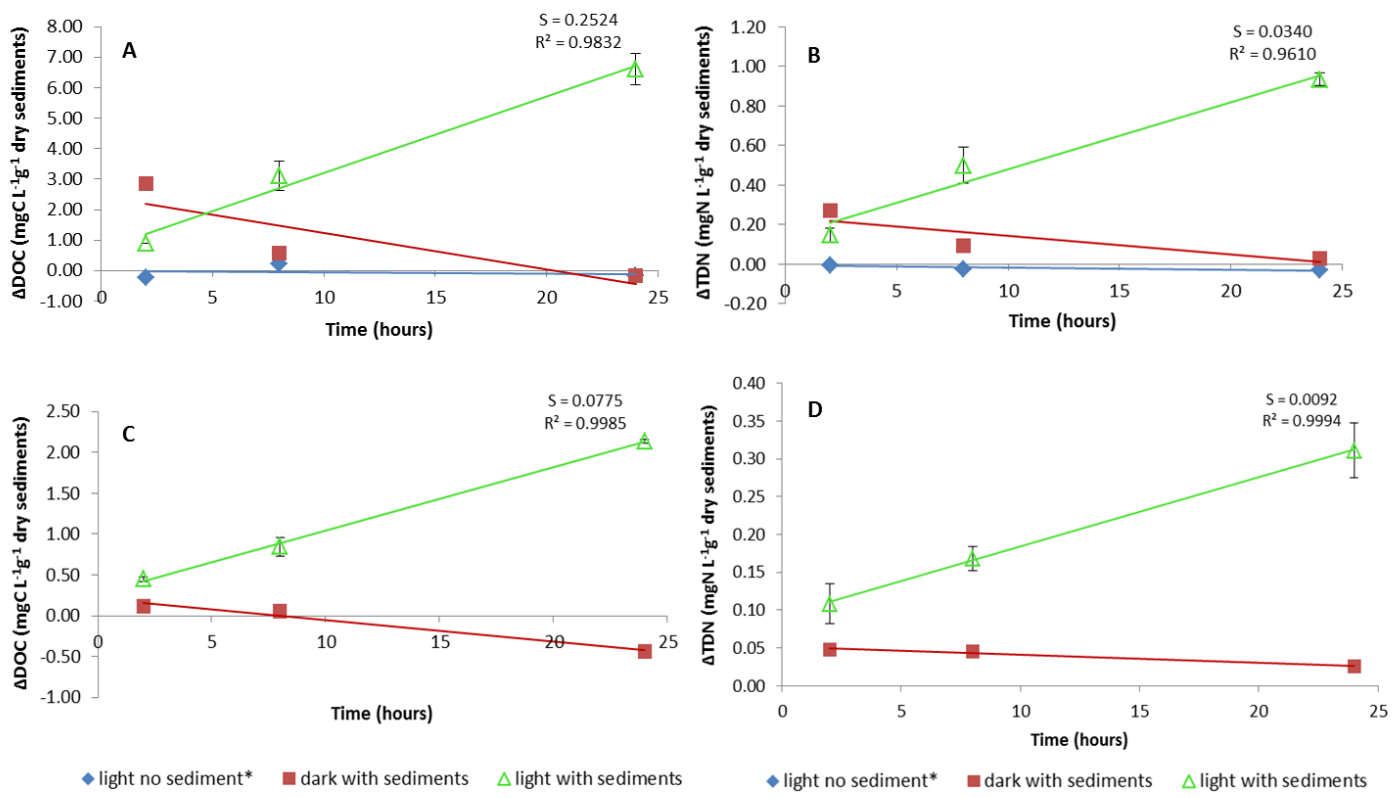

Figure 1.9. Changes in DOC (left) and TDN (right) concentrations with time normalized to $1 \mathrm{~g}$ of LLM seagrass bed sediment (dry weight) addition for irradiated sediment suspensions (light with sediments) and sediment suspensions in the dark (dark with sediments). Photodissolution experiments were performed on 6-22-2012 (A, B) and 12-6-2012 (C, D). Error bars represent \pm 1 standard deviation ( $N=2$ ). Lines are trend lines with linear regressions; $\mathrm{S}$ is the slope of trend line for the irradiated suspension indicating the rate of DOC/TDN production.

* Concentrations in "light no sediment" (irradiated water) treatments were not normalized. Data shown here represent the actual changes in DOC and TDN concentrations in each treatment. 


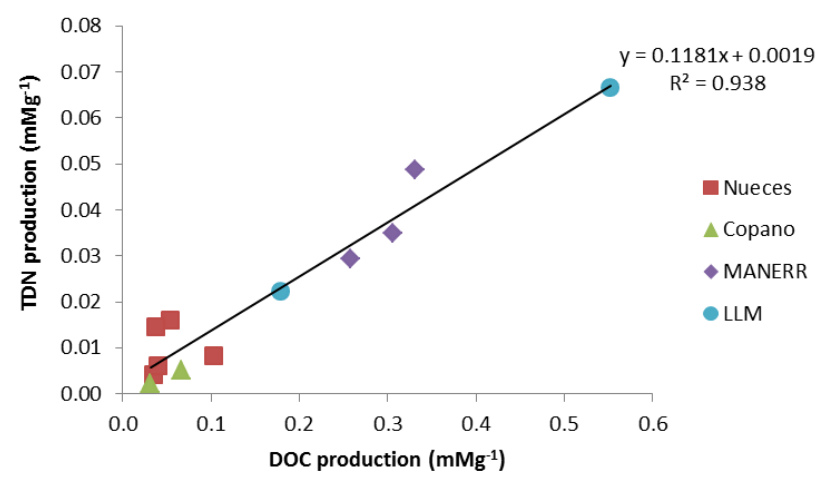

Figure 1.10. TDN versus DOC produced from photodissolution reactions at 24 hours normalized to $1 \mathrm{~g}$ of sediment (dry weight) addition. All the photodissolution experiments using sediments from Nueces Marsh, Copano West, MANERR seagrass bed and LLM seagrass bed were plotted together. The trend line is a linear fit of all the data points. DOC and TDN productions were measured in $\mathrm{mmol} \mathrm{L}^{-1} \mathrm{~g}^{-1}$. 

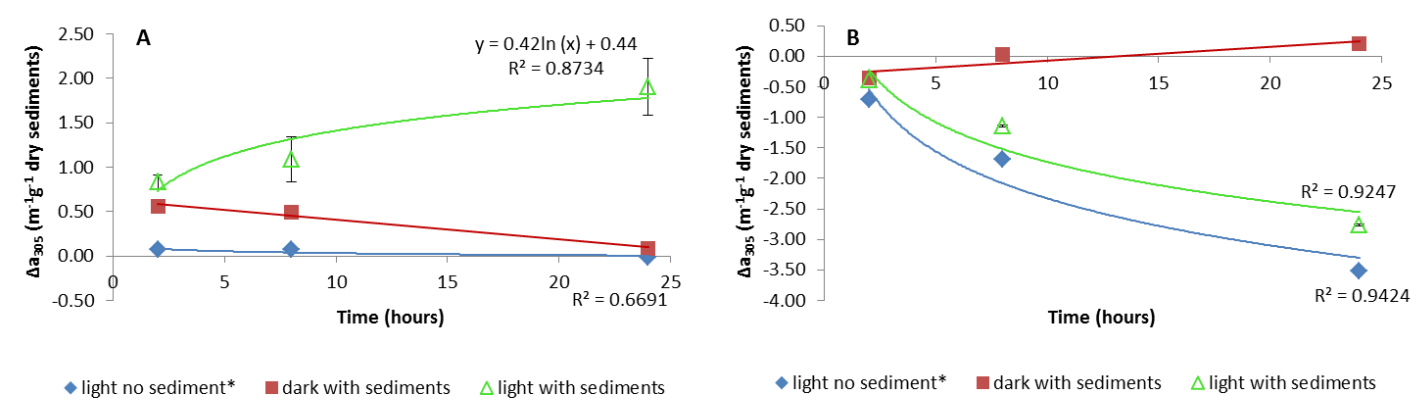

Figure 1.11. Changes in CDOM abundance $\left(a_{305}\right)$ with time normalized to $1 \mathrm{~g}$ of Nueces Marsh sediment (dry weight) addition for irradiated sediment suspensions (light with sediments) and sediment suspensions in the dark (dark with sediments). Photodissolution experiments were performed on 10-7-2012 (A) and 10-21-2012 (B). Error bars represent \pm 1 standard deviation $(\mathrm{N}=2)$. Curves are the trend lines with logarithmic $(\mathrm{ln})$ regression for the irradiated treatments. Lines are trend lines with linear regression for dark suspensions.

* Concentrations in "light no sediment" (irradiated water) treatments were not normalized. Data shown here represent the actual changes in $a_{305}$ in each treatment. 


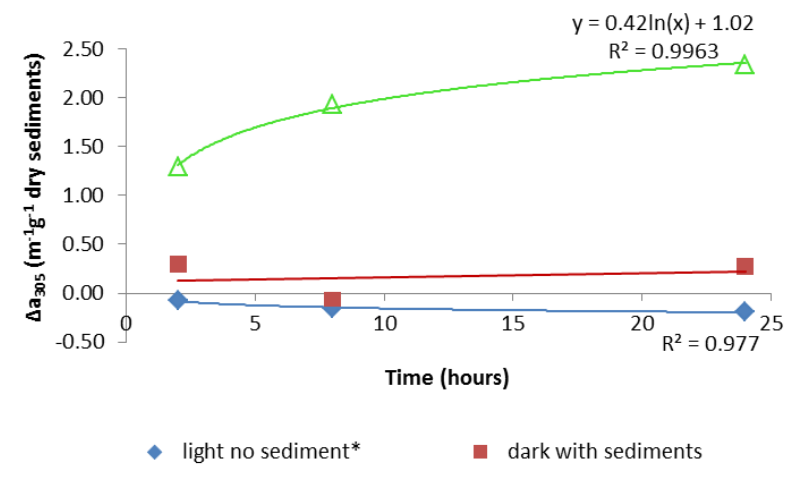

Figure 1.12. Changes in CDOM abundance ( $\left.a_{305}\right)$ with time normalized to $1 \mathrm{~g}$ of Copano West sediment (dry weight) addition for irradiated sediment suspensions (light with sediments) and sediment suspensions in the dark (dark with sediments). Photodissolution experiments were performed on 3-29-2012. Curves are the trend lines with logarithmic (ln) regression for the irradiated treatments. Lines are trend lines with linear regression for dark suspensions.

* Concentrations in "light no sediment" (irradiated water) treatments were not normalized. Data shown here represent the actual changes in $a_{305}$. 


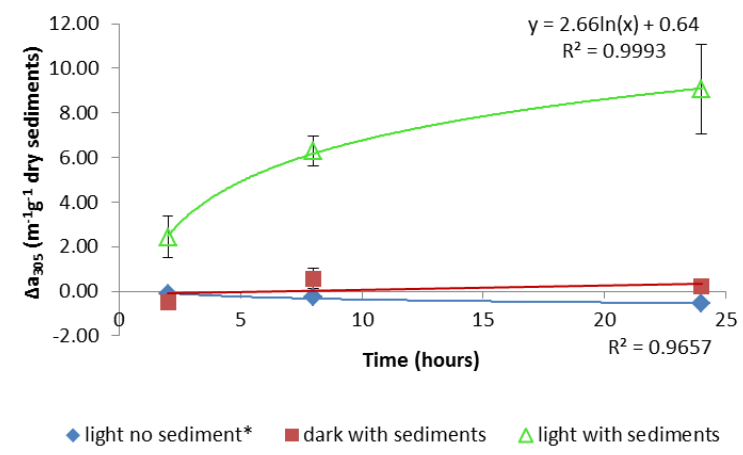

Figure 1.13. Changes in CDOM abundance $\left(a_{305}\right)$ with time normalized to $1 \mathrm{~g}$ of MANERR seagrass bed sediment (dry weight) addition for irradiated sediments suspension (light with sediments) and sediment suspensions in the dark (dark with sediments). Photodissolution experiments were performed on 7-30-2012 and 8-16-2012. Error bars represent \pm 1 standard deviation $(\mathrm{N}=2$ or 3 ). Curves are the trend lines with logarithmic (ln) regression for the irradiated treatments. Lines are trend lines with linear regression for dark suspensions.

* Concentrations in "light no sediment" (irradiated water) treatments were not normalized. Data shown here represent the actual changes in $a_{305}$. 

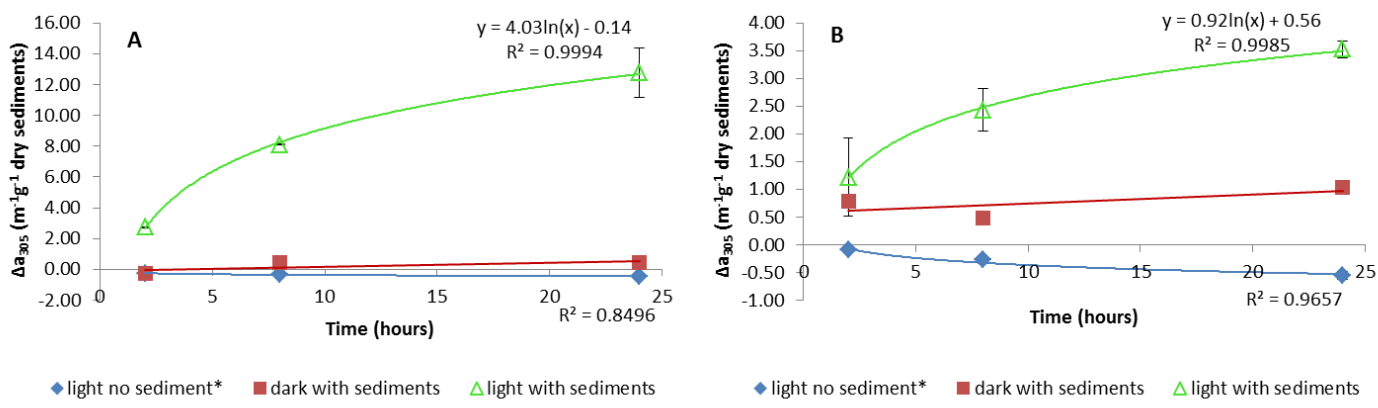

Figure 1.14. Changes in CDOM abundance ( $\left.a_{305}\right)$ with time normalized to $1 \mathrm{~g}$ of LLM seagrass bed sediment (dry weight) addition for irradiated sediment suspensions (light with sediments) and sediment suspensions in the dark (dark with sediments). Photodissolution experiments were performed on 6-22-2012 (A) and 12-6-2012 (B). Error bars represent \pm 1 standard deviation $(\mathrm{N}=2)$. Curves are the trend lines with logarithmic (ln) regression for the irradiated treatments. Lines are trend lines with linear regression for dark suspensions.

* Concentrations in "light no sediment" (irradiated water) treatments were not normalized. Data shown here represent the actual changes in $a_{305}$ in each treatment. 


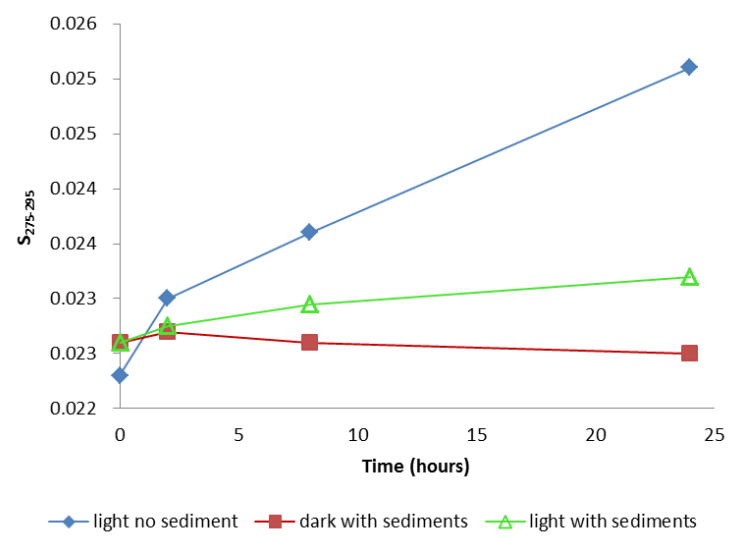

Figure 1.15. Spectral slope $\left(S_{275-295}\right)$ of CDOM pools in irradiated sediment suspensions (light with sediments), sediment suspensions in the dark (dark with sediments) and irradiated water (light no sediment). Experiment was performed on 10-21-2012 using Nueces Marsh sediments and Nueces Marsh water. 


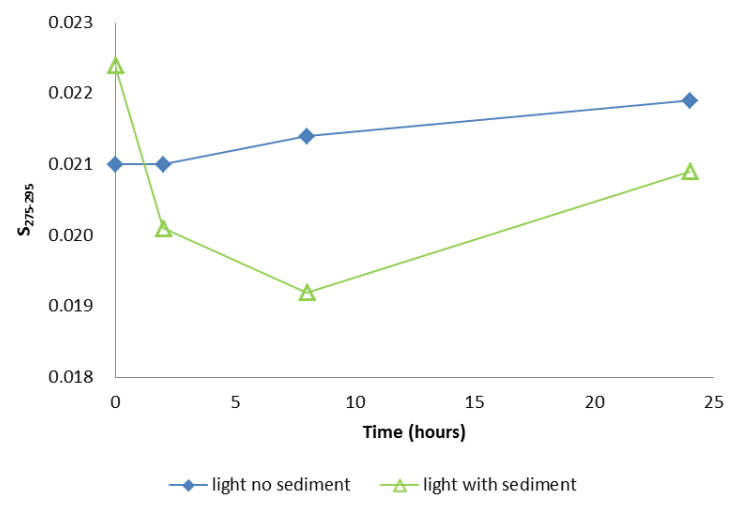

Figure 1.16. Spectral slope $\left(S_{275-295}\right)$ of CDOM pools in irradiated sediment suspensions (light with sediments) and irradiated water (light no sediment). Experiment was performed on 8-16-2012 using MANERR seagrass bed sediments and Ship Channel water. 


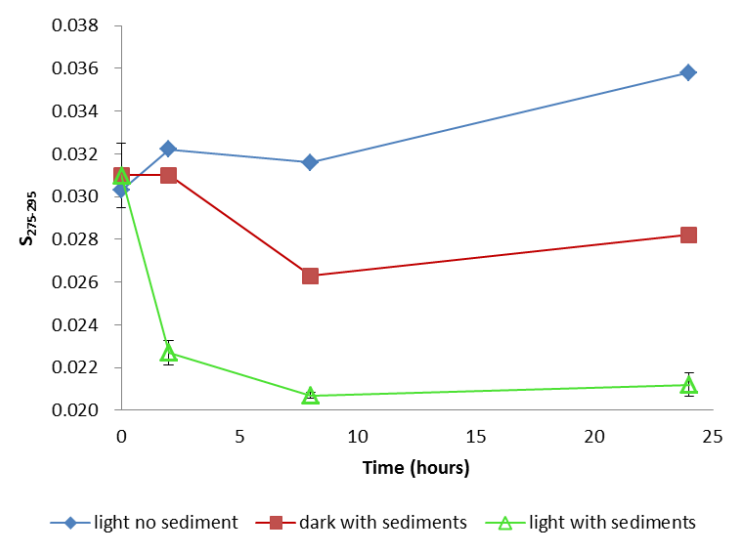

Figure 1.17. Spectral slope $\left(S_{275-295}\right)$ of CDOM pools in irradiated sediment suspensions (light with sediments), sediment suspensions in the dark (dark with sediments) and irradiated water (light no sediment). Experiment was performed on 6-22-2012 using LLM seagrass bed sediments and Ship Channel water mixed with Florida Key water. Error bars represent \pm 1 standard deviation $(\mathrm{N}=2)$. 


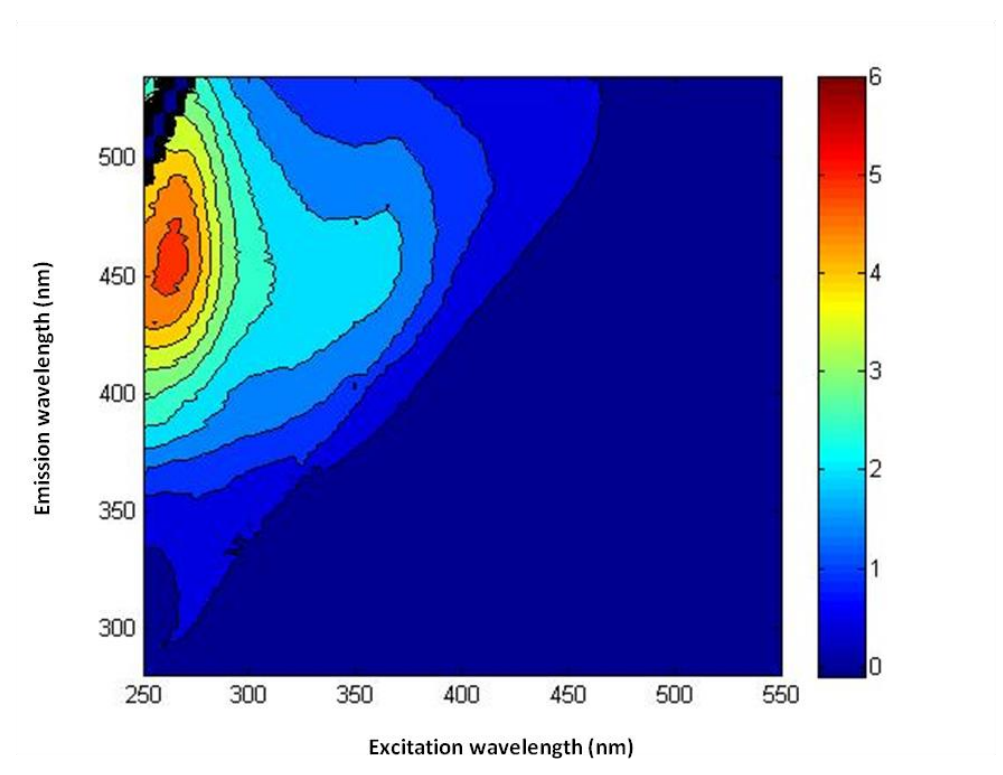

Figure 1.18. EEMs of CDOM in irradiated Nueces Marsh sediment suspension at 24 hours. Experiment was performed on 10-7-2012. Artificial seawater was used to prepare sediment suspensions. Scale bar represents fluorescence intensity (QSE). The dominant fluorescence peak $\mathrm{F}_{\max }$ was at $(256,464 \mathrm{~nm}), \mathrm{FI}=0.80$, BIX=0.54, HIX=0.94. 

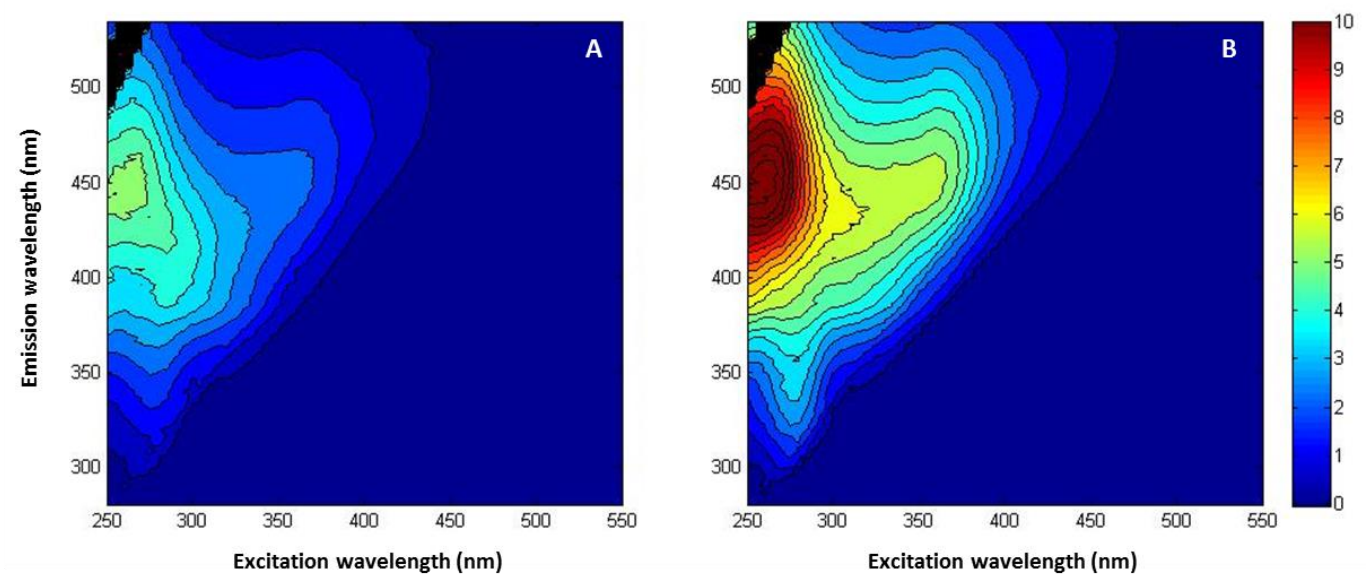

Figure 1.19. EEMs of CDOM in irradiated MANERR Seagrass Bed sediment suspension at 0 hours (A) and 24 hours (B). Experiment was performed on 8-16-2012. Ship Channel water was used to prepare sediment suspensions. Scale bar represents fluorescence intensity (QSE). Before photodissolution at 0 hour: $F_{\max }$ at $(265,450 \mathrm{~nm}), \mathrm{FI}=0.69$, $\mathrm{BIX}=0.76$, HIX $=0.66$. After photodissolution at 24 hours: $F_{\max }$ at $(260,446 \mathrm{~nm}), \mathrm{FI}=0.71$, $\mathrm{BIX}=0.61$, HIX $=0.80$. 

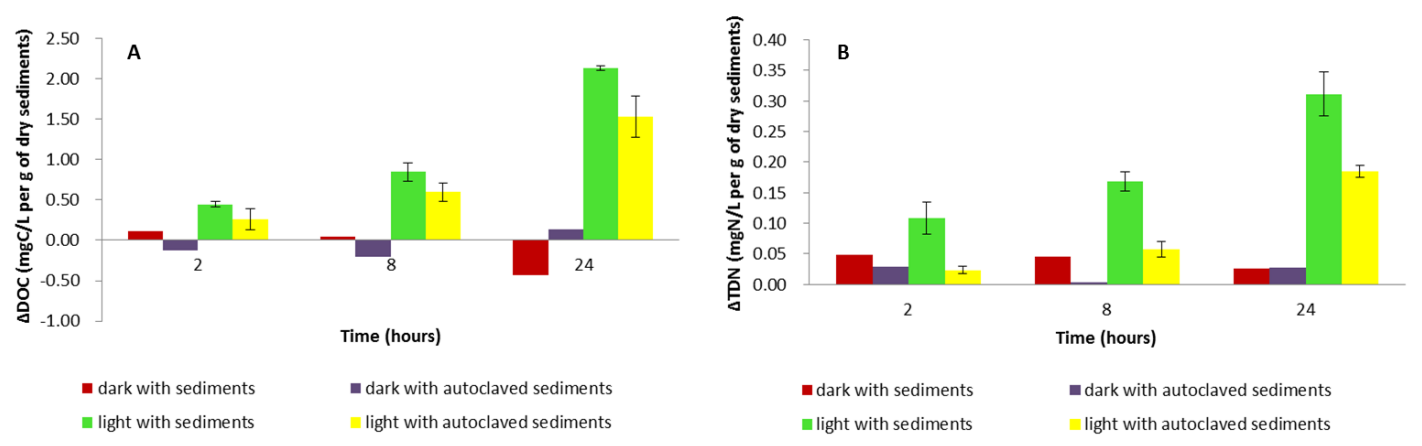

Figure 1.20. Comparison of photodissolution experiments using raw versus autoclaved sediments. Changes of DOC (A) and TDN (B) concentrations with time were normalized to $1 \mathrm{~g}$ of LLM seagrass bed sediment (dry weight) addition in sediment suspensions. Error bars represent \pm 1 standard deviation $(\mathrm{N}=2)$. 


\section{Chapter 2: Environmental and Mechanistic Limiting Factors on Photodissolution of Particulate Organic Matter in Texas Estuaries}

\section{Introduction}

Among the previous studies on photodissolution, only two have attempted to identify the environmental or mechanistic limiting factors controlling the extent of photodissolution (Mayer et al. 2006, Southwell et al. 2011). Mayer et al. (2006) tested the influences of several environmental factors on photodissolution and concluded that light intensity and temperature were strong controllers of the reaction extent and that solution conditions (salinity, ion composition, etc.) or iron oxyhydroxide removal did not have significant influences. Southwell et al. (2011) connected sediment characteristics to photodissolution efficiency and suggested that POM source and diagenetic state had significant effects on photodissolution.

Sediments undergo dry-rewet cycles in large areas of shallow estuarine systems but no study has investigated the effect of sediment desiccation on photodissolution. Water organic content in Texas estuaries varies greatly due to episodic fresh water input. Although it was observed that water type had little influence on photodissolution, Mayer et al. (2006) proposed that dissolved and particulate organic matter may compete absorbing light in water containing a significant amount of DOM. To further the study on factors controlling photodissolution, especially in Texas estuarine environments, this chapter investigated the effects of sediment desiccation, organic content of water samples, and sediment characteristics (organic content and lability of POM) on photodissolution.

\subsection{Sediment desiccation}

Coastal marsh sediments are subject to dry-rewet cycles due to fluctuations in river flows and precipitation, as well as tidal dynamics. Since the marsh sediment grain complex typically contains a mineral base and organic matter coating, its 3-D structure determines the chemical reactivity of the matrix. The 3-D structure of the sediment 
complex can be altered substantially in terms of volume, conformation, and surface functional groups under desiccation conditions (Liu and Lee 2006). For example, dry soil organic matter is degraded more easily by microbial activities (Marumoto et al. 1977). DOC concentrations can decrease substantially in dry-rewetted soil after rewetting, whereas the DOC concentrations are often consistent in moist soil and can be stable over a long period of time (Boyer and Groffman 1996, Lundquist 1997). Drying can augment sediment hydrophobicity and thus enable dry sediments to sorb more hydrophobic compounds but less hydrophilic compounds (Liu and Lee 2006, 2007).

The Nueces estuary, including Nueces delta, is influenced by a variety of hydro-meteorological factors, such as precipitation, river flow, winds and tides (Ward et al. 2002). The Nueces estuary is characterized by extreme variability in precipitation and freshwater inflow, resulting in distinct and intense drought or flooding periods (Forbes and Dunton 2006). The channels, ponds, and tidal creeks throughout the Nueces River Delta often dry up during the summer, leaving large hypersaline mudflats (Ward 1985). Climate changes and damming in the most recent decades have aggravated the severity of droughts (Bureau of Reclamation 2000). Over a smaller time scale, since winds and tides have substantial influences on water levels in tidal creeks throughout Nueces Marsh, sediments undergo desiccation-rewet events following tidal rhythms especially during low river flow seasons (Ward et al. 2002). Desiccation-rewet events can cause sedimentary organic matter to change conformation and its interaction with dissolved ions (Liu and Lee 2006). Therefore, if desiccation-rewet events could significantly influence photodissolution reactions, it may be a major factor affecting the extent of photodissolution in Nueces Estuary and many other intertidal estuarine regions.

\subsection{Interaction between DOM and POM in photoreactions}

Photoreactions alter the chemical structures of organic molecules, influence nutrient availability, oxidation capacity, extent of microbial activity, and water optical properties (Gao and Zepp 1998). Photochemical degradation of both DOM and POM occurs in aquatic systems, and photoalteration of DOM could possibly lead to changes in 
water chemistry and may further influence the extent of POM photoreactions within the same system. Because many organic molecules in solution are capable of adsorbing to the surfaces of sediment particles or/and being absorbed into the 3-D structure of sediment grain matrices (Stumm and Morgan 1996, Liu and Lee 2006), the photomineralization rates of sedimentary POM may be limited by organic matter adsorbed to grain surfaces (Keil et al. 1994, Mayer 1994). Further, when sorbed to sediment grains, non-photoreactive organic molecules may occupy the surface of the particles and inhibit the progress of POM photodissolution. Thus, the interactions between DOM and POM are of significant importance in investigating organic degradations during photodissolution processes.

\subsection{Characteristics of sedimentary POM}

Similar to DOM in aquatic systems, sedimentary POM generally falls into two categories: allochthonous/terrestrial and autochthonous/microbial originated. Terrestrial derived sedimentary POM (such as humic acid, fulvic acid, structural carbohydrates and black carbon) is typically refractory to biodegradation, and thus usually accounts for the majority of the sedimentary POM pool (Pusceddu et al. 2009). In contrast, microbial derived sedimentary POM (such as protein, carbohydrates and lipid) is often susceptible to rapid microbial degradation and consumed quickly in aquatic systems (Pusceddu et al. 2009). POM microbial degradation typically uses labile organic matter as substrates selectively; whereas recent studies have suggested that photochemical degradation of POM involves humic-like components primarily, with only minor effects on protein-like components (review by Zepp 2003, Shank et al. 2011, Pisani et al. 2011). Thus, the source and lability of POM may be an important factor controlling POM photoreactivity.

Sediment organic content depends on the interplay between the processes of supply and preservation of organic matter, and is also related to grain texture, diagenetic status/age and the biological lability of organic matter (Calvert 1987). When POM settles from the water column, it first accumulates at the sediment surface where it undergoes further degradation. Surface sediments typically contain higher amounts of organic matter 
that is more biologically labile because recently settled particles are more readily metabolized (Calvert 1987). Previously deposited sediments may resuspend in the water column, and the organic content of suspended particles is likely to affect the amount of organic matter released during photodissolution. Two studies (Kieber et al. 2006, Shank et al. 2011) investigated the influence of POM organic content on photoproduction of DOC from resuspened estuarine sediments and both concluded that DOC production was strongly proportional to the organic content of sediment samples. Overall, sediment characteristics may substantially influence the extent of photodissolution as a mechanistic controlling factor.

\subsection{Thesis statement}

The general research questions guiding this study are:

(1) What environmental/mechanistic factors control photodissolution processes, and

(2) To what extent does each factor influence photodissolution?

The hypotheses are:

(1) Drying enhances photodissolution of sedimentary POM;

(2) Organic content of water used in sediment suspensions has no significant effect on the extent of photodissolution, but a combined influence of drying and water organic content significantly influences photodissolution;

(3) Photodissolution reactions involve biologically refractory, humic-like sedimentary POM substrates preferentially;

(4) Sediment organic content is a strong controlling factor in photodissolution and the production of DOC and TDN is proportional to sediment organic content.

\section{Approaches and Methods}

2.1 Desiccated sediment suspension photodissolution experiments

Sediment samples were dried in an isothermo oven for $24-48$ hours at $60^{\circ} \mathrm{C}$ to prepare dry sediment suspensions. After drying, sediment samples were mixed with $1 \mathrm{~L}$ 
filtered water to make suspensions. Wet sediment suspensions were set up in the same way as described in Chapter 1, 2.5. The amount of dry sediment addition was the same as the dry weight of the samples added in wet sediment suspensions. Upon the onset of each photodissolution experiment, samples were collected for DOC, TDN, and CDOM analyses at $0,2,8$ and 24 hours.

2.2 Photodissolution experiments using organic rich VS. organic poor water samples

In photodissolution experiments using Nueces Marsh sediment samples, $0.2 \mu \mathrm{m}$ filtered water from Nueces Marsh was used as "organic rich" water, while artificial seawater (salinity=35 ppt) was used as "organic poor" water. Excluding controls, this experiment was composed of four treatments:

(1) Wet sediments mixed with Nueces Marsh water;

(2) Wet sediments mixed with artificial seawater;

(3) Dry sediments mixed with Nueces Marsh water; and

(4) Dry sediments mixed with artificial seawater.

Dry weights of sediments added were equal for each suspension. In experiments using MANERR seagrass bed sediments, water collected from the same seagrass site was filtered and used as the "organic rich" water, while filtered water from Port Aransas ship channel was used as "organic poor" water. Similarly, this experiment was composed of four treatments:

(1) Wet sediments mixed with MANERR water;

(2) Wet sediments mixed with Ship Channel water;

(3) Dry sediments mixed with MANERR water; and

(4) Dry sediments mixed with Ship Channel water.

All treatments were kept under the same incubation conditions and samples were collected at time intervals as described in Chapter 1, 2.5.

2.3 Photodissolution experiments using top $\sim 5 \mathrm{~mm}$ VS. upper $\sim 2 \mathrm{~cm}$ sediments

Top layer sediments are typically fresher, more labile, and contain more microbial 
biomass than deeper sediments (Calvert 1987). For this study, photodissolution of top layer sediments $(\sim 5 \mathrm{~mm})$ was compared to photodissolution of upper $\sim 2 \mathrm{~cm}$ sediments. The very top layer $(\sim 5 \mathrm{~mm})$ of sediment samples were collected from sediment core samples, upper $\sim 2 \mathrm{~cm}$ sediment samples were subsequently collected from the same core. Dry weights of sediment samples were equivalent for each sediment suspension. Photodissolution experiments were performed as described in Chapter 1, 2.5.

\section{Results}

\subsection{Influence of desiccation-rewet on photodissolution}

DOC, TDN, and CDOM abundance increased with time in both wet and dry-rewetted sediment suspensions under solar irradiation (Figure 2.1). However, photoproduction of DOC, TDN, and CDOM was substantially higher in dry-rewetted sediment suspensions than in wet sediment suspensions $(\mathrm{p}<0.03)$. After 24 hours of photoincubation, DOC, TDN, and $a_{305}$ concentrations increased by $0.47 \mathrm{mg} \mathrm{C} \mathrm{L}^{-1} \mathrm{~g}_{\text {sed }}{ }^{-1}$, $0.086 \mathrm{mg} \mathrm{N} \mathrm{L}^{-1} \mathrm{~g}_{\text {sed }}{ }^{-1}$ and $1.90 \mathrm{~m}^{-1} \mathrm{~g}_{\text {sed }}{ }^{-1}$ in wet sediment suspensions, respectively, and by $0.65 \mathrm{mg} \mathrm{C} \mathrm{L}^{-1} \mathrm{~g}_{\text {sed }}{ }^{-1}, 0.126 \mathrm{mg} \mathrm{N} \mathrm{L}^{-1} \mathrm{~g}_{\text {sed }}{ }^{-1}$ and $2.20 \mathrm{~m}^{-1} \mathrm{~g}_{\text {sed }}{ }^{-1}$ in dry-rewetted sediment suspensions, respectively.

Upon sediment addition, the $S_{275-295}$ values in dry-rewetted sediment suspensions were much higher than those in wet sediment suspensions (Figure 2.2). However, the difference did not persist: no significant difference in $S_{275-295}$ values was observed between wet and dry-rewetted suspensions after the second time point ( 2 hours). The $S_{275-295}$ values in irradiated wet sediment suspensions increased gradually with time throughout the incubation period, while the $S_{275-295}$ values in dry-rewetted sediment suspensions increased from 2 hours to 24 hours during photoincubation.

The EEMs peaks of both wet and dry-rewetted sediment suspensions were located at approximately the same location after 24 hours of irradiation (Figure $2.3 \mathrm{~A}, \mathrm{~B}$ ), representing the production of primarily humic-like organic matter in both photodissolution experiments. The peak fluorescence signal was more intense in 
dry-rewetted suspensions $\left(F_{\max }=6.39\right)$ than in the wet suspensions $\left(F_{\max }=5.24\right)$. To examine the difference in EEMs between the dry and the wet sediment suspensions, the fluorescence signal matrix of the 24 hours irradiated wet sediment suspension was subtracted from the dry sediment suspension (Figure $2.3 \mathrm{C}$ ). The peak of the resulting matrix was still located at the humic-like organic matter zone, implying that dry sediments released the same type of DOM during photodissolution as wet sediments, even though the dry sediment suspension produced more DOM quantitatively.

\subsection{Influence of organic content of water on photodissolution}

The magnitude of DOC photoproduction from resuspended Nueces Marsh sediments was similar in artificial seawater $\left(0.47 \mathrm{mg} \mathrm{C} \mathrm{L}^{-1} \mathrm{~g}_{\text {sed }}{ }^{-1}\right)$ and in Nueces Marsh water $\left(0.45 \mathrm{mg} \mathrm{C} \mathrm{L}^{-1} \mathrm{~g}_{\text {sed }}{ }^{-1}\right)$ throughout the photoincubation periods (Figure $2.4 \mathrm{~A}, \mathrm{C}$ ). However, the trend of TDN production was different in the two treatments: TDN concentration increased gradually in artificial seawater during 24 hours of irradiation (Figure $2.4 \mathrm{~B}$ ) whereas TDN increased fast in the first two hours and remained at approximately the same level during the rest of incubation period in Nueces Marsh water (Figure $2.4 \mathrm{D}$ ). By the end of 24 hours of photoincubation, about twice as much TDN was produced from POM in Nueces Marsh water compared to that produced in artificial seawater. Nevertheless, the differences between the irradiated treatment and the corresponding dark control were similar in both experiments at 24 hours ( $>0.05)$, with $\Delta \mathrm{TDN}=0.067 \mathrm{mg} \mathrm{N} \mathrm{L}^{-1} \mathrm{~g}_{\text {sed }}{ }^{-1}$ in artificial seawater (Figure $2.4 \mathrm{~B}$ ) and $0.091 \mathrm{mg} \mathrm{N} \mathrm{L}^{-1}$ $\mathrm{g}_{\text {sed }}{ }^{-1}$ in Nueces Marsh water (Figure 2.4 D).

Changes in DOC concentrations followed the same trend in both of the photodissolution experiments using MANERR seagrass bed sediments and Ship Channel water (organic-poor) versus MANERR water (organic-rich) (Figure $2.5 \mathrm{~A}, \mathrm{C}$ ). The amounts of DOC photoproduction were similar (3.41 versus $3.83 \mathrm{mg} \mathrm{C} \mathrm{L}^{-1} \mathrm{~g}_{\text {sed }}{ }^{-1}$ ) in both experiments despite the organic content of water $(p>0.05)$. The amounts of TDN produced in photodissolution were comparable in both of the experiments, at $0.58 \mathrm{mg} \mathrm{N}$ $\mathrm{L}^{-1} \mathrm{~g}_{\mathrm{sed}}{ }^{-1}$ in Ship Channel water (Figure $2.5 \mathrm{~B}$ ) and $0.41 \mathrm{mg} \mathrm{N} \mathrm{L}^{-1} \mathrm{~g}_{\mathrm{sed}}{ }^{-1}$ in MANERR 
water (Figure 2.5 D). TDN concentration increased gradually in Ship Channel water throughout the incubation period (Figure 2.5 B), but increased rapidly in the first 2 hours and slowed down after 2 hours in MANERR water (Figure 2.5 D). Regardless of water type, photodissolution of MANERR seagrass bed sediments produced much more DOC and TDN (Figure 2.5) as compared to those observed in Nueces Marsh sediment photodissolution experiments (Figure 2.4).

3.3 Combined influence of water organic content and desiccation on photodissolution

Artificial seawater was used as organic-poor water while Nueces Marsh water was used as organic-rich water in this experiment. In artificial seawater, dry-rewetted sediments produced more DOC and TDN than wet sediments under solar irradiation $(\mathrm{p}<0.03)$ (Figure $2.6 \mathrm{~A}, \mathrm{~B})$. By the end of the photoincubation periods, wet sediment suspensions produced $0.47 \mathrm{mg} \mathrm{C} \mathrm{L}^{-1} \mathrm{~g}_{\text {sed }}{ }^{-1} \mathrm{DOC}$ and $0.086 \mathrm{mg} \mathrm{N} \mathrm{L}^{-1} \mathrm{~g}_{\text {sed }}{ }^{-1} \mathrm{TDN}$, while dry-rewetted sediment suspensions produced $0.65 \mathrm{mg} \mathrm{C} \mathrm{L}^{-1} \mathrm{~g}_{\text {sed }}{ }^{-1}$ DOC and $0.126 \mathrm{mg} \mathrm{N}$ $\mathrm{L}^{-1} \mathrm{~g}_{\text {sed }}{ }^{-1} \mathrm{TDN}$. However, the trend was different in Nueces Marsh water. After 24 hour of irradiation, wet sediment suspensions produced $0.45 \mathrm{mg} \mathrm{C} \mathrm{L}^{-1} \mathrm{~g}_{\mathrm{sed}}{ }^{-1} \mathrm{DOC}$, slightly higher than that in dry-rewetted sediment suspensions (0.35 $\mathrm{mg} \mathrm{C} \mathrm{L}^{-1} \mathrm{~g}_{\text {sed }}{ }^{-1}$ ) (Figure 2.6 C). DOC concentrations in wet sediment suspensions using Nueces Marsh water were not always lower than those in dry-rewetted sediment suspensions, but the wet suspensions tended to produce more DOC eventually after 24 hours of photoincubation (Figure $2.6 \mathrm{C}$ ). However, photoproduction of TDN in wet sediment suspensions was $0.20 \mathrm{mg} \mathrm{N} \mathrm{L}^{-1} \mathrm{~g}_{\text {sed }}{ }^{-1}$, substantially higher than that in dry-rewetted sediment suspensions $\left(0.058 \mathrm{mg} \mathrm{N} \mathrm{L}^{-1} \mathrm{~g}_{\text {sed }}{ }^{-1}\right)$ $(\mathrm{p}=0.03)$ (Figure $2.6 \mathrm{D})$. In summary, dry-rewetted sediments went through more extensive photodissolution than wet sediments in organic-poor water, whereas the opposite occurred in organic-rich water.

\subsection{Substrate preference during photodissolution}

After 24 hours of incubation, the suspension using the upper $\sim 2 \mathrm{~cm}$ sediments in the dark showed single peaks at $(265,456 \mathrm{~nm})$ (Figure $2.7 \mathrm{~A})$, representing humic-like 
organic matter. However, the dark suspension using top layer $(\sim 5 \mathrm{~mm})$ sediments gave two peaks (Figure $2.7 \mathrm{~B}$ ), representing humic-like (at 260, $462 \mathrm{~nm}$ ) and amino acid-like (at 280,360 nm) organic matter respectively. Nevertheless, both of the treatments under solar irradiation demonstrated a single, intense peak at (260, 452-454 nm) (Figure $2.7 \mathrm{C}$, D), representing humic-like organic matter. At 0 hour, suspensions with top $\sim 5 \mathrm{~mm}$ sediments $(\mathrm{FI}=0.68, \mathrm{BIX}=0.65, \mathrm{HIX}=0.90)$ and those with $\sim 2 \mathrm{~cm}$ surface sediments $(\mathrm{FI}=0.70, \mathrm{BIX}=0.62, \mathrm{HIX}=0.92)$ exhibited a similar microbial-derived organic matter fluorescence character, and their fluorescence intensities were generally low ( $<2$ QSE). After 24 hours of incubation, for top $\sim 5 \mathrm{~mm}$ sediment suspensions, BIX=0.56 in irradiated suspensions while $\mathrm{BIX}=0.88$ in dark suspensions, indicating more intense biotic activity in dark suspensions compared to that in irradiated suspensions using top layer sediments. With regard to $\sim 2 \mathrm{~cm}$ surface sediment suspensions, however, no significant difference between the dark $(\mathrm{BIX}=0.59)$ and irradiated $(\mathrm{BIX}=0.53)$ treatments was observed.

\subsection{Influence of sediment organic content (\%OC) on photodissolution}

Photoproduction of DOC and TDN during photodissolution experiments using raw (wet) sediments from four sample sites and a variety of filtered water was compared to the organic content of sediments (Figure 2.8). The extent of photodissolution, in terms of DOC and TDN production, had a strong correlation with the organic content of sediment samples (Figure 2.8). Photoproduced DOC was proportional to the amount of POC addition $\left(\mathrm{R}^{2}=0.97\right)$. On average, $69.2 \pm 11.0 \mathrm{mg} \mathrm{C}$ of DOC was photochemically produced from $1 \mathrm{~g}$ of organic carbon added in sediment suspensions. It was no surprise that TDN production was also proportional to the amount of organic carbon addition in sediment suspensions $\left(\mathrm{R}^{2}=0.88\right)$ because TDN and DOC photoproduction correlated strongly (Chapter 1, 4.1.4). An average of $9 \pm 3.1 \mathrm{mg} \mathrm{N}$ was photoreleased per $1 \mathrm{~g}$ of organic carbon addition. Sediment samples from seagrass beds (in MANERR and LLM) were typically more organic-rich than those from Nueces marsh and Copano Bay. Thus, sediment suspensions using seagrass bed sediments generally produced more DOC and TDN than the suspensions using sediment samples from Nueces marsh and Copano Bay. 
Even with sediment samples from the same sample site, such as the two data points representing LLM sediment photoproduction, the same pattern applied: the more organic-rich the sediment sample was, more DOC and TDN was produced during photodissolution experiments.

\section{Discussion}

\subsection{Influence of sediment desiccation on photodissolution}

Dry-rewetted sediments in artificial seawater produced significantly more DOC/CDOM and TDN than wet sediments under solar irradiation (Figure 2.1), implying that sediment dry-wet cycle may be a major controller of photodissolution reactions in salt marsh systems. Humic substances are complex, large, photoreactive molecules and can comprise the major portion of DOM pool in natural waters (Repeta et al. 2002). Particle-associated humic substances commonly form a coating on sediments in low-carbon waters (Murphy et al. 1990). Since humic substances are typically hydrophobic (Martin-Mousset et al. 1997, Latch and McNeill 2006), this coating may enhance the hydrophobicity of sediment particles (Davis and Gloor 1981, Morse 1986). Liu and Lee $(2006,2007)$ studied the effect of desiccation on marsh sediments and suggested that drying can greatly change the 3-D structure of sediment grain matrices and augment sediment hydrophobicity. Thus, dry-rewetted sediments should sorb more hydrophobic compounds but less hydrophilic compounds. Based on their conclusions, the mechanism for my results is proposed as the following: the molecular make-up of sedimentary POM was altered under desiccation, allowing hydrophobic functional groups to be exposed at the surface of sediment grains. A substantial portion of these exposed hydrophobic functional groups might be humic moieties that contain chromophoric groups. This alteration could have thus enhanced the vulnerability of POM to photochemical degradation, which enabled dry-rewetted sediments to produce more DOM (measured as DOC and TDN) under solar irradiation (Figure 2.1). A smaller proportion of humic substance leads to lower hydrophobicity within the DOM pool, and a 
lower overall molecular weight (Martin-Mousset et al. 1997). Therefore, based on the optical character ( $S_{275-295}$ value) of sediment suspensions, the average molecular weight of DOM in dry-rewetted sediment suspensions was lower than in wet sediment suspensions at 0 hours (Figure 2.2) because dry sediments released hydrophilic molecules and adsorbed hydrophobic molecules upon rewetting.

4.2 Combined influence of sediment desiccation and water organic content on photodissolution

DOC and TDN production during photodissolution was not significantly different when organic-rich versus organic-poor water was used in sediment suspensions (Figure 2.4 and 2.5), indicating that DOM in ambient water did not affect photochemical reactions on POM. My results agreed with a previous study by Mayer et al. (2006) in which the authors compared photodissolution reactions using Mississippi river water and distilled water and observed little difference in POC loss between these two treatments. They concluded that DOM in natural water was not important to photodissolution reaction. Nevertheless, although organic content of ambient water did not significantly affect DOC or TDN photoproduction by itself, the combined influence of water organic content and sediment dry-rewet event played a substantial role in controlling the extent of photodissolution in this study (Figure 2.6), especially for TDN production (Figure 2.6 B, D). Dry-rewetted sediments produced more DOC and TDN in organic-poor water, but the opposite was observed in organic-rich water.

As discussed above, when POM was altered by desiccation, its susceptibility to degradation via solar irradiation was likely augmented and therefore the extent of photodissolution was enhanced in organic-poor water. On the other hand, as sediment desiccation may facilitate hydrophobic functional group exposure at the surface of sediment grains, dry-rewetted sediment particles are more hydrophobic and able to sorb more DOM from ambient water if water is organic-rich (Murphy et al. 1990). The sorbed DOM molecules may occupy the surface of sediment particles and serve as "protectors" for the functional groups that are vulnerable to photodegradation. Therefore, dry-rewetted 
sediments produced less DOC and TDN than wet sediments in organic-rich marsh water (Figure 2.6). The combined influences of water organic content and desiccation could have significant effects on photodissolution due to altered interactions between DOM and POM, while water organic content alone does not influence the extent of photodissolution.

\subsection{Substrate preference during photodissolution}

As observed in the EEMs results from photodissolution experiments using Nueces Marsh sediment samples (Chapter 1, 3.3), DOM produced in photodissolution was dominated by humic-like organic matter. However, this result was not surprising as it agreed with the conclusions from a study on sediment sources to the Nueces-Corpus Christi estuary by Yeager et al. (2006), in which sedimentation patterns and sediment isotope characteristics suggested that the sediment supply to Nueces estuary was largely derived from terrestrial sources via river inputs. During my study, it is possible that available substrates, rather than preferential reaction, resulted in dominant production of humic-like organic matter during photodissolution. To help identify the mechanism of photoproduction of humic-like organic matter, the top layer $(\sim 5 \mathrm{~mm})$ sediment samples were compared to upper $\sim 2 \mathrm{~cm}$ sediments that were normally used in photodissolution experiments, because top layer sediments are typically more biologically labile than deeper sediments and commonly contain a large portion of plant detritus (Calvert 1987). After 24 hours of incubation, the dark top layer sediment suspensions exhibited a substantial amino acid-like fluorescence peak as well as an intense humic peak, suggesting that biologically labile organic matter (e.g. protein) was likely available for degradation (Billen 1991, Cowie and Hedges 1992). However, similar to irradiated $\sim 2 \mathrm{~cm}$ surface sediment suspensions, irradiated top layer sediment suspensions showed single humic-like fluorescence peaks after photoincubation. These results indicate that photodissolution produces humic-like DOM dominantly even though protein-like organic matter was available in sediments. Two possible mechanisms are proposed to explain the results: 
(1) Photochemical reactions preferentially occur with humic-like rather than protein-like organic matter, or/and

(2) Photochemical reactions inhibit bacterial activities strongly so that biological degradation of protein-like organic matter is weak.

My results agreed with previous studies reporting preferential photodissolution of humics (Mayer et al. 2009a, Shank et al. 2011, Pisani et al. 2011). Photochemical degradation of humic-like components is likely greater than for protein-like components. Mayer et al. (2009a) irradiated phytoplankton detritus and found that photoproduced CDOM exhibited humic-like fluorescence. Shank et al. (2011) suggested that DOM produced during photodissolution of Florida Bay sediments included primarily humic-like components, with a minor contribution from protein-like components. It is possible that bacterial activity could be inhibited under intense simulated sunlight due to direct photo-inhibition (Xie and Zafiriou 2009, Mayer et al. 2009b) or/and actions of oxidants (e.g. hydroxyl radicals) produced in UV-driven photochemical reactions (Lund and Hongve 1994). Although it is difficult to distinguish preferential photoreaction of humic POM from photo-inhibition as the reason for dominant humics production, the majority of work on humic photoreactivity suggests the former as the primary cause.

\subsection{Influence of sediment organic content (\%OC) on photodissolution}

DOC and TDN production during photodissolution was strongly proportional to the amount of POC in sediment suspensions (Figure 2.8). On average, $69.2 \pm 11.0 \mathrm{mg} \mathrm{C}$ of DOC and $9 \pm 3.1 \mathrm{mg} \mathrm{N}$ of TDN was produced from $1 \mathrm{~g}$ of organic carbon in sediment suspensions after 24 hours of photodissolution. This result indicates that $\mathrm{C}$ and $\mathrm{N}$ are both subject to transformation from particulate to dissolved phase as sedimentary POM undergoes photodissolution. My results agree with previous studies on DOC production in photodissolution (Shank et al. 2011, Pisani et al. 2011) in which DOC increments under solar irradiation well correlated with \%OC of sediments in suspensions. However, my results showed linear relationship between DOC/TDN production and \%OC in sediments, whereas Shank et al. (2011) observed an exponential relationship. This 
inconsistency may be due to the difference in sediment characteristics since the Florida Bay sediment samples were more organic rich than those used in this study. Also, the number of data points and data processing method may be different. Additionally, in both of the previous studies (Shank et al. 2011, Pisani et al. 2011), $200 \mathrm{mg} \mathrm{C} \mathrm{gC}^{-1}$ DOC was produced by the end of photoincubation, but $\sim 70 \mathrm{mg} \mathrm{C} \mathrm{gC}^{-1}$ DOC production after 24 hours of photodissolution was observed in my study. The lower DOC production in my study is likely due to differences in sediment characteristics such as sediment type and diagenetic status. Further, the method used to measure \%OC (loss on ignition method) in this study may be an overestimation and thus lead to underestimations of DOC production normalized to POC addition. Kieber et al. (2006) compared loss on ignition method to CHN analysis after acid digestion and suggested that both methods gave comparable results for muddy-to-sandy, low carbonate sediments. However, in my study, sediment samples from Copano Bay, MANERR and LLM seagrass bed are commonly carbonate-rich. Therefore, carbonate loss during combustion may be attributed to organic carbon loss, resulting in an overestimation of \%OC. 

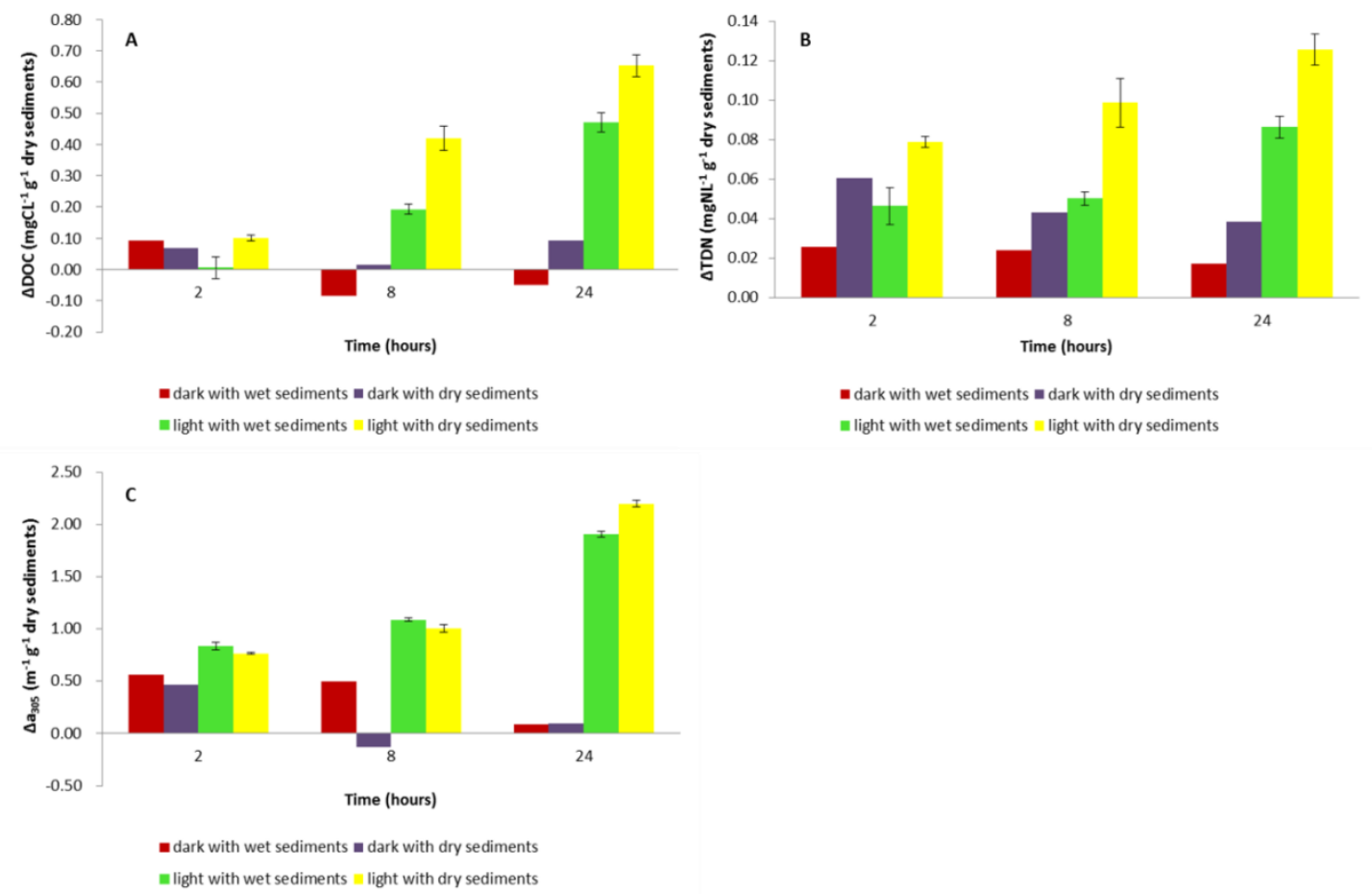

Figure 2.1. Comparison of photodissolution experiments using wet versus dry-rewetted sediments. Changes of DOC (A), TDN (B) and CDOM (C) abundances with time were normalized to $1 \mathrm{~g}$ of Nueces Marsh sediment (dry weight) addition in sediment suspensions. Artificial seawater was used to prepare sediment suspensions. Error bars represent \pm 1 standard deviation $(\mathrm{N}=2)$. 


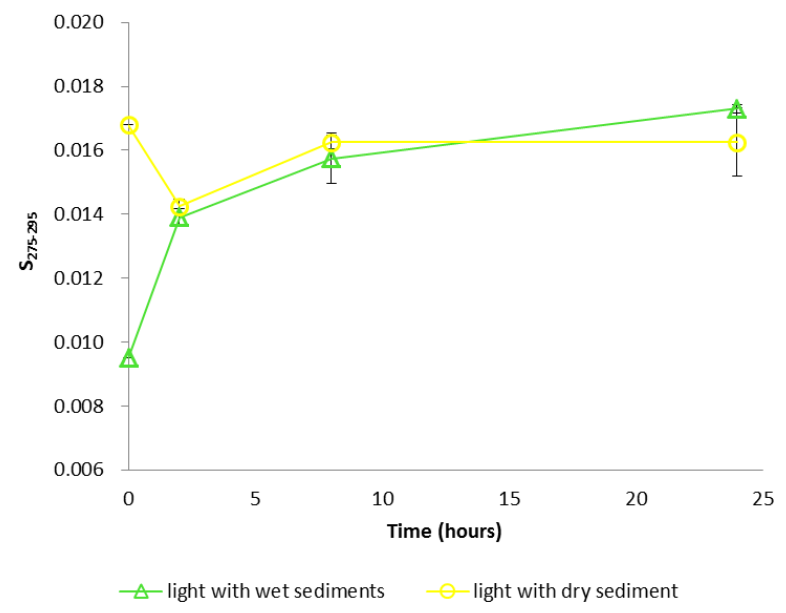

Figure 2.2. Spectral slope $\left(S_{275-295}\right)$ of CDOM pools in irradiated wet sediment suspensions (light with wet sediments) and irradiated dry-rewetted sediment suspensions (light with dry sediments). Sediment suspensions were prepared using Nueces Marsh sediments and artificial seawater. Error bars represent \pm 1 standard deviation $(\mathrm{N}=2)$. 

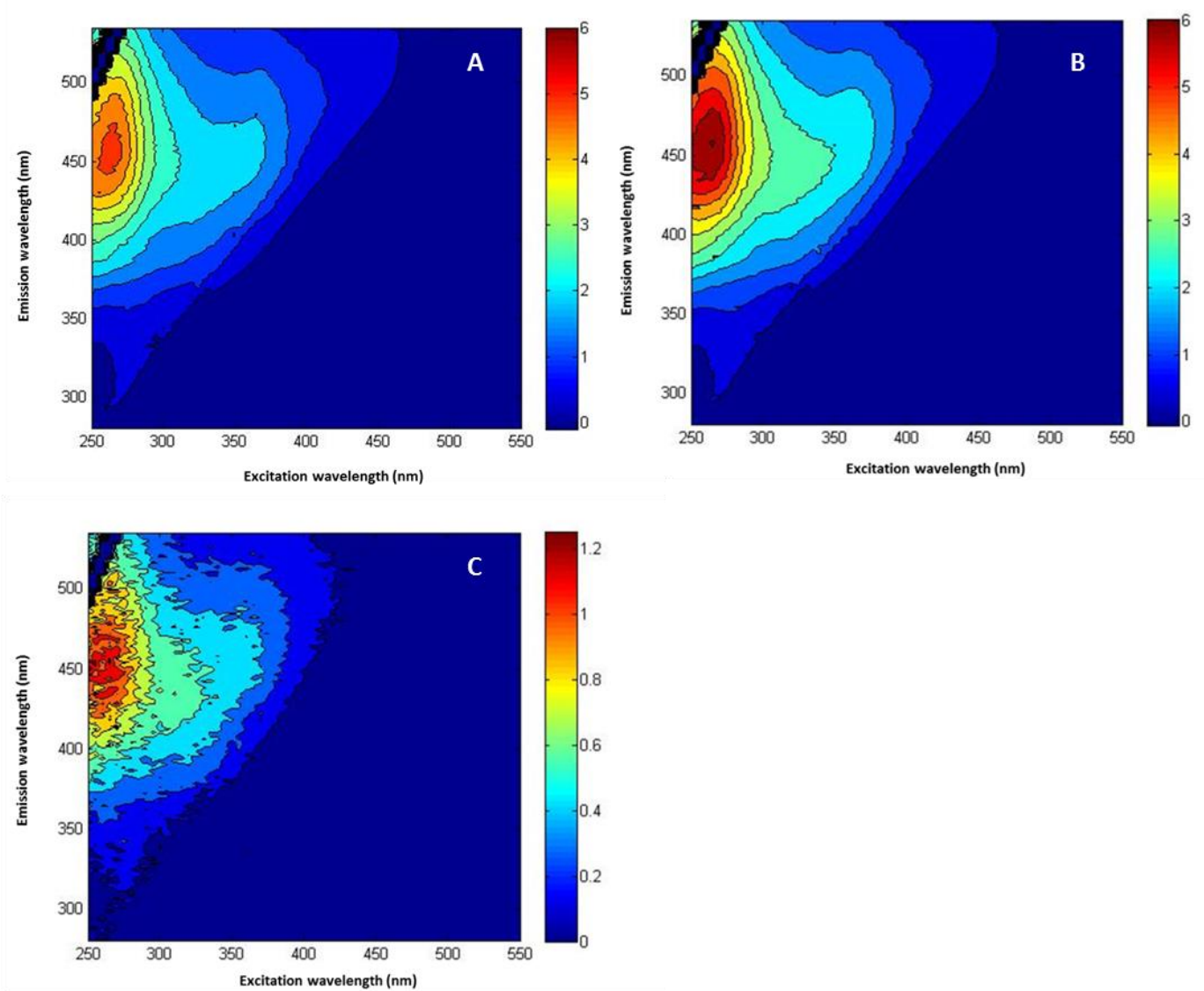

Figure 2.3. EEMs of CDOM in irradiated wet sediment suspension (A) and irradiated dry-rewetted sediment suspension (B) at 24 hours. The difference in EEMs between (A) and (B) were calculated with matrix calculation and plotted in (C). Nueces Marsh sediments and artificial seawater was used to prepare sediment suspensions. Scale bars represent fluorescence intensity (QSE). The dominant fluorescence peak $\mathrm{F}_{\max }$ was at (265, $464 \mathrm{~nm})$ in $(\mathrm{A})$, at $(265,458 \mathrm{~nm})$ in $(B)$, and at $(250,450 \mathrm{~nm})$ in $(C)$. 

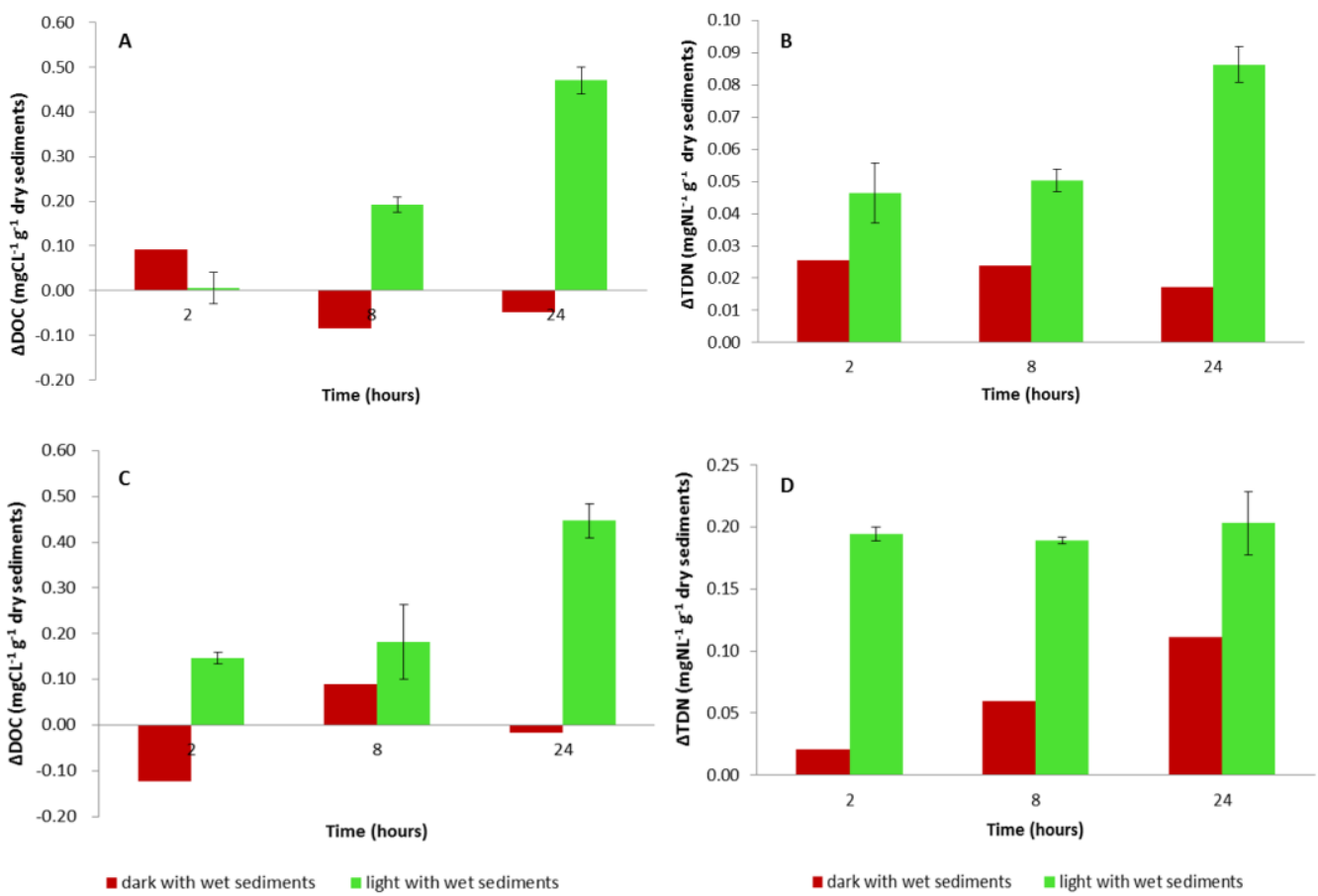

- dark with wet sediments = light with wet sediments

Figure 2.4. Comparison of photodissolution experiments using artificial seawater (organic-poor) (A, B) versus Nueces Marsh water (organic-rich) (C, D). Changes of DOC $(\mathrm{A}, \mathrm{C})$ and TDN $(\mathrm{B}, \mathrm{D})$ concentrations with time were normalized to $1 \mathrm{~g}$ of Nueces Marsh sediment (dry weight) addition in sediment suspensions. Error bars represent \pm 1 standard deviation $(\mathrm{N}=2)$. 

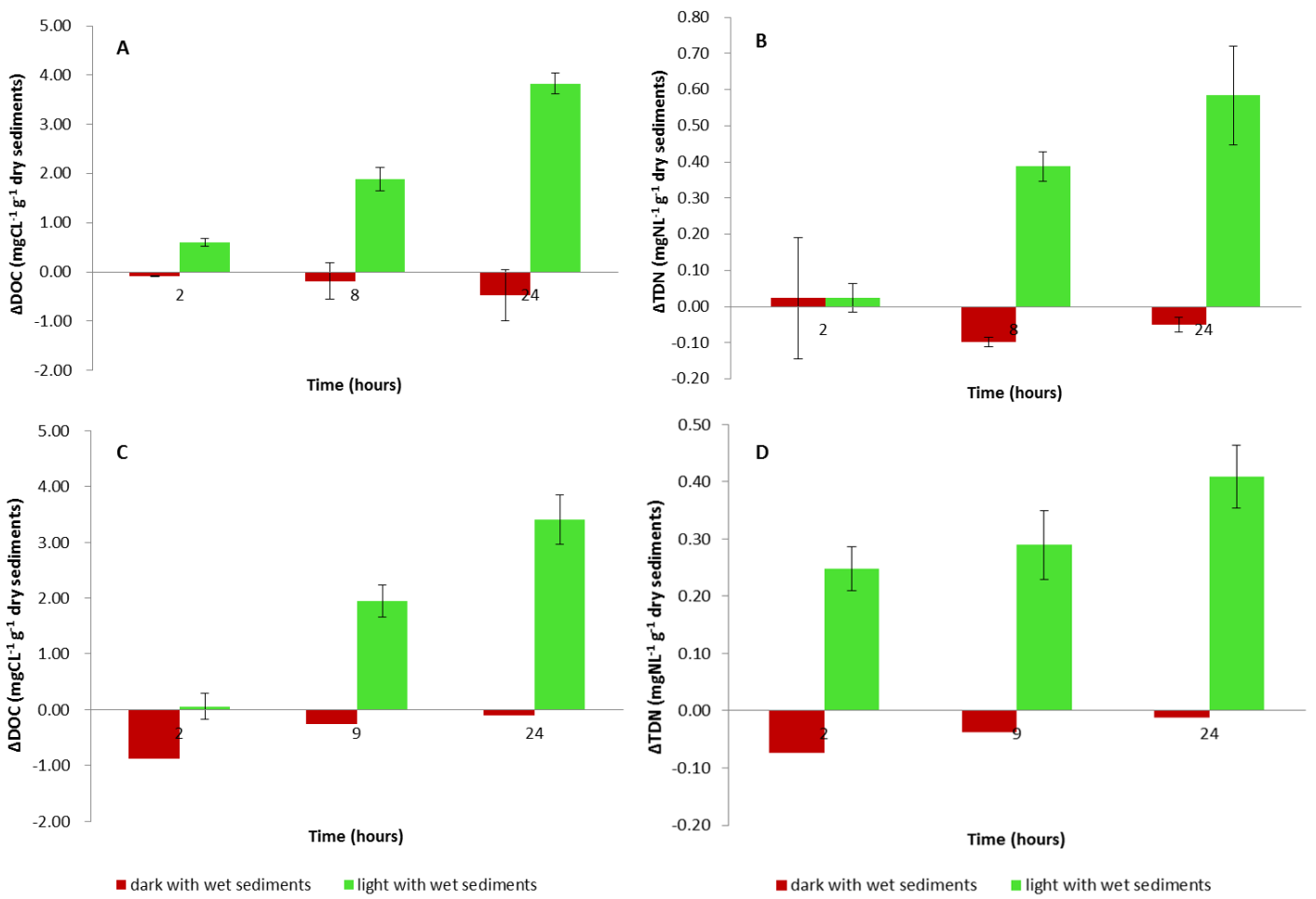

Figure 2.5. Comparison of photodissolution experiments using Ship Channel water (organic-poor) (A, B) versus MANERR water (organic-rich) (C, D). Changes of DOC (A, C) and TDN (B, D) concentrations with time were normalized to $1 \mathrm{~g}$ of MANERR seagrass bed sediment (dry weight) addition in sediment suspensions. Error bars represent \pm 1 standard deviation $(\mathrm{N}=2)$. 

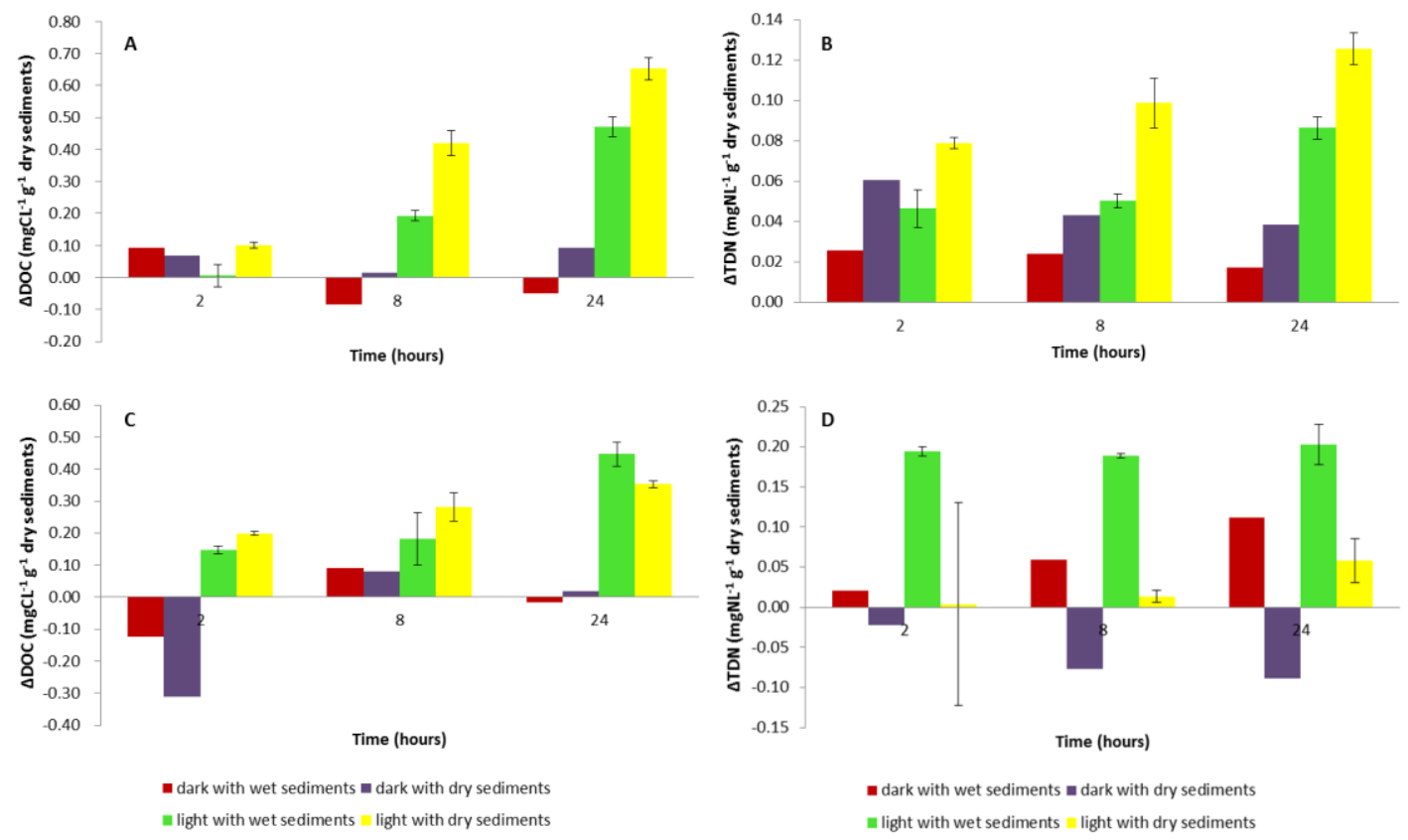

Figure 2.6. Comparison of photodissolution experiments using wet versus dry-rewetted sediments mixed with artificial seawater (organic-poor) (A, B) versus Nueces Marsh water (organic-rich) $(\mathrm{C}, \mathrm{D})$. Changes of DOC $(\mathrm{A}, \mathrm{C})$ and TDN $(\mathrm{B}, \mathrm{D})$ concentrations with time were normalized to $1 \mathrm{~g}$ of Nueces Marsh sediment (dry weight) addition in sediment suspensions. Error bars represent \pm 1 standard deviation $(\mathrm{N}=2)$. 

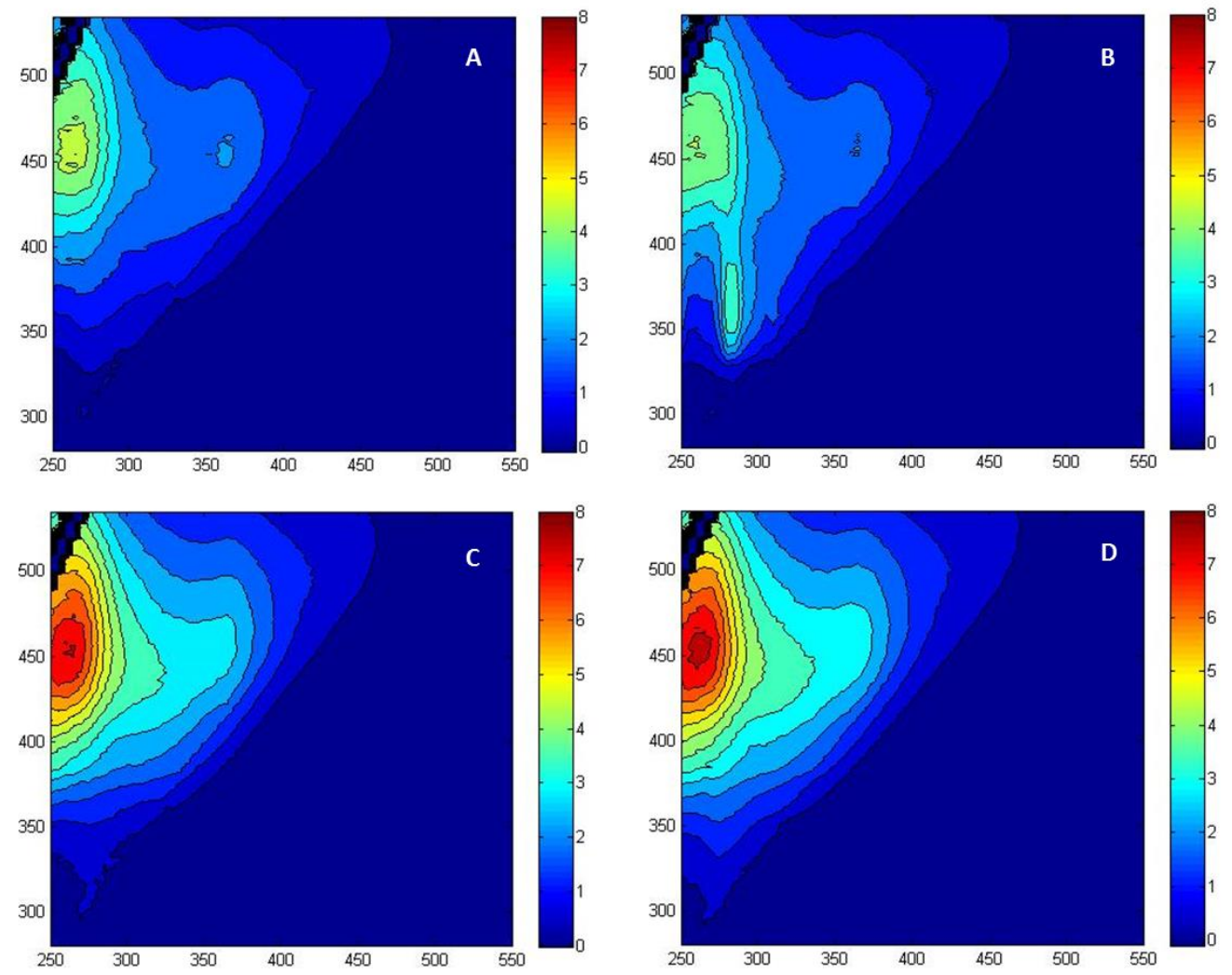

Figure 2.7. EEMs of CDOM in dark upper $\sim 2 \mathrm{~cm}$ sediment suspension (A), dark top layer $(\sim 5 \mathrm{~mm})$ sediment suspension (B), irradiated upper $\sim 2 \mathrm{~cm}$ sediment suspension $(C)$, and irradiated top layer $(\sim 5 \mathrm{~mm})$ sediment suspension (D) at 24 hours. Nueces Marsh sediments and artificial seawater was used to prepare sediment suspensions. Scale bars represent fluorescence intensity (QSE). 

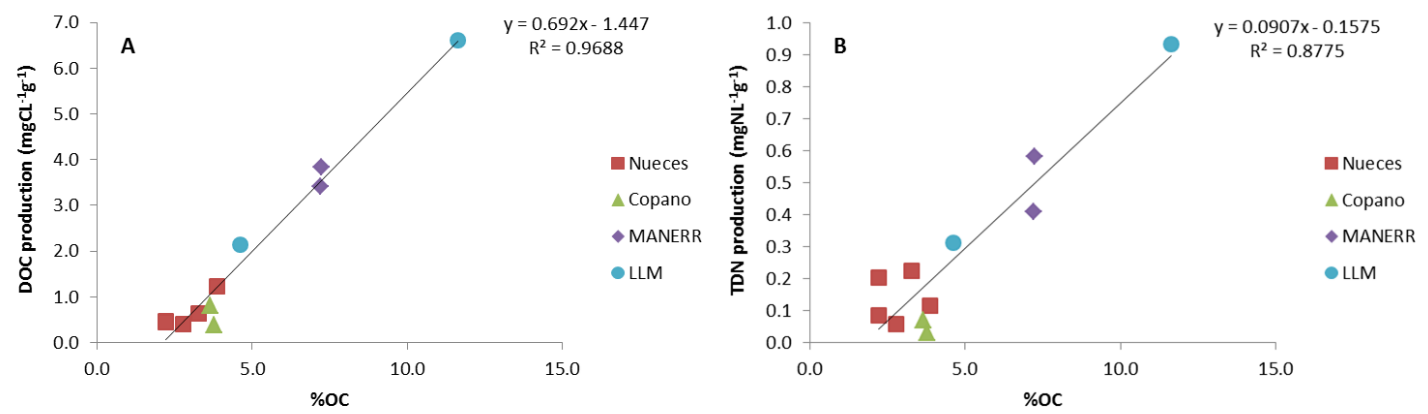

Figure 2.8. Correlations between DOC (A) and TDN (B) production at 24 hours and \%OC of sediment samples in photodissolution. DOC and TDN concentrations were normalized to $1 \mathrm{~g}$ of sediment (dry weight) addition. All the photodissolution experiments using raw (wet) sediments from Nueces Marsh, Copano West, MANERR seagrass bed and LLM seagrass bed were plotted together. The trend lines are linear fits of all the data points. 


\section{References}

Alperin, M. J., Martens, C. S., Albert, D. B., Suayah, I. B., Benninger, L. K., Blair, N. E. and Jahnke, R. A. 1999. Benthic fluxes and porewater concentration profiles of dissolved organic carbon in sediments from the North Carolina continental slope. Geochim. Cosmochim. Acta 63: 427-448.

Amon, R. M. W. and Benner, R. 1994. Rapid cycling of high-molecular-weight dissolved organic matter in the ocean. Nature 369: 549-551.

Amon, R. M. W., Fitznar, H. P. and Benner, R. 2001. Linkages among the bioreactivity, chemical composition, and diagenetic state of marine dissolved organic matter. Limnol. Oceanogr. 46 (2): 287-297.

Anderson, B. H. and Magdoff, F. R. 2005. Autoclaving soil samples affects algal-available phosphorus. J. Environ. Qual. 34: 1958-1963.

Anesio, A. M., Tranvik, L. J. and Graneli, W. 1999. Production of inorganic Carbon from aquatic macrophytes by solar radiation. Ecology 80: 1852-1859.

Armstrong, N. E. 1982. Responses of Texas estuaries to freshwater inflows. In: V. S. Kennedy (ed.), Estuarine Comparisons. Academic Press, New York. pp. 103-120.

Azaml, F., Fenche, T., Field, J. G., Gray, J. S., Meyer-Reil, L. A. and Thingstad, F. 1983. The Ecological Role of Water-Column Microbes in the sea. Mar. Ecol. Prog. Ser. 10: 257-263.

Benner, R. B., Pakulski, J. D., Mccarthy, M., Hedges, J. I. and Hatcher, P. G. 1992. Bulk chemical characteristics of dissolved organic matter in the ocean. Science 255: 1561-1564.

Benner, R., 2002. Chemical composition and reactivity. In: Hansell, D. A., Carlson, C. A. (eds.), Biogeochemistry of Marine Dissolved Organic Matter. Academic Press, New York, pp. 59-90.

Bianchi, Thomas S. 2011. The role of terrestrially derived organic carbon in the coastal ocean: A changing paradigm and the priming effect. PNAS 108: 19473-19481.

Billen, G. 1991. Protein degradation in aquatic environments. Microbial enzymes in aquatic environments. Springer, New York, 123-143.

Birdwell, J. E. and Engel, A. S. 2010. Characterization of dissolved organic matter in cave and spring waters using UV-Vis absorbance and fluorescence spectroscopy. Org. Geochem. 41: 270-280.

Blough, N. V. and Del Vecchio. R. 2002. In: Biogeochemistry of marine dissolved organic matter. Hansell, D. A. and Carlson, C. A. (eds.). Academic Press: Amsterdam.

Blough, N. V., and Green, S. A. 1995. Spectroscopic characterization and remote sensing of nonliving organic matter. In: Role of nonliving organic matter in the earth's carbon cycle. Zepp, R.G. and Sonntag, C. (eds). New York: Wiley, pp. 22-45.

Boyer, J. N. and Groffman, P. M. 1996. Bioavailability of water extractable organic carbon fractions in forest and agricultural soil profiles. Soil Biology \& Biochemistry 28: 783-790. 
Brezonik, P., Menken, K. D. and Bauer, M. 2005. Landsat-based remote sensing of lake water quality characteristics, including chlorophyll and colored dissolved organic matter (CDOM). Lake and Reserv. Manage. 21: 373-382.

Bricaud, A., Morel, A. and Prieur, L. 1981. Absorption by dissolved organic matter of the sea (yellow substance) in the UV and visible domains. Limnol. Oceanogr. 26: 43-53.

Bronk, D. A. 2002. Dynamics of DON. In: Biogeochemistry of Marine Dissolved Organic Matter. Hansell, D. A. and Carlson, C. A. (Eds). San Diego: Academic Press, pp. 153-249.

Bronk, D. A., See, J. H., Bradley, P. and Killberg, L. 2007. DON as a source of bioavailable nitrogen for phytoplankton. Biogeosciences 4: 283-296.

Bureau of Reclamation. 2000. Concluding report: Rincon bayou demonstration project. U.S. Department of the Interior, Bureau of Reclamation, Austin, Texas.

Bushaw, K. L., Zepp, R. G., Tarr, M. A., Schulz-Jander, D. Bourbonniere, R. A., Hodson, R. E., Miller, W. L., Bronk, D. A. and Moran, M. A. 1996. Photochemical release of biologically available nitrogen from aquatic dissolved organic matter. Nature 381: 404-407.

Buskey, E. J., Liu, H., Collumb, C., and Bersano, J. G. F. 2001. The decline and recovery of a persistent Texas brown tide algal bloom in the Laguna Madre (Texas, USA). Estuaries 24: 337-346.

Buskey, E. J., Wysor, B. and Hyatt, C. 1998. The role of hypersalinity in the persistence of the Texas 'brown tide' in the Laguna Madre. J. Plankton Res. 20: 1553-1565.

Calvert, S. E. 1987. Oceanographic controls on the accumulation of organic matter in marine sediments. Geological Society, London, Special Publications 26: 137-151.

CCBNEP report. 1996. Living Resources - Habitat. In: Current Status and Historical Trends of the Estuarine Living Resources within the CCBNEP Study Area - Volume 1. Center for Coastal Studies. Texas A\&M University-Corpus Christi, pp. 45-94.

Chen, R. F., Bissett, P., Coble, P., Conmy, R., Gardner, G. B., Moran, M. A., Wang, X. C., Wells, M. L., Whelan, P. and Zepp, R. G. 2004. Chromophoric dissolved organic matter (CDOM) source characterization in the Louisiana Bight. Mar. Chem. 89: 257-272.

Coble, P. G. 2007. Marine optical biogeochemistry: The chemistry of ocean color. Chem. Rev. 107: 402-418.

Cowie, G. L. and Hedges, J. I. 1992. Sources and reactivities of amino acids in a coastal marine environment. Limnology and Oceanography 37: 703-724.

Daniel, C., Graneli, W., Kritzberg, E. S. and Anesio, A. M. 2006. Stimulation of metazooplankton by photochemically modified dissolved organic matter. Limnol. Oceanogr. 51(1): 101-108.

Davis, J. A. and Gloor, R. 1981. Adsorption of dissolved organics in lake water by aluminum oxide. Effect of molecular weight. Environ. Sci. Technol. 15: 1223-1229.

Day, J. W., Hall, C. A. S., Kemp, W. M. and Yanes-Arancibia, A. 1989. Estuarine ecology. Chichester: A Wiley-Intercience Publication/John Wiley \& Sons, pp. 79-85.

Del Vecchio, R. and Blough, N. V. 2002. Photobleaching of chromophoric dissolved 
organic matter in natural waters: kinetics and modeling. Mar. Chem. 78: 231-253.

Estapa, M. L. and Mayer, L. M. 2010. Photooxidation of particulate organic matter, carbon/oxygen stoichiometry, and related photoreactions. Mar. Chem. 122: 138-147.

Estapa, M. L., Mayer, L. M. and Boss, E. 2012. Rate and apparent quantum yield of photodissolution of sedimentary organic matter. Limnol. Oceanogr. 57: 1743-1756.

Farrington, J. 1992. Over view and key recommendations. Marine organic geochemistry workshop, January 1990. Mar. Chem. 39:5-9.

Flint, R. W., and Kamykowski, D. 1984. Benthic nutrient regeneration in South Texas coastal waters. Estuarine, Coastal and Shelf Science 18: 221-230.

Forbes, M. G. and Dunton, K. H. 2006. Response of a subtropical estuarine marsh to local climatic change in the southwestern Gulf of Mexico. Estuaries and Coasts 29: 1242-1254.

Frangipane, G., Pistolato, M., Molinaroli, E., Guerzoni, S. and Tagliapietra, D. 2009. Comparison of loss on ignition and thermal analysis stepwise methods for determination of sedimentary organic matter. Aquatic Conser. Mar. Freshw. Ecosyst. 19: 24-33.

Gao, H. and Zepp, R. G. 1998. Factors influencing photoreactions of dissolved organic matter in a coastal river of the southeastern United States. Environ. Sci. Technol. 32: 2940-2946.

Gardner, W. S., and John, P. A. St. 1991. High-performance liquid chromatographic method to determine ammonium ion and primary amines in seawater. Anal. Chem. 63: 537-540.

Gardner, W. S., McCarthy, M. J., An, S., Sobolev, D., Sell, K. S. and Brock, D. 2006. Nitrogen fixation and dissimilatory nitrate reduction to ammonium (DNRA) support nitrogen dynamics in Texas estuaries. Limnol. Oceanogr., 51: 558-568.

Geller, A. 1986. Comparison of mechanisms enhancing biodegradability of refractory lake water constituents. Limnol. Oceanogr. 31: 755-764.

Granéli, W., Lindell, M. and Tranvik, L. 1996. Photo-oxidative production of dissolved inorganic carbon in lakes of different humic content. Limnol. Oceanogr. 41: 698-706.

Hansell, D. A. and Carlson, C. A. (eds.) 2002. Biogeochemistry of Marine Dissolved Organic Matter. Academic Press, pp. 774.

Helms, J. R., Stubbins, A., Ritchie, J. D. and Minor, E. C. 2008. Absorption spectral slopes and slope ratios as indicators of molecular weight, source, and photobleaching of chromophoric dissolved organic matter. Limnol. Oceanogr. 53: 955-969.

Hong, H., Wu, J. Shang, S. and $\mathrm{Hu}$, C. 2005. Absorption and fluorescence of chromophoric dissolved organic matter in the Pearl River Estuary, South China. Mar. Chem. 97: 78-89.

Ingle, J. D. and Crouch, S. R. 1988. Spectrochemical analysis. Upper River (NJ), Prentice-Hall, pp. 608.

Jones, M. N. 1984. Nitrate reduction by shaking with cadmium: Alternative to cadmium columns. Water Res. 18: 643-646. 
Keil, R. G., Montlucon, D. B., Prahl, F. G. and Hedges, J. I. 1994. Sorptive preservation of labile organic-matter in marine-sediments. Nature 370: 549-552.

Kieber, R. J., Whitehead, R. F. and Skrabal, S. A. 2006. Photochemical production of dissolved organic carbon from resuspended sediments. Limnol. Oceanogr. 51(5): 2187-2195.

Kirk, J. T. O. 1980. Spectral absorption properties of natural waters: Contribution of the soluble and particulate fractions to light absorption in some inland waters of South-eastern Australia. Aust. J. Mar. Freshwater Res. 31: 287-296.

Kirk, J. T. O. 1994. Light and Photosynthesis in Aquatic Ecosystems, 2nd edition. Cambridge University Press, Cambridge, U.K.

Kowalczuk, P., Cooper, W. J., Whitehead, R. F., Durako, M. J. and Sheldon, W. 2003. Characterization of CDOM in an organic-rich river and surrounding coastal ocean in the South Atlantic Bight. Aquatic Sciences 65: 384-401.

Latch, D. E. and McNeill, K. 2006. Microheterogeneity of Singlet Oxygen Distributions in Irradiated Humic Acid Solutions. Science 24: 1743-1747.

Liu, Z and Lee, C. 2006. Drying effects on sorption capacity of coastal sediment: The importance of architecture and polarity of organic matter. Geochim. Cosmochim. Acta 70: 3313-3324.

Liu, $\mathrm{Z}$ and Lee, C. 2007. The role of organic matter in the sorption capacity of marine sediments. Mar. Chem. 105: 240-257.

Lund, V. and Hongve, D. 1994. Ultraviolet irradiated water containing humic substances inhibits bacterial metabolism. Wat. Res. 28: 1111-1116.

Lundquist, E. J. 1997. Rapid changes in soil microbial biomass and carbon and nitrogen pools in response to agricultural practices. Ph.D. Thesis, University of California, Davis.

Mannino, A. and Harvey, H. R. 1999. Lipid composition in particulate and dissolved organic matter in the Delaware Estuary: Source and diagenetic patterns. Geochim. Cosmochim. Acta 63: 2219-2235.

Martin-Mousset, B., Croue, J. P., Lefebvre, E. and Legube, B. 1997. Distribution and characterization of dissolved organic matter of surface waters. Water Research 31: 541-553.

Marumoto, T., Kai, H., Yoshida, T. and Harada, T. 1977. Dry effect on mineralization of microbial cells and their cell walls in soil and contribution of microbial cell walls as source of decomposable soil organic matter due to drying. Soil Sci. Plant Nutr. 23: 9-19.

Mayer, L. M. 1994. Surface-area control of organic-carbon accumulation in continental-shelf sediments. Geochim. Cosmochim. Acta 58: 1271-1284.

Mayer, L. M., Schick, L. L. and Skorko, K. 2006. Photodissolution of particulate organic matter from sediments. Limnol. Oceanogr. 51(2): 1064-1071.

Mayer, L. M., Schick, L. L., Bianchi, T. S. and Wysocki, L. A. 2009b. Photochemical changes in chemical markers of sedimentary organic matter source and age. Marine Chemistry 113: 123-128.

Mayer, L. M., Schick, L. L., Hardy, K. R. and Estapa, M. L. 2009a. Photodissolution and 
other photochemical changes upon irradiation of algal detritus. Limnol. Oceanogr. 54(5): 1688-1698.

McCallister, S. L., Bauer, J. E., Kelly, J. and Ducklow, H. W. 2005. Effects of sunlight on decomposition of estuarine dissolved organic $\mathrm{C}, \mathrm{N}$ and $\mathrm{P}$ and bacterial metabolism. Aquatic Microbial Ecology 40: 25-35.

Meybeck, M. 1982. Carbon, nitrogen and phosphorus transport by world rivers. Am. J. Sci. 282: 401-450.

Mooney, R. F. 2009. Watershed export events and ecosystem responses in the Mission-Aransas National Estuarine Research Reserve. M.S. Thesis, University of Texas at Austin.

Moran, M. A. and Zepp, R. G. 1997. Role of photoreactions in the formation of biologically labile compounds from dissolved organic matter. Limnol. Oceanogr. 42: 1307-1316.

Moran, M. A., Sheldon Jr., W. M. and Zepp, R. G. 2000. Carbon loss and optical property changes during long-term photochemical and biological degradation of estuarine dissolved organic matter. Limnol. Oceanogr. 45: 1254-1264.

Morin J. and Morse J. W. 1999. Ammonium release from resuspended sediments in the Laguna Madre estuary. Marine Chemistry 66: 97-110.

Morse, J. W. 1986. The surface chemistry of calcium carbonate minerals in natural waters: An overview. Mar. Chem. 20: 91-112.

Morton, R. A. and Paine, J. G. 1984. Historical shoreline changes in Corpus Christi, Oso and Nueces bays, Texas Gulf coast. Geological Circular 84-6. Bureau of Economic Geology, University of Texas, Austin, Texas.

Murphy, E. M., Zachara, J. M. and Smith, S. C. 1990. Influence of mineral-bound humic substances on the sorption of hydrophobic organic compounds. Environ. Sci. Technol. 24: 1507-1516.

Obernosterer, I. and Benner, R. 2004. Competition between biological and photochemical processes in the mineralization of dissolved organic carbon. Limnol. Oceanogr. 49: $117-124$.

Ogawa, H. and Ogura, N. 1992. Comparison of two methods for measuring dissolved organic carbon in sea water. Nature 356: 696-698.

Ohno T. 2002. Fluorescence inner-filtering correction for determining the humification index of dissolved organic matter. Environ. Sci. Technol. 36: 742-746.

Onuf, C. P. 2007. Laguna Madre. In: Handley, L., Altsman, D., DeMay, R., Gulf of Mexico Program (U.S.), and United States Environmental Protection Agency (eds.), Seagrass Status and Trends in the Northern Gulf of Mexico, 1940-2002. U.S. Geological Survey Scientific Investigations Report 2006-5287, pp. 267.

Osburn, C. L. and Morris, D. P. 2003. Solar ultraviolet radiation and aquatic carbon, nitrogen, sulfur and metals cycles. In: Helbling, E.W., Zagarese, H. (Eds.), UV Effects in Aquatic Organisms and Ecosystems. Royal Society of Chemistry, Cambridge, UK. pp. 185-250.

Osburn, C. L., Retamal, L. and Vincent, W. F. 2009. Photoreactivity of chromophoric dissolved organic matter transported by the Mackenzie River to the Beaufort Sea. 
Mar. Chem. 115: 10-20.

Oviatt, C., Doering, P., Nowicki, B., Reed, L., Cole, J., Frithsen, J. 1995. An ecosystem level experiment on nutrient limitation in temperate coastal marine environments. Mar. Ecol. Prog. Ser. 116: 171-179.

Pisani, O., Yamashita, Y. and Jaffé., R. 2011. Photo-dissolution of flocculent, detrital material in aquatic environments: Contributions to the dissolved organic matter pool. Water Research 45: 3836-3844.

Pusceddu, A., Dell'Anno, A., Fabiano, M. and Danovaro, R. 2009. Quantity and bioavailability of sediment organic matter as signatures of benthic trophic status. Mar. Ecol. Prog. Ser. 375: 41-52.

Repeta, D. J., Quan, T. M., Aluwihare, L. I. and Accardi, A. 2002. Chemical characterization of high molecular weight dissolved organic matter in fresh and marine waters. Geochim. Cosmochim. Acta 66: 955-962.

Roelke, D. L., Cifuentes, L. A. and Eldridge, P. M. 1997. Nutrient and phytoplankton dynamics in a sewage-impacted Gulf Coast estuary: A field test of the PEG-Model and equilibrium resource competition theory. Estuaries 20: 725-742.

Ryther, J. H., Dunstan, W. M. 1971. Nitrogen, phosphorus and eutrophication in the coastal marine environment. Science 171: 1008-1013.

Seitzinger, P. and Sanders, R. W. 1997. Contribution of dissolved organic nitrogen from rivers to estuarine eutrophication. Mar. Ecol. Prog. Ser. 159: 1-12.

Seitzinger, S. P., Sanders, R. W., Styles, R. 2002. Bioavailability of DON fromnatural and anthropogenic sources to estuarine plankton. Limnol. Oceanogr. 47: 353-366.

Shank G. C., Nelson, K. and Montagna, P. A. 2009. Importance of CDOM distribution and photoreactivity in a shallow Texas estuary. Estuaries and Coasts.

Shank, G. C., Evans, A., Yamashita, Y and Jaffe, R. 2011. Solar radiation-enhanced dissolution of particulate organic matter from coastal marine sediments. Limnol. Oceanogr. 56: 577-588.

Shank, G. C., Skrabal, S. A., Whitehead, R. F. and Kieber, R. J. 2004. Fluxes of strong $\mathrm{Cu}$-complexing ligands from sediments of an organic-rich estuary. Est. Coast. Shelf. Sci. 60: 349-358.

Shank, G. C., Zepp, R. G., Whitehead, R. F. and Moran, M. A. 2005. Variations in the spectral properties of freshwater and estuarine CDOM caused by partitioning onto river and estuarine sediments. Estuarine, Coastal and Shelf Science 65: 289-301.

Shideler G. L. 1978. A sediment-dispersal model for the South Texas continental shelf, northwest Gulf of Mexico. Marine Geology 26: 289-313.

Shideler, G. L. 1980. Reconnaissance observations of some factors influencing the turbidity structure of a restricted estuary: Corpus Christi Bay, Texas. Texas Journal of Science 32: 59-71.

Siegel, D. A., Maritorena, S., Nelson, N. B., Behrenfeld, M. J. and McClain, C. R. 2005. Colored dissolved organic matter and the satellite-based characterization of the ocean biosphere. Geophysical Research Letters 32: L20605.

Sinsabaugh, R. L. and Findlay, S. E. G. 2003. Dissolved organic matter: Out of the black box and into the mainstream, In: Findlay, S. E. G. and Sinsabaugh, R. L. (eds.), 
Aquatic Ecosystems: Interactivity of Dissolved Organic Matter. Aquatic Ecology Series, Academic Press, San Diego, California. pp. 479-498.

Solis, R. S. 1994. Patterns of inflow and salinity. In: Longley, W. L. (ed.), Freshwater inflows to Texas Bays and estuaries: Ecological relationships and methods for determination of needs, pp. 386:23-40.

Southwell, M. W., Kieber, R. J., Mead, R. N., Avery, G. B. and Skrabal, S. A. 2010. Effects of sunlight on the production of dissolved organic and inorganic nutrients from resuspended sediments. Biogeochemistry 98: 115-126.

Southwell, M. W., Mead, R. N., Luquire, C. M., Barbera, A., Avery, G. B., Kieber, R. J. and Skrabal, S. A. 2011. Influence of organic matter source and diagenetic state on photochemical release of dissolved organic matter and nutrients from resuspendable estuarine sediments. Marine Chemistry 126: 114-119.

Stedmon, C. A., and Markager, S. 2003. Behaviour of the optical properties of coloured dissolved organic matter under conservative mixing. Estuarine, Coastal and Shelf Science 57: 1-7.

Stordal, M. C., Gill, G. A., Wen, L.-S. and Santschi, P. H. 1996. Mercury phase speciation in the surface waters of three Texas estuaries: Importance of colloidal forms. Limnol. Oceanogr. 41: 52-61.

Strome, D. J. and Miller, M. C. 1978. Photolytic changes in dissolved humic substances. Verh. Internat. Verein. Limnol. 20:1248-1254.

Stumm, W. and Morgan, J. J. 1996. Aquatic chemistry: Chemical equilibria and rates in natural waters. New York, Wiley.

Swan, C. M., Siegel, D. A., Nelson, N. B., Carlson, C. A. and Nasir, E. 2009. Biogeochemical and hydrographic controls on chromophoric dissolved organic matter distribution in the Pacific Ocean. Deep-Sea Research I 56: 2175-2192.

Thingstad, T. F., Bellerby, R. G. J., Bratbak, G., Børsheim, K. Y., Egge, J. K., Heldal, M., Larsen, A., Neill, C., Nejstgaard, J., Norland, S., Sandaa, R. A., Skjoldal, E. F., Tanaka, T., Thyrhaug, R. and Töpper, B. 2008. Counterintuitive carbon-to-nutrient coupling in an Arctic pelagic ecosystem. Nature 455: 387-390.

Thurman, E. M. 1985. Organic geochemistry of natural waters. E. M. Thurman (ed.). Nijhoff/Junk Publishers, Boston.

Tolan, J. M. and Fisher, M. 2009. Biological response to changes in climate patterns: Population increases of gray snapper (Lutjanus griseus) in Texas bays and estuaries. Fish. Bull. 107: 36-44.

Tuominen, L., Kairesalo, T. and Hartikainen, H. 1994. Comparison of methods for inhibiting bacterial activity in sediment. Appl. Environ. Microbiol. 60: 3454-3457.

Twilley, R. R., Cowan, J., Miller-Way, T., Montagna, P. A. and Mortazavi, B. 1999. Benthic nutrient fluxes in selected estuaries in the Gulf of Mexico. In: T. S. Bianchi, J. R. Pennock and R. R. Twilley (ed.), Biogeochemistry of Gulf of Mexico estuaries. John Wiley and Sons, pp. 163-202.

Vincent, W. F. and Belzile, C. 2003. Biological UV exposure in the polar oceans: Arctic-Antarctic comparisons. In: Huiskes, A. H. L., Gieskes, W. W. C., Rozema, J., Schorno, R. M. L., van der Vies, S. M., Wolff, W. J. (eds.), Antarctic Biology in a 
Global Context. Backhuys Publishers, Leiden, The Netherlands, pp. 176-181.

Wakeham, S. G. and Canuel, E. A. 1988. Organic geochemistry of particulate matter in the eastern tropical North Pacific Ocean: Implications for particle dynamics. Journal of Marine Research 46: 183-213.

Wang, Z., Liu, Z., Liu, M. and Xu, K. 2013. Impact of drying associated with drought on the rapid release of polycyclic aromatic hydrocarbons from salt marsh sediments in South Texas, USA. Envir. Scien. Tech. In review.

Ward, G. H. 1985. Marsh enhancement by freshwater diversion. Journal of Water Resources Planning and Management 111: 1-23.

Ward, G. H., Irlbeck, M. J. and Montagna, P. A. 2002. Experimental River Diversion for Marsh Enhancement. Estuaries 25: 1416-1425.

White, W. A., Calnan, T. R., Morton, R. A., Kimble, R. S., Littleton, T. J., McGowen, J. H. 1983. Submerged lands of Texas, Corpus Christi area: Sediments, geochemistry, benthic macroinvertebrates and associated wetlands. In: Bureau of Economic Geology. Uniersity of Texas, Austin.

White, W. A., and Calnan, T. R. 1990.Sedimentation and historical changes in fluvial-deltaic wetlands along the Texas Gulf coast with emphasis on the Colorado and Trinity River deltas. University of Texas at Austin, Bureau of Economic Geology.

Wickland, K. P., Neff, J. C. and Aiken, G. R. 2007. Dissolved organic carbon in Alaskan boreal forest: Sources, characteristics and biodegradability. Ecosystems 10: 1323-1340.

Xie, H., and Zafiriou, O. C. 2009. Evidence for significant photochemical production of carbon monoxide by particles in coastal and oligotrophic marine waters. Geophys. Res. Lett. 36: L23606.

Yeager, K. M., Santschi, P. H., Schindler, K. J., Andres, M. J. and Weaver, E. A. 2006. The relative importance of terrestrial versus marine sediment sources to the Nueces-Corpus Christi Estuary, Texas: An isotopic approach. Estuaries and Coasts 29: 443-454.

Zepp, R. G. 2003. Solar ultraviolet radiation and aquatic carbon, nitrogen, sulfur and metals cycles. In: Helbling, E. W., Zagarese, H. (eds.), UV Effects in Aquatic Organisms and Ecosystems. Royal Society of Chemistry, Cambridge, UK, pp. 137-183.

Zepp, R. G., Callaghan, T. V. and Erickson, D. J. 1995. Effects of increased solar ultraviolet radiation on biogeochemical cycles. Ambio 24: 181-187.

Zsolnay, A., Baigar, E., Jimenez, M., Steinweg, B. and Saccomandi, F. 1999. Differentiating with fluorescence spectroscopy the sources of dissolved organic matter in soils subjected to drying. Chemosphere 38: 45-50. 


\section{Vita}

Qiyuan Liu was born in China. She received the degree of Bachelor of Science from Ocean University of China in June 2010. In the same year, she moved across the Pacific Ocean and entered the University of Texas at Austin as a graduate student in Marine Science.

Email Address: qliu@utexas.edu

This thesis was typed by the author. 